\title{
Leadership Development Return on Investment: The Influence of Followership
}

Presented to the

School of Information Management

\section{Victoria University}

in fulfilment of the requirements for the course

Research Project in Information Management

(MMIM 592)

Presented by:

Mark Harris

Date: 14 October 2010

Student ID: 300132137

Supervisor: Hans Lehmann 


\section{Preface}

\section{Acknowledgements}

The author would like to sincerely thank the members of the governance team. Their assistance and guidance has been invaluable and has helped improve the quality of this research.

To all those that participated in the interviews I have deep respect and appreciation for the openness of the conversation and insightful observations. For me personally your participation was very rewarding and inspirational.

To all those that undertook the on-line survey, I am most grateful.

Thanks to Hans, my supervisor for guidance, encouragement and keeping me on track. Thanks also to all the MMIM lecturers who have been full of enthusiasm and energy and who make learning exciting and relevant.

Finally, I am ever grateful to my partner, Gayna Vetter, who has been so wonderfully supportive throughout the fours years I have taken to complete my MMIM and through the last several months of toil while I have wrestled with this research paper. You have led the way with the achievement of your own Masters and in doing so provided inspiration to me. Thank you so much for being my proof reader. I am forever in your debt.

\section{Confidentiality}

This work is not confidential. The research findings presented in this paper are summarised, therefore individual participants are unable to be identified. Only the researcher and the research supervisor have access to the detailed transcripts. Interview transcripts were created by the researcher. 
Author's own work verification

\section{Statement of academic integrity}

1. This research paper is my own work.

2. I have not allowed, and will not allow, anyone to copy my work with the intention of passing it off as his or her own work

Signature

Date ...14.../...10.../...2010.....

Full name of student: Mark Raymond Harris 


\section{Abstract}

In this research paper the role of followers in a leader's development is explored. The research findings show that leadership development remains a "slippery" subject and in spite of all the commitment made by organisations to develop leadership, the return on this investment, as viewed by followers is poor. Even though followers are the indirect recipients of leadership development and without them the role of leader does not exist, they are largely excluded from the process. Leaders see the important contribution they could have if provided the opportunity. Moreover, the development of followership is not evident even though both followers and leaders alike see the critical role of followership in a leader's success.

The focus of leadership and followership is dominated by the leader's views. While not researching sensemaking in depth, this research presents evidence that the sensemaking of followers is accurate, insightful and meaningful. The research begins to explore the reasons for the low return on leadership development and highlights harmful aspects that can arise where care is not taken to consider a leader's maturity and situational context.

The research shows how organisations are not actively encouraging authenticity and inner development of followers. Where this occurs it is largely a passive process and takes place through mimicry. Given the imbalance of resource allocation to be almost totally to the benefit of leadership, authenticity awareness and development is seen to be reserved for those that desire the title of leader.

Finally, the research suggests that implementing followership development in a similar way to that which occurs in leadership would be positive although limiting. The current commoditisation of leadership results from the way mainstream thinking considers the leader's role and encourages a relational and dualistic view between the leader and follower. This view does not align to the everyday experience of people who share conversation, who create meaning together and who together help construct the leader role. 


\section{Contents}

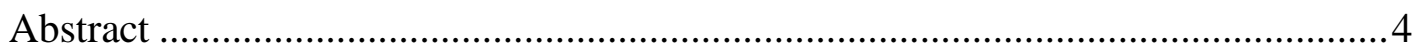

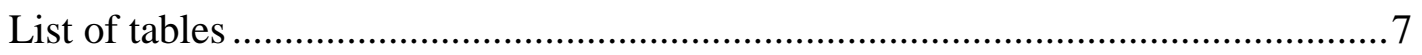

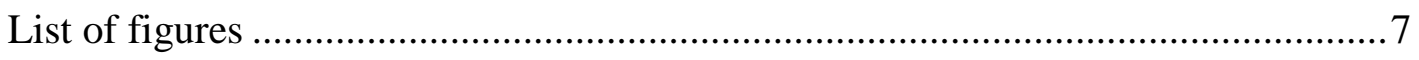

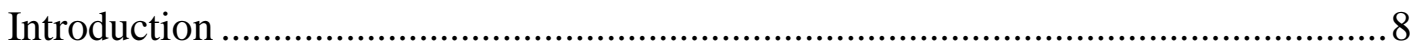

Research domain: From Leadership to Followership .............................................. 9

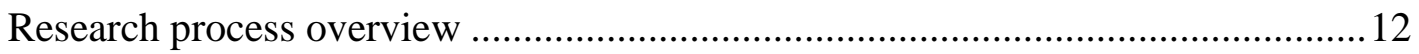

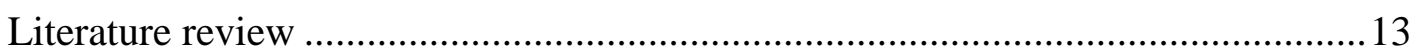

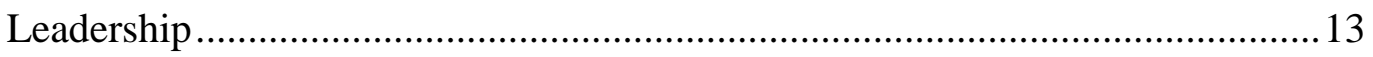

Leadership - summary of research relevance ….............................................28

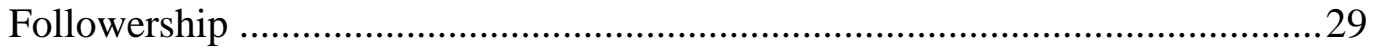

Followership - summary of research relevance ............................................52

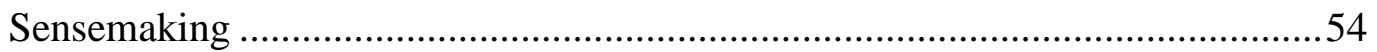

Sensemaking - summary of research relevance .............................................5 57

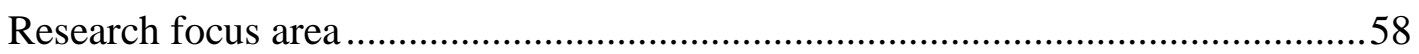

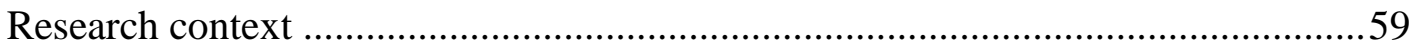

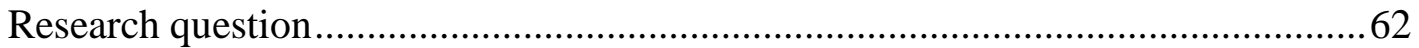

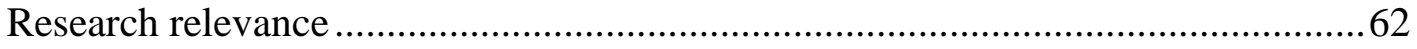

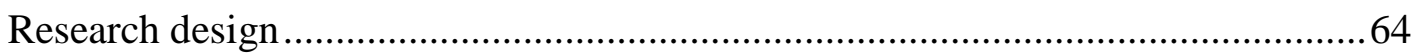

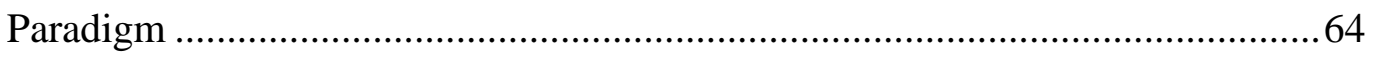

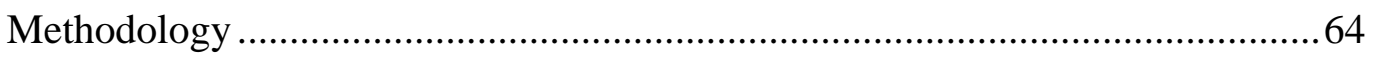

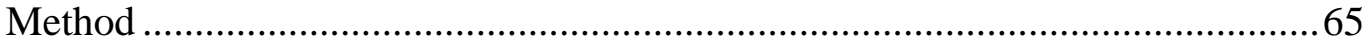

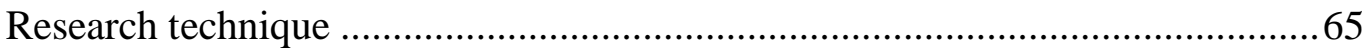

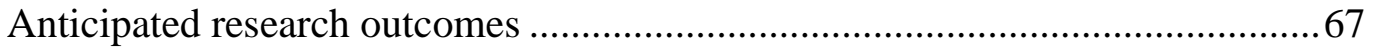

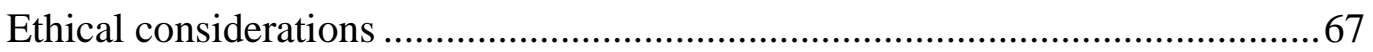

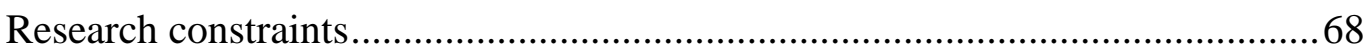

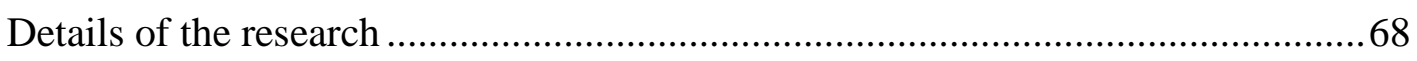

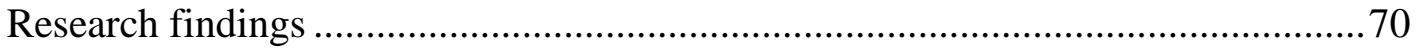

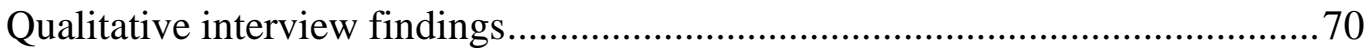

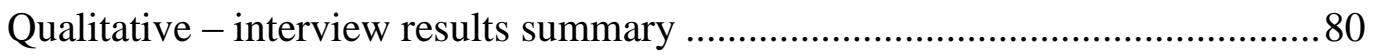

Qualitative - interview descriptive summary ................................................. 82

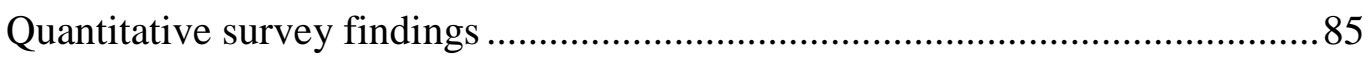

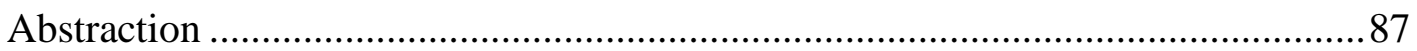




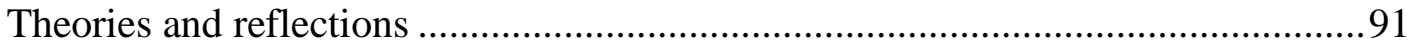

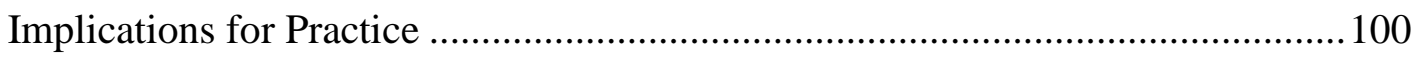

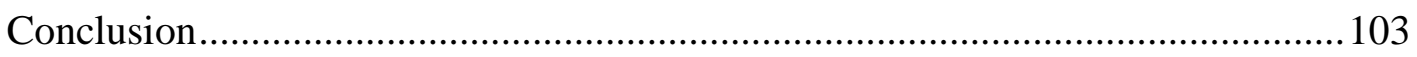

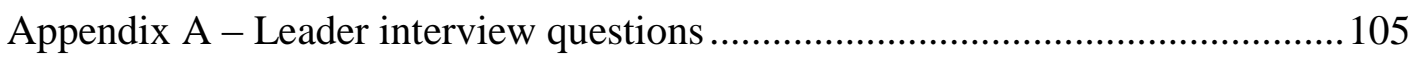

Appendix B - Follower interview questions ...................................................... 111

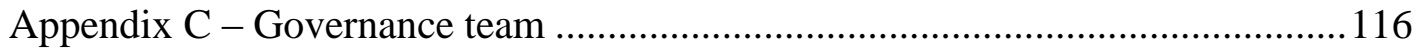

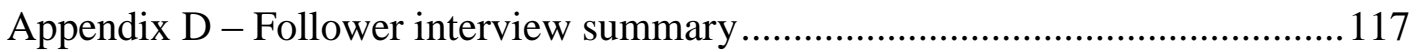

Appendix E - Leader interview summary ........................................................ 119

Appendix F - Programmes attended by leaders ................................................. 120

Appendix G - On-line survey questions ...................................................... 121

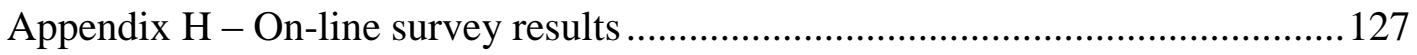

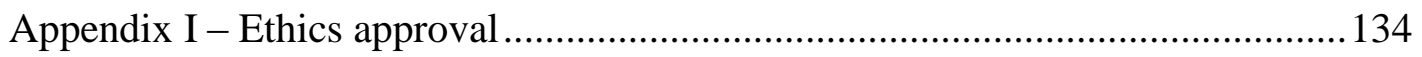

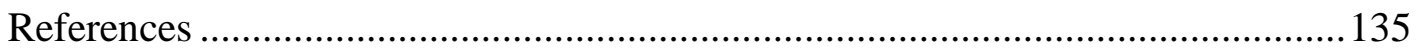




\section{List of tables}

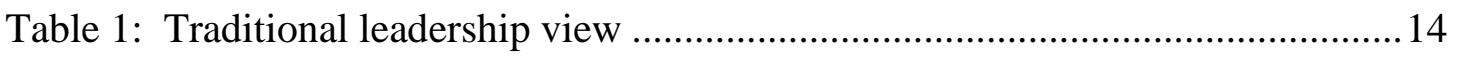

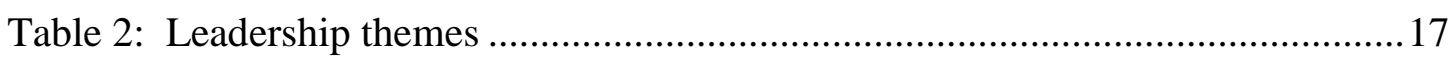

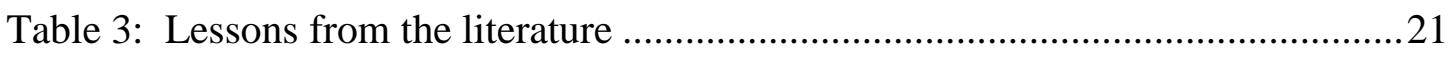

Table 4: Contemporary leadership effects on management .....................................2

Table 5: Traditional Followership Views .................................................................. 30

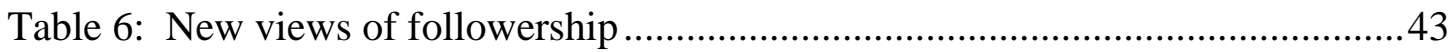

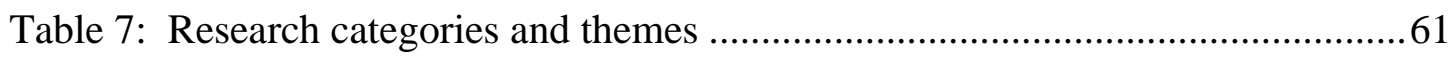

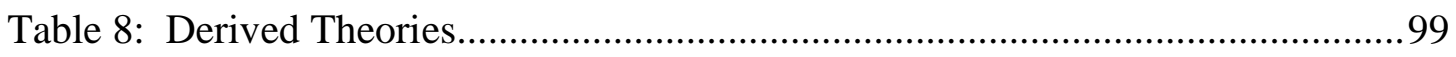

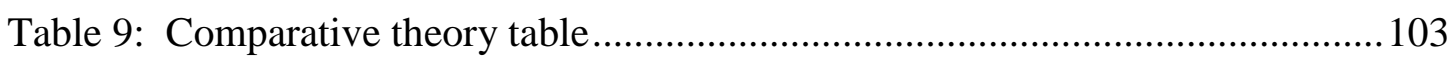

\section{List of figures}

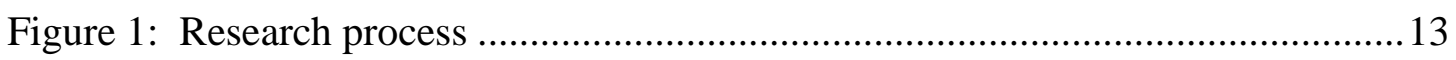

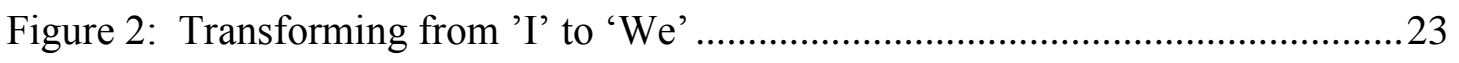

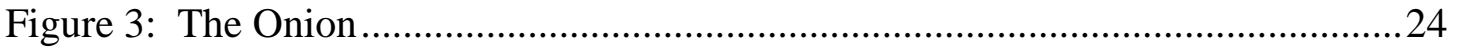

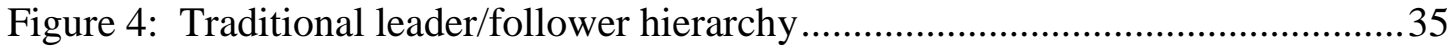

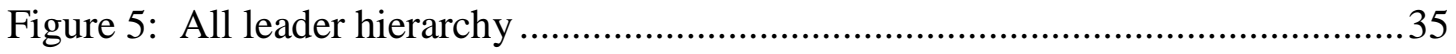

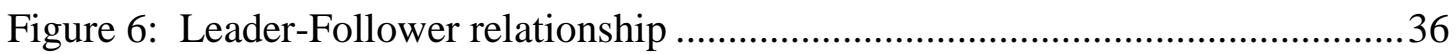

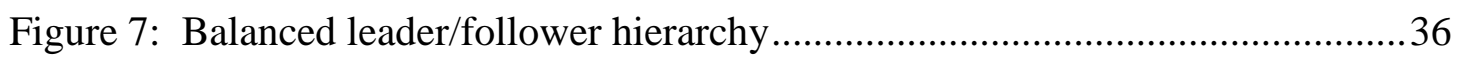

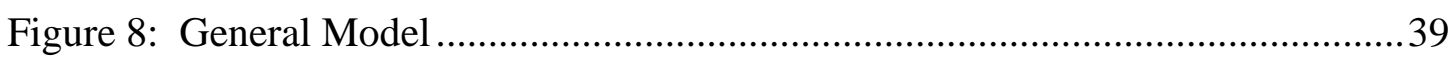

Figure 9: Framework for authentic leader and follower development.......................48

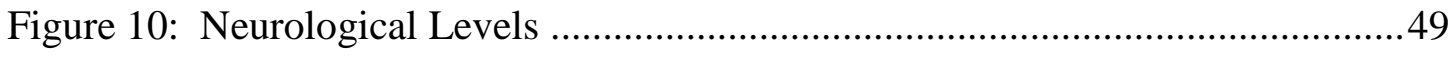

Figure 11: Linking culture and leadership to subordinate self-regulatory structures .51

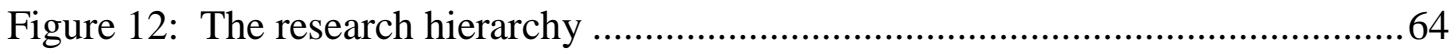

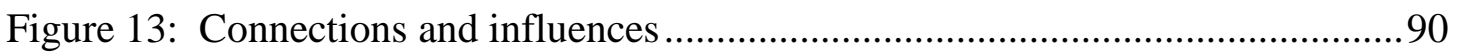

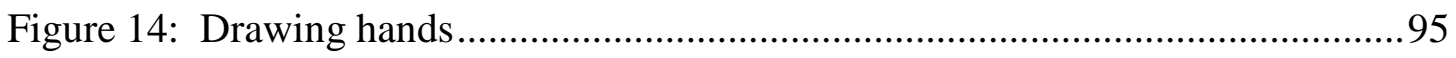




\section{Introduction}

"It's just another one of these leadership training courses" Liz said... "I see no benefit to me or the organisation" was Joe's comment.... "I agree, everything will remain the same around here, there won't be any tangible outcomes" were the observations provided by Jennifer ${ }^{1}$.

These colleagues, highly competent professionals in their own right demonstrate a degree of scepticism toward the array of leadership programmes their managers attend. They expressed doubt as to the value of the development initiatives. The research question discussed in this paper arose from such comments while the researcher was employed as a middle manager in a mid-sized government agency in New Zealand from 2005 to 2010.

Whenever leadership development was discussed with the followers, those whom the leaders lead, many different perceptions had formed in their minds. How did these perceptions emerge? Could they help or constrain a leader's development? What was the impact of the follower's view on a leader's development? For it seems that if a leader is to be successful, the followers would need to see their development in a beneficial light. David MacKenzie (2001) observes "For all the time, enormous human resources, and money spent on promoting leadership and learning, our ROI has been low." Could a low ROI in any way be linked to the sensemaking of the follower?

Further ideas formed after the researcher discussed leadership development with a local leadership development organisation. This organisation was not clear as to the ongoing benefit of their work once a leader returned to their daily routine. When managers return from a leadership development programme what are the outcomes for the followers? Can the leader's managers see positive outcomes as a result? Importantly, in line with MacKenzie's view, was there a positive return on the leadership investment?

What appeared clear was that followers were uncertain as to the benefit to themselves and their organisations. This uncertainty has led them to form assumptions on leaders and their development. This research project formed from these observations and

\footnotetext{
${ }^{1}$ Names used are fictional
} 
sets out to ask questions such as: what are the follower's perceptions and assumptions of their leader's development, how did it get there and what impact does it have on a leader's success? Can a leader benefit from knowledge of the perceptions and assumptions their followers have? Are they able to influence it and, if so, how? Does the follower understand their role in a leader's development? Can we understand the leadership return on investment more accurately if seen from the follower's perspective?

\section{Research domain: From Leadership to Followership}

Every year millions of dollars are spent on the development of leaders. Referring to research by O'Leonard and Lamoureus (2009), O'Leonard (2009) writes that US companies spent $\$ 500,000$ on average in 2008 on leadership development or just over \$2000 per participant.

Airport bookshops overflow with titles on leadership. It is likely that most senior level managers have read about leadership, have talked about and understand leadership as being critical to business and organisational success and subsequently most have undertaken some form of leadership training.

Managers are informed that leadership can be learned and this is just as well, otherwise leadership development would hardly have become an industry. Leadership as a learned quality includes skills such as being able to create a shared vision, how to establish high performing teams, how to inspire followers, understanding the different leadership styles and how to adjust style based on changing context. For most budding leaders there is a lot to learn.

We hear of great leaders and their achievements: Churchill, Ghandi, Mandela, etc. It is unlikely they ever took a leadership development course, rather their success stems from unique circumstances and personality and contexts that are rarely if ever repeated in organisations. We study such individuals in depth to determine what makes them successful. Our study and apparent attempts to emulate their qualities are common in leadership learning programmes. Often, these qualities are distilled to bullet pointed best practices such as 'The Five Practices of Exemplary Leaders' (Kouzes \& Posner, 2007, p. 14) or 'The 21 Irrefutable Laws of Leadership' (Maxwell, 1998). 
While the outstanding success of notable leaders is not in dispute, it is difficult to determine how our businesses and organisations, society and politics are benefiting from the localised leadership development trends. Organisations, often with good intention, implement leadership development designed to inspire localised benefit. For these activities, the return on leadership development is not clear. Believing that there are benefits implies that we need to be mindful of them, to be on the lookout for them and to acknowledge that they have been derived from our leadership investments and not by chance. Conversely, if the leadership developments are having no impact or even a negative effect, then it seems we would want to consider altering the course of action.

It is said that leadership leads to action and that action to the achievement of a desirable outcome. That outcome may be increase in profit and growth or the long term sustainability of the enterprise. It may be the reduction in crime rates or infant mortality, of extreme poverty or extreme wealth, in $\mathrm{CO}^{2}$ emissions or the increase in the number of souls saved. Measurement of leadership success is often seen as a tangible delivery of an outcome. In traditional project management terms that usually means being on time, in scope and within budget (the three classic project management success measures). Reflecting a linear and causal orientation, this thinking works within the boundaries of a stable world where cause and effect views are useful and usually provide a reliable explanation of the world. Where stability and certainty are assumed measurement of leadership success in these terms would seem plausible.

Noted by Eisenhardt \& Martin (2000) we don't establish long or medium term strategies any more, we develop dynamic capability, strategies and systems that are capable of changing "on the fly" as the environment changes. Responding in this way informs us how we consider the surrounding environment. Firstly we appreciate that the world is not stable, linear and predictable. Secondly, that the leader cannot predict what will happen tomorrow.

Whatever the outcome, leadership does not take place without followers. It is through followers that outcomes are delivered. It is through the efforts of followers that great leaders such as Churchill, Ghandi and Mandela achieved their success, for on their own they are only great individuals. Leadership as a noun is a quality. Leadership as 
a verb is an action, a process that requires participation of followers. Leadership outcomes occur through the efforts of followers not the qualities of the leader.

Successful leadership will likely be seen differently between followers. Imagine a new leader trying to inspire a shared vision - a frequently cited undertaking of quality leadership. Each follower will construct a unique view of the words and language of the leader. What each individual pays attention to will be different and will help contribute to the development of their mental schematic (model) based on their past experiences - personal and organisational. Conversations "around the water cooler" further elaborate meaning and this social construction brings possible conformity (positive or negative) but also a shaping and reinforcing of individual meaning and understanding. A follower's reality is complex and rarely linear and causal. Their identity will likely be constantly shifting. Their view of leadership success will differ between followers themselves and also their view of the leader. Measuring success and leadership ROI then becomes difficult - whose version of success is considered and at what time and in what space?

Moreover, the implications of this dynamic are that the idea of creating a "shared vision" becomes difficult. At best all one can hope for is some degree of consensus and from this point enlist participation. Shared vision could be considered an oxymoron that blinds leaders into the false belief that creating one is possible. The rather unpredictable, complex and individualistic world is difficult to control, perhaps it cannot be. The follower has considerable power and influence over the outcome of the leader, a power perspective that is rarely considered. Given the prominence on leadership development it appears as though followership development is forgotten and gives the impression that leadership development misses a critical influence and thus organisational development is missing a valuable learning source. In addition, if followers have significant impact on the development of a leader beyond the usual 360 feedback (usually a one-time only occurrence), it is surprising that followers' contributions are not more readily sought and their sensemaking of leadership development brought into view. Not to include followers' inputs into leadership development appears to leave out a valuable part of the equation.

This leader-follower dynamic also reminds us that leadership development where no relationships or social context (there are no followers) is present is nonsensical. 
Leadership does not happen in isolation of a social context. The context is usually local and brings into view issues of personality and underpinning perceptions of power and competitiveness. Are leadership development programmes relevant to local context, are issues of power surfaced, or do they simply provide anecdotes that are actually difficult to implement back on the job?

The ramifications of this discussion are that to understand leadership means to understand followership. Specifically, what is needed is to gain insight into the way followers make sense of their leader's development. It would seem sensible to suggest that regardless of the level of leadership development and leadership competency, if, in the followers mind, leader development is seen as just "another one of those off-site events that are a waste of time" then the resultant participation of the follower is already in jeopardy. Should this be the case, the ROI of the programme is limited at the very start and this knowledge might change the way that leadership is developed.

Given this understanding, we turn to the followers to understand their epistemological and ontological view of leadership and leadership development initiatives. Here is opportunity to see the success or failure of leadership development through the follower. The views a follower holds of a leader will lead to how they, the follower, will participate and have significant impact on not only how the leader will lead, but how successful they do it and who the leader will actually be. That understanding will help us apply relevant leadership development methodology. To study followers, their view and sense-making phenomena becomes an extremely valuable exercise.

\section{Research process overview}

This research effort follows a familiar path, starting from the literature review through to data abstraction and theory formation. The overall process is shown in Figure 1 on the following page. A stylised version of this figure is used throughout this document to help orientate the reader. 


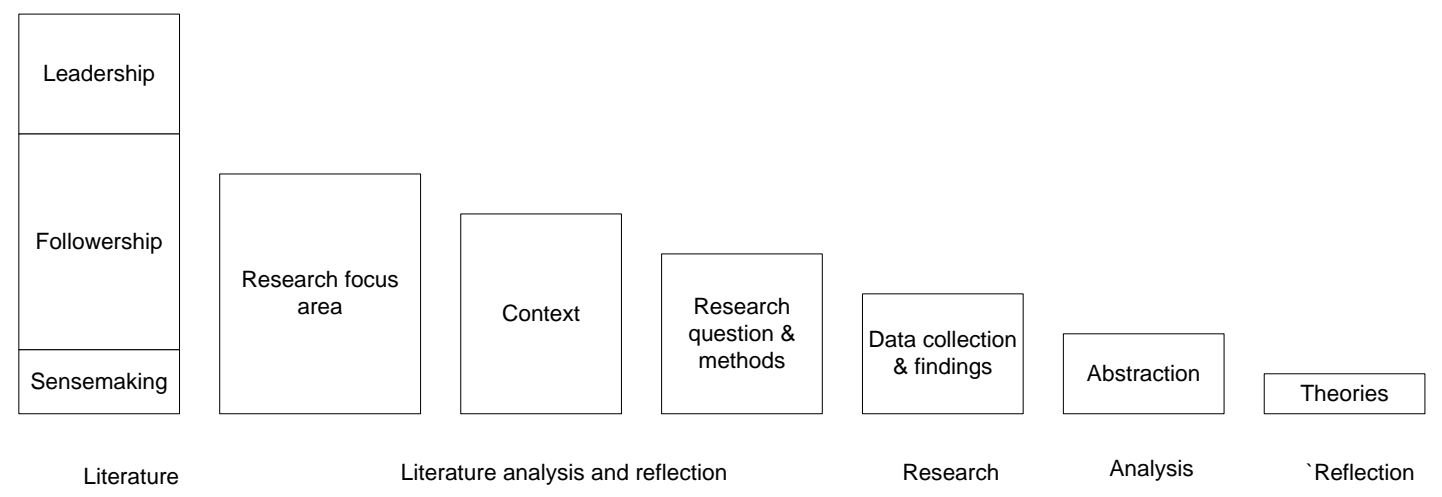

Figure 1: Research process

\section{Literature review}

Leadership, followership and sensemaking provide the focus for this research literature review. While the emphasis is on the latter two, leadership development trends are presented first. This is important given the close relationship between leadership and followership (as will soon become clear). This provides a suitable and relevant frame and point of leadership orientation from which to launch a review of followership.

\section{Leadership}

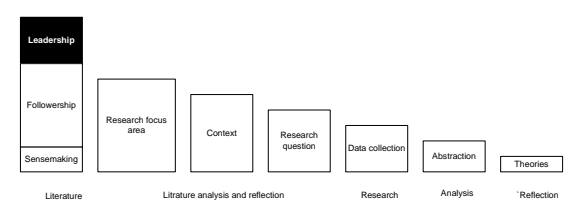

"The concept of leadership eludes us or turns up in another form to taunt us again with its slipperiness and complexity. So, we have invented an endless proliferation of terms to deal with it... and still the concept is not sufficiently defined." Citing Warren Bennis from 1959, (Karps \& Helgo, 2008, p. 31)

These words are just as true today. After years of research nobody has accurately articulated the real definition of leadership; it is one of those qualities that you know when you see it but have difficulty in trying to describe it and greater difficulty trying to define it. Whether talking about the board room, the local church or the rugby field, leadership today is widely recognised as being vital to success; however as Bennis notes 40 years later "for all the ink it gets in scholarly, business, and popular journals, leadership remains an elusive concept”" (Bennis, 1999, p. 1). 
For its "slipperiness" and high profile its elusiveness suggests that our inability to "catch and define it" is as much about how and where we are looking than any form of leadership stealth.

Based upon recent leadership literature this section draws our attention to leadership, to highlight new thinking that can juxtapose the old. As will be presented, new explanations of leadership are more compelling and more at the core of a leader's daily experience of leading through changing, often conflicting, and complex situations. Malcolm Higgs observes "the drivers of interest in leadership are clearly associated with change and complexity in business and organisational environment" (Higgs, 2002, p. 274). Like Higgs, most leadership writers (this paper included) will cite the dynamic, complex, fast paced and information driven global world as a primary reason why leadership is important.

The formal study of leadership originated from the military and the study of battlefield tactics (Tzu, 2003). Plato argued that ruling is a skill and given people differ innately in their various skills those that exhibit the greatest capacity for ruling should be trained and be made rulers (Popkin \& Stroll, 1956, p. 53). Plato provided an anti-democratic philosophy of leadership. From Plato to recent times, the leadership landscape has been dominated with the traditional leader as hero image, the solitary 'Joan of Ark' figure that saves the day and rides into the sunset. Traditional views of leadership are presented in Table 1 below.

\begin{tabular}{|ll|}
\hline \multicolumn{3}{|c|}{$\begin{array}{l}\text { Leadership - Traditional view } \\
1\end{array}$} & $\begin{array}{l}\text { Leadership is viewed as a specialised role usually from people higher on the organisational } \\
\text { chart. }\end{array}$ \\
\hline 2 & Interventions are made by the leader. \\
\hline 3 & Leadership is viewed as the attainment of certain attributes and competencies. \\
\hline 4 & $\begin{array}{l}\text { Leadership development is not inherent within the organisational culture. Leadership is } \\
\text { learnt off-site. }\end{array}$ \\
\hline 5 & $\begin{array}{l}\text { Leaders view structural interventions rather than managerial or leadership changes as tools } \\
\text { to bring organisational change (Hamel \& Breen, 2007). }\end{array}$ \\
\hline 6 & A focus on fixing weaknesses through competency development. \\
\hline 7 & Completed outcomes are the primary measure of successful leadership. \\
\hline 8 & Leadership decisions are applied through policy and procedure. \\
\hline
\end{tabular}

Table 1: Traditional leadership view 
Today, leadership focus is on achieving results rather than winning the battle. Considering the book titles 'Results-Based Leadership: How Leaders build the business and improve the bottom line' (Ulrick, et al., 1999), or 'The New Leaders: Transforming the art of leadership on the science of results' (McKee, et al., 2002). These titles reflect social and economic values (Stead \& Stead, 1994) and they direct attention and therefore influence what is chosen to learn about leadership; this guides and filters our understanding of leadership, wisely or not.

As these titles reveal that today's leadership is seen to have critical impact on the achievement of results; this is evident in leadership learning and development programmes where successful leadership is viewed as being about people that initiate positive change toward a desirable end goal.

There are different means to the end. To cite some well admired contemporary leadership writers, Warren Bennis in his seminal book 'On Becoming a Leader' makes clear the different attributes between leaders and managers (1994, p. 44) and later states that "Character is the key to leadership" (1999, p. 4). Daniel Goleman (2004) views leaders through their level of emotional intelligence. Chaos and complexity theories help the likes of Margaret Wheatley (1999), Douglas Griffin and Ralph Stacey (2005) explain new leadership ideas. Systems thinking forms the foundation for others such as Peter Senge (1990) and Robert Flood (1999). There is an increasing number of writers presenting theories of spiritual leadership (Burke, 2006; Cacioppe, 1997; Cammock, 2001).

Common leadership themes are found in the literature (Higgs, 2002) and are listed and described in Table 2 (below and following pages).

\section{Theme Description}

Traits Theory: The understanding of the specific qualities/characteristics that leaders need to possess. For example: honesty, integrity, self confidence, ability to motivate.

Issues: The lists of traits assume that they are required in any given situation. The lists can be long and tend to mix behaviours with traits. The lists may differ between genders and are typically male oriented (Doyle \& Smith, 2008).

Example leader: Maximus, the main character from the movie Gladiator 


\section{Theme Description}

demonstrated many of the traits we associate with a leader: courage, toughness, determination, etc. Ginger, the lead chicken in the movie Chicken Run (while displaying rather different traits to Maximus) demonstrated traits such as loyalty, vision and a wonderful ability to motivate all the other chickens, enabling them to free themselves from the run.

Authors: Warren Bennis (1994), George Day and Paul Schoemaker (2008)

$\begin{array}{ll}\text { Situational } & \text { Theory: An understanding that leadership style needs to change from situation to } \\ & \text { situation. For example, in an emergency leadership style would be different to } \\ & \text { when co-conscious and participation was required. }\end{array}$

Issues: Does not address cultural differences well. There are also gender issues: men being task and outcome oriented whereas women are more participative with a focus on establishing relationships (Doyle \& Smith, 2008).

Example leader: Nelson Mandela.

Authors: Paul Hersey (1984)

Transactional Theory: Transactional leadership works through creating structures whereby it is clear what is required of their subordinates and the rewards that they get for following.

Issues: Assumes that people are always motivated by reward and it does not build on people's need for meaningful work, self fulfilment or to tap into their creativity.

Example leaders: Robert Muldoon, Homer Simpson's boss :-;

Authors: James Burnes (1978)

Transformational Theory: The leader has a challenging vision that is communicated, that motivates and that inspires followers.

Issues: Focus is on the charismatic and personal power of the leader and less on service supporting the development of the people.

Examples leader: Martin Luther King

Authors: Bernard Bass and Ronald Riggio (2005), James Burnes (1978). 


\section{Theme Description}

Servant $\quad$ Theory: The understanding that the focus for the leader is on others, rather than an individual self. Servant leaders develop people with their primary objective to serve others (Stone, et al., 2004). The servant leader is seen as a steward.

Issues: Servant leadership takes time to develop, it can be seen as soft, listening and empathising may lead to indecisiveness and lack of vision.

\section{Example leader: Ghandi}

Authors: Robert Greenleaf, Larry Spears and Stephen Covey (2002), Margaret Wheatley (2005) Theory: A focus on self and through the recognising, reflecting on, developing and owning personal characteristics such as values, emotion, thoughts and beliefs. Acting authentically and expressing oneself as one's true self. Through modelling such behaviour, this will build trust and motivated followers.

Issues: Nobody is fully authentic - people are either more or less authentic. The process takes time and is likely never complete. As with servant leadership, it can be seen as soft.

Example: Ed Hillary

Authors: William Gardner, Bruce Avolio , Fred Luthans, Douglas R. May Fred Walumbwa (2005), Bill George, Peter Sims, Andrew N. McLean Diana Mayer (2007)

Spiritual Theory: Providing a sense of connectivity and wholeness; to find meaning and
purpose in one's life and work, an inner and personal discovery process.

Issues: As with servant and authentic leadership, it can be seen as soft. Individual spiritual fulfilment is a life long process and may lead to indecisiveness and lack of vision.

Examples: Dalai Lama

Authors: Peter Cammock (2001), Ron Cacioppe (1997), Robert Burke (2006)

Table 2: Leadership themes

Adapted from (Doyle \& Smith, 2008) 
The themes presented above demonstrate how leadership is not static but is evolving. The heroic 'Maximus' leadership style has been outgrown and new themes, more suitable to the dynamics of modern organisations are continuously forming. Noted by Higgs (2002), the diverse and sometimes contradictory views of the nature of leadership share common themes; the focus remains on the top level leaders and the measure of success is usually the financial performance of the business.

Leadership is impacted by the larger systems within which it functions. The sensemaking mechanisms that enable meaning making of the wider environment, that help to form mental imagery and establish behaviour patterns need to be understood within a wider context. Leadership operates within and is influenced by this context and suggests a wide systems view needs to be considered and understood as part of a leader's development. Jackson (2004) suggests that knowledge of the ontology of complexity embedded within a system becomes a starting point for understanding how interventions and change can take place.

The leadership literature seeks to explain such phenomena. Goleman's (2004) emotional intelligence ideas have been based on neuroscience and attempt to demonstrate the importance of brain chemistry. He observes that sections of the brain that help form leadership qualities such as empathy develop largely in early years and are slower to develop as we age. He suggests that a seminar or how-to manual is not effective. The regions of the brain that govern emotion that are important for the development of leadership qualities require a different mode of learning; importantly the brain needs lots of repetition and practice for the appropriate neural pathways to develop (McKee, et al., 2002). Supporting Goleman's thinking Higgs (2002), presenting emotional intelligence elements such as self-awareness, emotional resilience, interpersonal sensitivity and intuitiveness, suggests that these qualities are strongly linked to effective leadership.

It is interesting to note how other disciplines, notably quantum physics, biology, psychology, chaos and systems theory are used to provide definition of and insight into leadership (Griffin \& Stacey, 2005; Senge, et al., 2007; Wheatley, 1999). 
The new sciences ${ }^{2}$ (Stacey, 2001; Wheatley, 1999), the writing on spiritual intelligence (SQ) ${ }^{3}$ (Cacioppe, 1999) and writers from the field of positive psychology are examples. From the complexity and quantum physics view we learn:

- Leadership dynamically emerges within a specific context (Griffin \& Stacey, 2005), it happens moment by moment (Cacioppe, 1997), emerging from an individual's life story (George, et al., 2007).

- A leader requires the ability to articulate emerging themes; to "make sense" of the patterns as they are developing (Griffin \& Stacey, 2005; Senge, 1990; Snowden, 2005).

- A leader needs to be able to deal with ambiguity, incomplete information, complexity and disorder (Snowden, 2005). All that may be possible is to vaguely identify emergent patterns and themes.

- Sensemaking and sense unmaking, as an activity, enables the bridging of gaps in knowledge (Dervin, 1998). Management of disorder through heuristics, the management of boundaries, attractors and identity will likely be more effective in complex situations than using management and leadership techniques which assume stability and certainty (Dervin, 1998; Snowden, 2005)

- Small changes can have large impacts (Wheatley, 1999).

- Chaotic, complex systems find balance with simple rules (Wheatley, 1999) . The implications are that control is less about complex policy, structure or a suitable organisational chart, ideas often associated with traditional leadership style. Rather control is inherent in complex and chaotic systems and order is maintained with simple and uncomplicated rules.

- Leadership is a paradox. Leaders are both leaders and followers at the same time (Litzinger \& Schaefer, 1982).

- Vision emerges from need and what people care about (Wheatley, 1999).

\footnotetext{
${ }^{2}$ The new sciences refers to quantum physics, chaos theory, biology, and complexity science

${ }^{3} \mathrm{SQ}$ refers to inner development and not formal and orthodox religious dogma.
} 
- Free flow of information is vital for open system survival (Fairholm, 2004).

- Relationships are the lifeblood through which information flows (Fairholm, 2004).

Literature discussing SQ notes the pace of modern life and the stress it places on individuals and families. Many people question the meaning of work in their lives, how work contributes to happiness and the individual's connectedness with the wider world. Leadership ideas noted from the SQ authors are:

- Leadership development is an inner journey. It requires an understanding of personal values and beliefs, of strengths and weaknesses and personal identity (Gardner, et al., 2005).

- Leadership emerges from a person's life story (George, et al., 2007) rather than from developing leadership traits.

- Self-awareness is an important quality for a leader (George, et al., 2007).

- The leader needs to be present in mind and spirit. Mark Gerzon described presence as being "awake" (Gerzon, 2006) and in the moment.

- Leaders need to consider the wellbeing and happiness of the employees, the communities they live in and the impact their organisations have on the environment (Stead \& Stead, 1994).

From the positive psychology writers such as Seligman (2002) and Buckingham and Clifton (2004) we see themes: to be aware of and manage emotion, and to develop individual strengths as opposed to fixing weaknesses.

Rather than trying to provide all the answers as we expect, authors note (Isaacs \& Brown, 2005; Marquardt, 2005) that leaders need to be seeding their organisation with the right questions and, with a few simple rules, letting solutions emerge (Fairholm, 2004). While this level of autonomy may be viewed as one step away from madness, the new sciences suggest that stability is found in freedom, not control (Fairholm, 2004). 
Summarising the ideas from the literature just described, Table 3 below provides an analysis of leadership change that is brought about by these recent leadership observations. The Table presents, in the left column, the status as described in Table 1 as a basis for comparison to summarised observations from recent literature.

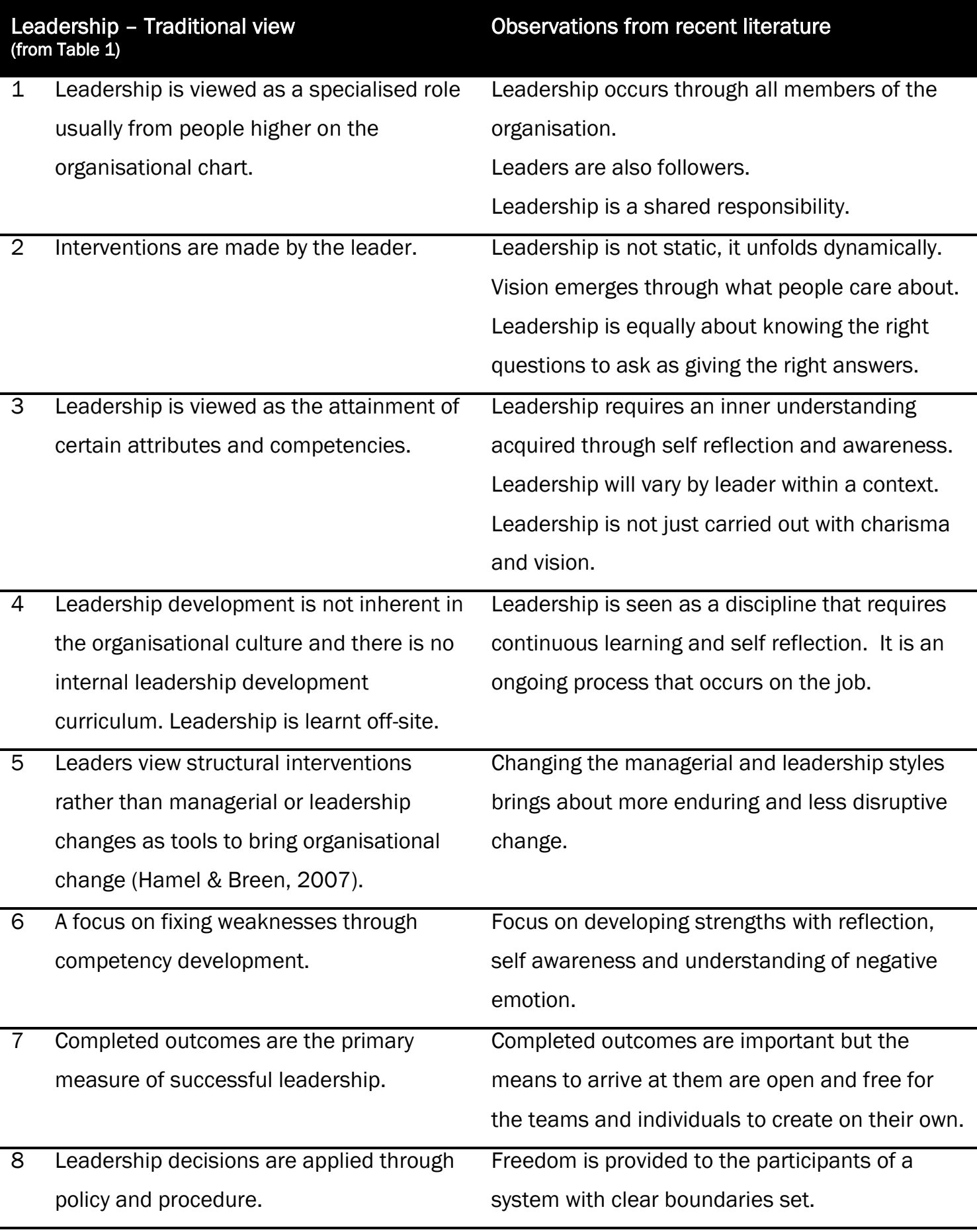

Table 3: Lessons from the literature

Further learning from the literature we see that influencing through vision and charisma (transformational theme) is now insufficient to lead in the future (Karps \& 
Helgo, 2008) . Gardner and colleagues (Gardner, et al., 2005) write that a leader cannot be viewed as charismatic without the follower and that they are viewed in part as more or less charismatic because of characteristics of the follower. Creating the vision and "selling it" implies that a leader can sit "outside" and apply interventions to move an organisation forward (Karps \& Helgo, 2008). When leaders need to "get buy-in" to a vision the important leadership principle of shared vision is already lost, leaders then need to "sell" their ideas. It is also likely that important and current knowledge, collected and often held tacitly, is not factored, or is significantly attenuated. Karps and Helgo (2008, p. 33) write that "what is being recognised in the leader-follower relationship is a configuration of power in which the power balance is tilted towards the leader. The one recognised as the leader is the one who has the capacity to influence the group" and the role of leader can shift moment by moment and therefore a leader can be in control one moment and not the next.

Authentic leadership development, noted as a leadership theme in Table 3 above, has been the first leadership theme that "explicitly acknowledges leadership development as an interactive process among leaders, followers and the context in which they find themselves embedded over time" (Avalio \& Reichard, 2008, p. 237). Gardner and colleagues (2005) suggest that authenticity, while having a base in positive phycology, is focused around the leader "owning one's personal experiences (values, thoughts, emotions and beliefs) and acting in accordance with one's true self", (Gardner, et al., 2005, p. 344). These authors also observe the importance of the follower: "we treat authentic followership as an integral component and consequence of authentic leadership development" (Gardner, et al., 2005, p. 346).

Gardner and colleagues suggest that "By being true to one's core beliefs and values, and exhibiting authentic behaviour, the leader positively fosters the development of associates until they become authentic leaders" (Gardner, et al., 2005, p. 345). They suggest that authentic follower development occurs by the followers modelling authentic practices and authentic leader behaviour. The likely result will be increased engagement, increase in job satisfaction, and heightened levels of trust that forms between the leader and the follower. They write "as a positive role model, authentic leaders serve as a key input for the development of authentic followers" (Gardner, et al., 2005, p. 347). Here leadership is seen as developing a relationship with followers. 
Bill George in his book 'True North - Discover your Authentic Leadership' (George \& Sims, 2007) recognises that developing authenticity as a leader takes considerable time and effort, certainly more than an occasional leadership training programme. According to George and Sims (ibid) dropping the ego state from an 'I' or 'Me' view to a more holistic 'We' view of the world is a critical part of a leader's transformation and developing authenticity. They believe that there are three life stages that are part of authenticity development. The three stages are presented in Figure 2 below.

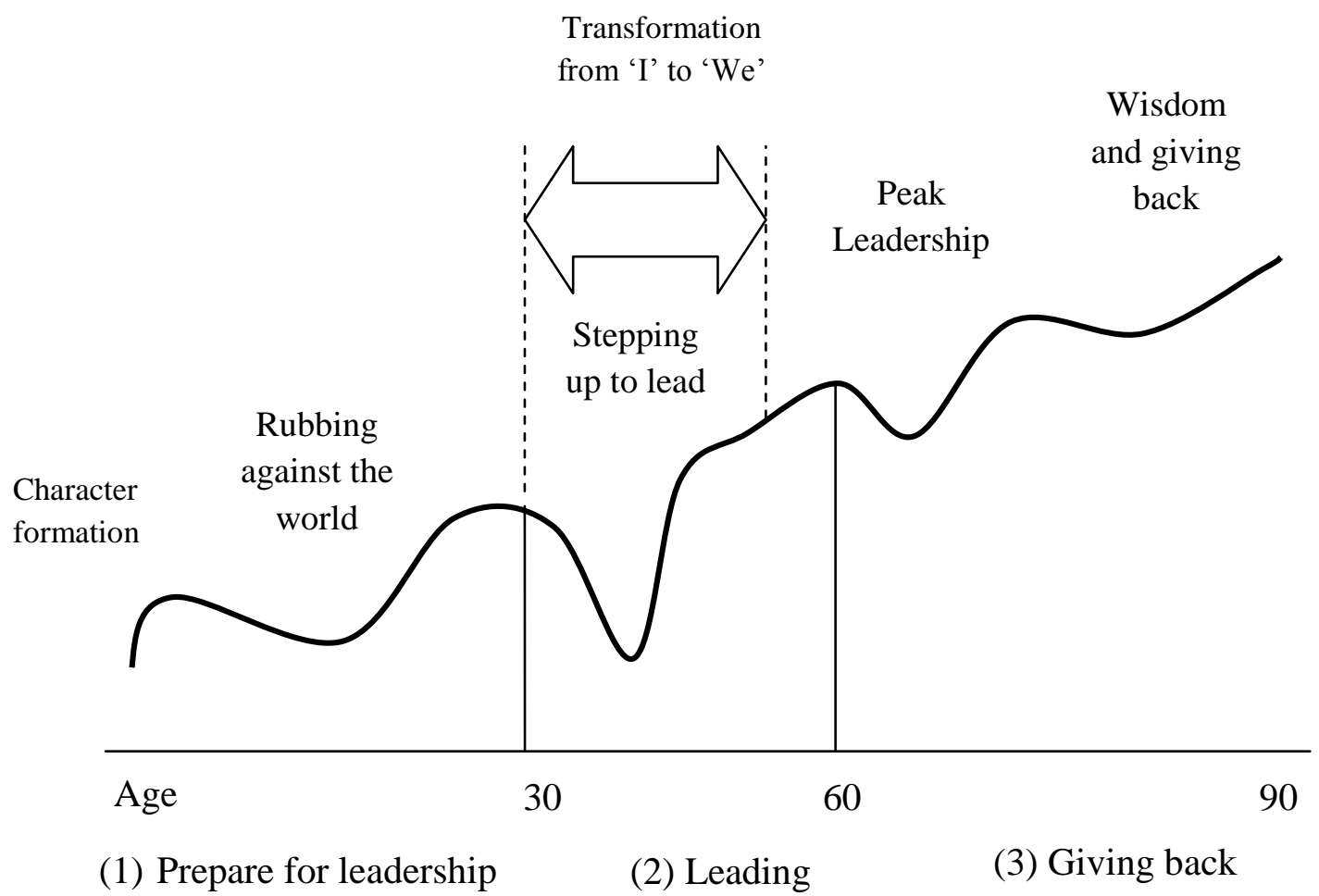

Figure 2: Transforming from 'I' to 'We'

(George \& Sims, 2007)

George and Sims suggest that "if our supporters are merely following our lead, then their efforts are limited to our vision and our directions about what needs to be done" (ibid, p. 45), meaning that excluding followers may also exclude possibility and insight.

From a leader's view George and Sims describe a process of peeling the onion such as in Figure 3 on the following page. Peeling back the various layers is required in order to discover one's authentic nature. 


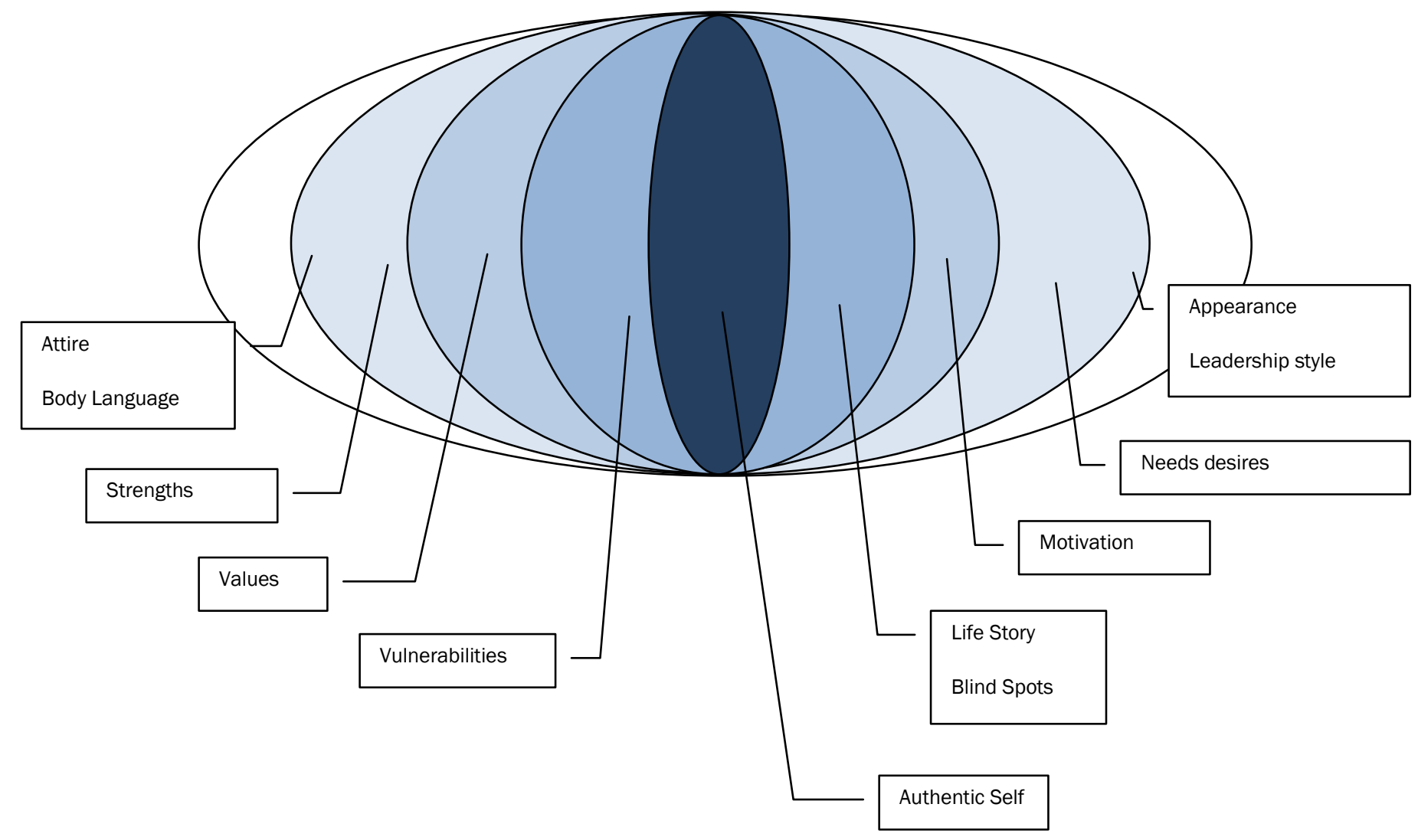

Figure 3: The Onion

(George \& Sims, 2007, p. 77)

Shamir and Eilam (2005) suggest that in order to develop authenticity in leadership a different approach to leadership development is needed. They propose the concepts of a life-story creation through the development of which self-knowledge and selfconcept clarity occurs. With respect to existing leadership development programmes, developing life-stories as a part of authentic leadership development "is different from most leadership development programmes which tend to focus on the acquisition of concepts, skills and behaviours either in courses and workshops or through on-thejob experiences, mentoring and coaching” (Shamir \& Eilam, 2005, p. 409). The authors go on to suggest that the life-story approach to authentic leader development implies that the development process is highly personal and furthermore may have to be largely neutral in order to be authentic.

The authors are wary of standardised programmes because authenticity in their view is personal. They believe that this process cannot be expected to gain much from the standardisation training programmes carried out within the framework of the leadership development 'industry'. 
An authentic leader "begins to occur when a leader incorporates the leader into their personal identity" (Gardner, et al., 2005, p. 351). The suggestion is that authenticity is a pre-requisite and that leadership will form and become part of a person's identity as the person sees himself or herself as being influential. Perhaps paradoxically, people that perceive themselves as leader and are uncomfortable or unwilling to let the role of leader change in a dynamic fashion because there is an attachment to the role, are unlikely to be effective in the longer term. In effect they have adopted an ego position to the role of leader (George \& Sims, 2007).

The internalisation of the leadership role into a leader's identity is also mentioned by Lord and Hall (2005) who write when the role becomes part of the leader's selfidentity it provides a) a structure for knowledge to be organised b) a source for motivation and direction for leadership learning and c) access to inner qualities that may also help understand followers.

Lord and Hall (2005) also suggest that leadership skill development needs to go beyond traditional acquisition of surface structure skills. They write that surface level leadership development minimises consideration of the deeper, principled aspects of leadership that may be especially important for understanding long term development. They reflect that as a leader develops there is a change in the way they access and use knowledge as well as the content of the knowledge in relation to their leader role. They suggest that leadership skill development changes a leader's information processing activities. In effect, surface level cognitive understanding and assumptions are replaced with meta-level, domain specific principled appreciation for values, emotions and identities. Deeper interpretive understanding of expert leaders allows them to develop ways of organising knowledge. Having a richer picture to draw upon and a principled rather than purely cognitive means to interpret events and issues, sensemaking is improved. As noted by Weick (2001) this enables the leader to stay within and interpret context.

As the leader matures, identity shifts from individual (self), to group, to relational. Lord and Hall (2005) write that as this identify shift occurs, there is a shift to a deeper structure and this is the hallmark of expert level knowledge. Knowledge for an expert leader does not need to be composed or discovered as it might for a new leader and the expert leaders can assimilate differences in people and circumstances with their 
own underlying values to create leadership that is sensitive to the follower context. The deeper awareness also means that a person is able to maintain access to knowledge even when physiological states change. As the leader matures they gain skill and a widening understanding of their self view. Thus as the identity of a leader is established there is an increased willingness to seek development opportunity and to take social responsibility, to play a leadership social role (Lord \& Hall, 2005, p. 594).

Wisdom themes are surfacing within the leadership literature (Rooney \& McKenna, 2006; Smith, 2007). Almost as "slippery" and as difficult to define as the concept of leadership, according to these authors, wisdom provides a foundation in dealing with the issues leaders face.

Rooney's and McKenna's (2006) definition of wisdom helps to establish wise decision making, learning organisations and leadership. The five principles that they based on Aristotle's notion of practical wisdom are summarised below

1. Reason:

Making careful observation and logical argument to correct decision making.

2. Non Rational and Subjective:

Acknowledging metaphysical and spiritual traditions

Understanding contingency of life and circumstances and connectedness

Visionary: Seeing possibilities into the future; is long term

3. Directed to humane and virtuous outcomes

Wisdom is virtuous and tolerant through empathy and personal insight

4. Practical: Displaying a sensible worldliness

5. Articulate: able to communicate with accuracy and authenticity

McKenna, Rooney and Boal (2009) further elaborate the ideas of wisdom and leadership suggesting that while the ideas introduced through transformation leadership and authentic leadership reflect significant advances, they fall short 
because of the emphasis on cognitive orientation and "it fails to acknowledge the role of non-rational and it insufficiently accounts for the ethical dimension of leadership" (McKenna, et al., 2009, p. 181). These authors also raise the interesting connection between leadership and knowledge noting that wisdom can become a central meta theoretical basis for evaluating leadership. They suggest this is possible because wisdom provides a framework for dealing with not just a wide range of complex knowledge difficulties but also with changing ontological structures (McKenna, et al., 2009). In their view wisdom does this because it is a transcendental process.

Not all leadership is good. History is scattered with examples of toxic leaders. Barbara Kellerman in her book 'Bad Leadership' (2004) categorises such leaders as incompetent, rigid, intemperate, callous, corrupt, insular and evil. She also draws attention to the role of followers in the development of and support for a bad leader.

The changing leadership trends are observed it management literature. Many authors suggest we are moving to a post managerial age (Hamel \& Breen, 2007; Karps \& Helgo, 2008; Whyte, 2001) and that changes in our understanding of management are influenced by changes in leadership. How this is occurring is summarised in Table 4 below.

\begin{tabular}{|c|c|}
\hline Traditional management view & Management and leadership observations \\
\hline $\begin{array}{l}\text { Control is issued through policy, } \\
\text { procedure and hierarchy. }\end{array}$ & $\begin{array}{l}\text { Control is through self organisation, simple rules } \\
\text { and established boundaries. }\end{array}$ \\
\hline Chaos must be avoided or managed. & The natural order of chaos is recognised. \\
\hline $\begin{array}{l}\text { Organisational charts show the } \\
\text { connections and the hierarchy }\end{array}$ & $\begin{array}{l}\text { Organisational charts are re drawn to show the } \\
\text { networks and energy flows. }\end{array}$ \\
\hline $\begin{array}{l}\text { Change is managed, complexity is created } \\
\text { e.g. through policy, rules and regulation. }\end{array}$ & Complexity is managed, change is encouraged. \\
\hline Weaknesses are "fixed". & Strengths are developed. \\
\hline Work is separate to personal life. & $\begin{array}{l}\text { Life is a journey, personal fulfilment and spiritual } \\
\text { needs are not separate from work life. }\end{array}$ \\
\hline $\begin{array}{l}\text { Feedback is provided at the end of the } \\
\text { year. }\end{array}$ & $\begin{array}{l}\text { Feedback occurs in the moment. In the spirit of } \\
\text { the complexity theorists, management is practiced } \\
\text { in the moment therefore it is learnt in the moment. }\end{array}$ \\
\hline $\begin{array}{l}\text { Problems are fixed by finding the faulty } \\
\text { part. }\end{array}$ & $\begin{array}{l}\text { Problems are fixed but with reference to their } \\
\text { impact on the whole. }\end{array}$ \\
\hline
\end{tabular}

Table 4: Contemporary leadership effects on management 
All the contemporary authors of leadership remind us that $21^{\text {st }}$ century leadership is different. The world has changed, it is smaller, some even suggest it is flat (Friedman, 2005). Gardner, Avolio, Luthans, May, \& Walumbwa write "We are entering into the age where nearly all information is readily accessible. In this period of organisational transformation and change, more and more individuals are involved in the leadership process of organisations; therefore more people know what is the right and wrong thing to do. Information now penetrates organisations at all levels and oftentimes the persons in a position at the bottom of the traditional hierarchy (the follower) knows the most about technology implementation, customers, vendors, changes in markets and variations in performance” [emphasis added] (p. 368).

Many of the leadership books remind readers that change as the only constant, requires new forms of leadership that were not required in the past. Leadership development has tended to move from outcomes achievement to inner development, to giving control rather than taking it, to shared and equal participation from traditional hierarchy. This is impacting on leadership development and on the leader/follower relationship.

\section{Leadership - summary of research relevance}

Even if this paper were only to review leadership literature it shows a changing leadership dynamic that would likely continue to evolve and therefore remain a subject of interest for some time. As described above, the traditional leader as controller has disappeared, the leader as hero has gone. Transformation leadership is recognised within its limits. Authentic and spiritual leadership are recent views. Wisdom is making a comeback as an underlying leadership quality.

Recent leadership literature suggests there exists a changing, perhaps more in-depth relationship between leaders and followers. This has relevance for this research and the details are summarised below:

- Leadership is being seen as an increasing role for followers.

- As workers gain knowledge, power shifts rank to those lower down the organisational chart. This changes the current leader and follower dynamic and, in turn, the way leaders lead. 
- Authentic leadership development exemplifies inner/personal development and suggests that modelling authentic behaviour will help establish authentic leader and follower relationships.

- In complex unordered environments (Dervin, 1998; Snowden, 2005) participation (rather than getting "buy-in") becomes critical for sense-making and sense-unmaking, changing the relationship engagement of leader and follower.

- In a global fast paced world, knowledge and information is often incomplete we live in a 'gappy' world as Dervin calls it (Dervin, 1998). Knowledge is a critical bridge-building tool that fills the gaps and provides meaning, enabling improved orientation. Leader and follower relationships must "grease the knowledge wheels" so that its flow is smooth, with little friction.

- Individual and organisational identity discovery and realisation are equally important for leader and follower.

Followership is attracting increasing attention, in part because of the shifting power balance and the resulting effect on leadership, also because there is uncertainty with regards the ROI and real benefits to leadership development. We turn now to a literature review of followership and attempt to understand this change and its impact on the development of leadership.

\section{Followership}

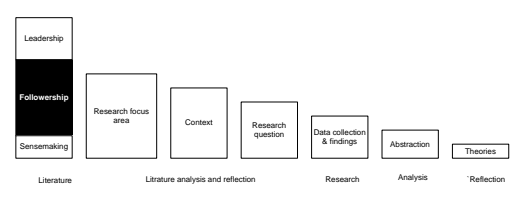

"He who learns to lead must, as men say, first of all learn to obey" Aristotle (cited in Litzinger \& Schaefer, 1982)

Stanley Milgram's (Blass, 2008) obedience experiments provide evidence supporting the idea that ordinary people will follow destructive orders and that it does not require evil people to carry out actions that are cruel and reprehensible. There are many historical events that portray the follower as blindly and almost unconsciously following behind the leader; like a sheep. 
Traditional followership views, shown in table 5 below, have evolved from the leadership perspective outlined above. Followers are largely powerless and certainly not the recipients of the glamour often associated with leadership.

\begin{tabular}{|cl|}
\hline \multicolumn{3}{|c|}{ Followership - Traditional View } \\
\hline 1 & Leaders lead, followers follow. \\
\hline 2 & Leaders are at the top of the hierarchy and do not follow. \\
\hline 3 & Interventions are made by the leader, not by followers. \\
\hline 5 & $\begin{array}{l}\text { Followership is viewed as the attainment of certain attributes and demonstrates } \\
\text { important behaviours that benefit organisational goals. }\end{array}$ \\
\hline 6 & Followers believe they have little influence on the development of a leader. \\
\hline 7 & Leaders have power, followers do not. \\
\hline
\end{tabular}

Table 5: Traditional Followership Views

Important themes exist in recent followership literature that have largely dispelled the traditional ideas of followership. Given that work is often knowledge-based and diverse in terms of ethnicity, gender and geography, Maccoby (2008) suggests that social character, the learned part of personality that is shared by people in a culture or social class, is moving from 'bureaucratic' to 'interactive'. Maccoby explains that a significant portion of the workforce has grown up with TV and playing video games, women have become a significant portion of the workforce, therefore hierarchy has given way to networks and independence. According to Maccoby (2008, p. 215) in this environment, the "interactive character" prefers leaders who facilitate participation, the idea of being a follower, or even the concept of a leader becomes almost irrelevant and the traditional hierarchy-based power relationships are turned inside-out.

The traditional leadership/followership hierarchy assumes that the leader has all the required knowledge and skills and can hold in view all the situational variables sufficient to make informed decisions. As suggested by Lord (2008) that when complex dynamic systems emerge locally followers become a critical component in decision making given they will usually already have made sense of events and be able to accurately interpret meaning. 
Why is this happening? Paul Glen (2003) describes some of the reasons when discussing the nature of "geek work". Subordinates know more than the managers, in geek work "managers rarely know all the details about the work of subordinates. It is not possible and it is not necessarily desirable” (ibid, p. 65). In geek work ambiguity and complexity mean that it is often never clear when embarking on a project what the outcome may be or how to get there. Glen observes that even defining what work is can be difficult. Geeks deliver most of their value through thought, not behaviour (ibid, p. 58). Thought takes place at work, by the "water cooler", on the drive home or in the shower. Limiting thought reduces value. In their paper entitled 'Leading clever people' Goffee \& Jones write "If clever people have one defining characteristic, it is that they do not want to be led" (2007, p. 6). This supports Glen's thinking that the role of leader changes as knowledge and expertise shift to the clever people and so changes the power relationships.

The growing awareness of the importance of followers, in particular since Robert Kelley's influential paper titled 'In Praise of Follower' (1988), authors of followership have used follower categorisation approaches in attempts to better understand followership, often however from the vantage point of leadership.

For example, Kelley himself, created a set of follower categories based on motivation and behaviour in the workplace. He listed the follower types summarised from Kellerman (2007) below:

Alienated follower: thinks critically but does not willingly participate.

Passive follower: does not think critically and does not willingly participate.

Conformists: does not participate, content to take orders.

Exemplary follower: performs well across the board.

Pragmatic follower: plays both sides of the fence, ranking in the middle of independent thinking and their level of activity.

Ira Chaleff in the Courageous Follower (Chaleff, 2009) categorised followers based on the degree to which they supported and challenged the leader (Kellerman, 2007).

Subordinates: will do enough to retain position, but no more. 
Individualists: withhold support, use contrarian, often challenging view.

Implementers: gets the work done but won't challenge.

Partners: assume responsibility for their own and leader's behaviour.

Kellerman's 2007 paper 'What Every Leader Needs to Know about Followers' (2007) suggests that the previous typologies (those of Kelley and Chaleff) have had little impact on the leader/follower relationship and suggests that in part this has been due to impacts of technology and changes of generations in the work force. Kellerman's own typology metric is based on engagement - from low to high.

Isolates: do not really care and are detached. Passively support the status quo and leaders who already have the upper hand.

Bystanders: observe but do not participate. They choose to fly under the radar.

Participants: engaged and try to make an impact and invest something of themselves.

Activists: eager and energetic. Act according to their feeling about a leader and organisation (support or undermine).

Diehards: will go down for the cause. Exhibit all-consuming dedication to something or someone.

Rodger Adair in his chapter in 'The Art of Followership' (2008, p. 144) presents the 4-D followership model, with the following typology:

Disgruntled: have decided that the organisation is of little value to them and they to the organisation. Angry and ready to jump ship.

Disengaged: see the value in keeping position. Not congruent with mission and value.

Doer: good worker, but usually looking elsewhere.

Disciple: aligned with the vision and values and highly motivated. 
Noting that literature on followership largely rejects the validity of subservient followers in modern organisations, Howell and Mendez (2008) suggest that the leader-follower relationship is characterised by follower role orientation. The authors suggest three active role orientations that will impact on the leader-follower relationship effectiveness:

Interactive role: where followership may complement and support the leadership role.

Independent role: where followers act more independently.

Shifting role: where there is a need to alternate between the leader/follower role.

Kellerman (2007) observes that the typologies are more similar than different. The typologies allow "superiors and subordinates alike to discern who in the group or organisation is doing what - and why” (Kellerman, 2007, p. 3).

Ira Chaleff (2008) suggests these typologies help generate a language of followership that in turn provides a developmental path. He notes that such approaches can also be useful where people self-access their style as a starting point for reflection and orientation. Chaleff suggests that followership style will change depending on leadership style and that there tends to be a core style. He suggests that "it is the core style that we want to identify so that participants can begin to understand the consequences of that style and make choices about reinforcing or changing it" (Riggio, et al., 2008, p. 75).

The more recent literature focuses the attention from romancing the leader to romancing the follower (Hurwitz \& Hurwitz, 2009). The following is noted:

- Leadership and followership are two sides of the same coin (Williams, 2008).

- Action is carried out by followers (Dixon, 2008). Followers execute strategy (Hurwitz \& Hurwitz, 2009) that can be more significant than the strategy itself.

- Most leaders spend the majority of their day as followers (Brown \& Thornborrow, 1996). 
- All leaders will have a personal history and that is likely to be as a follower and at different times in their careers, even at different times of the day, managers play both roles (Kelley, 1988, p. 143), although seldom equally well.

- Bosses are not necessarily good leaders, subordinates are not necessarily effective followers (Kelley, 1988).

- To be an effective leader, you must be a good follower (Townsend \& Gebhardt, 1997).

- "The leader, in short must not merely have been a follower. He must, here and now, be a follower in the fullest sense; in a sense, paradoxically, that the follower cannot be. The leader is more a follower than the follower" (Litzinger \& Schaefer, 1982, p. 79).

Follower, the noun, being considered an inappropriate word has been raised by several authors. "The very word follower conjures up unfavourable images of passive, low status underlings, unable or unwilling to achieve anything significant" (Brown \& Thornborrow, 1996, p. 5). Joseph Rost (2008, p. 57) comments "the word followers will never work in the post-industrial view of leadership because it comes with too much baggage, most of which contradicts the idea of collaboration in any meaningful sense". Ira Chaleff (2009, p. 45) states "Follower is not synonymous with subordinate".

Rost (2008) asks the question, how do we want those people who are not leaders to act and suggests that being active, intelligent, responsible and involved are some of these follower qualities. These are not the qualities of passive sheep. Rost suggests terms such as collaborative leadership, or collaborators. Chaleff (2009) suggests "courageous follower" as courage is opposite the current prevailing images of followers.

Gene Dixon (Dixon, 2008) notices that a similar shift is needed in the manner in which leadership and followership is represented in the organisation. The traditional 
leader/follower hierarchy as reflected in the organisational chart, Figure 4 below:

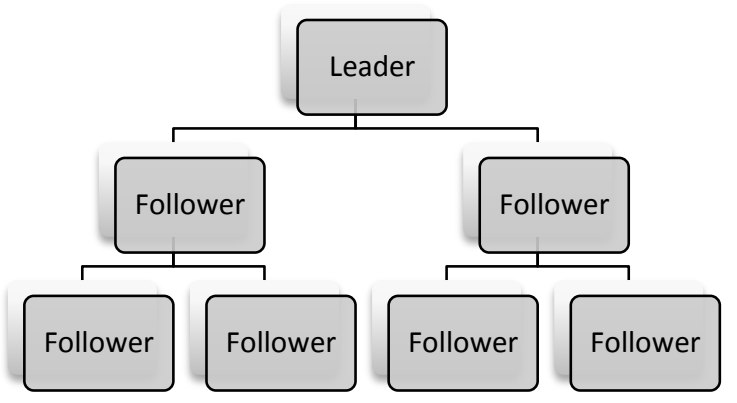

Figure 4: Traditional leader/follower hierarchy

Adapted from (Dixon, 2008, p. 161)

What Dixon does not portray in this diagram is the dual leader/follower roles often played by the "middle tier" or indeed recognise the problems this can create. Stech (2008) suggests that given leadership and followership are different states, held by different people (leaders and followers) at different times in different contexts, it is at odds with the traditional leader-follower hierarchy. That realisation results in a new and different way of looking at leadership development, namely that everyone in an organisation should be exposed to leadership training (ibid, p. 52). This trend is observed by Dixon (2008) who notes that leadership development has tended to try to create an all-leader hierarchy as shown in Figure 5.

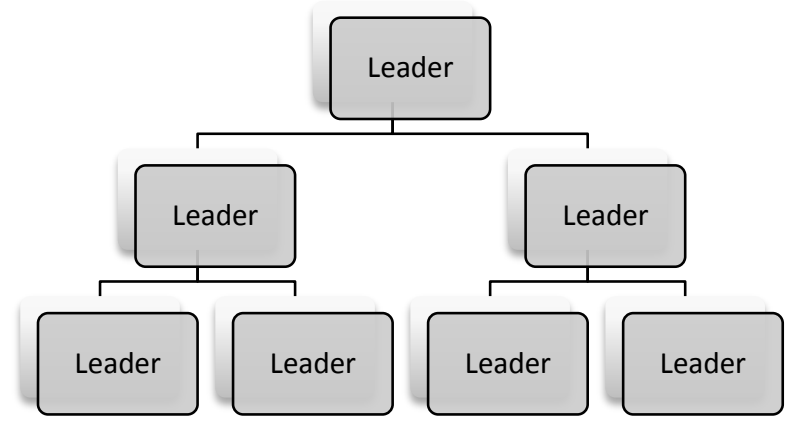

Figure 5: All leader hierarchy

Adapted from (Dixon, 2008, p. 159)

Hurwitz and Hurwitz (2009, p. 81) suggest that leaders often have difficulty in evaluating productive followership behaviours if they don't know what they are. Focusing solely on leadership reduces the desire of followers to participate. The authors notice that people higher in the organisational chart have a greater awareness of followership and its importance to their careers but are often unable to articulate what constitutes followership (Hurwitz \& Hurwitz, 2009, p. 83). 
Dixon's (2008) research found followership behaviours at opposite levels of the organisation, the front-line supervisors and the senior executives. Citing Chaleff (Chaleff, 2009) Dixon suggests that an organisation is a triad consisting of followers and leaders joined in a common purpose. Purpose and values are the atomic glue that followers and leaders orbit around, followers do not orbit around the leader (Dixon, 2008). Dixon recognises that the relationship is not dissimilar to an atom, Figure 6 below. It is the relationship between the parts that provide energy and life, not an individual component on its own.

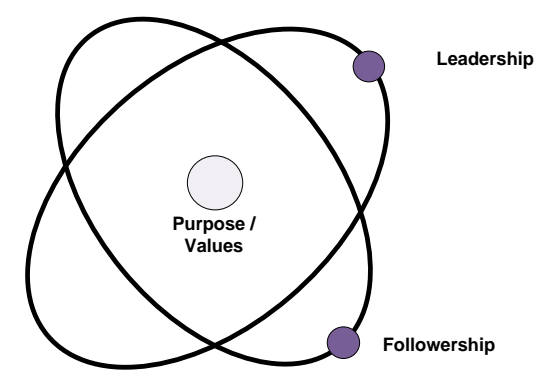

Figure 6: Leader-Follower relationship

Adapted from (Dixon, 2008, p. 175)

Dixon (2008) then suggests that the leader/follower relationships are more an organic state where individual members move fluidly between roles, i.e. they are able to transition between leading and following while remaining consistent in treatment of others. In such an organisation the organisational chart changes to reflect Figure 7 below and Dixon notes how the all-leader idea (see Figure 5 above) is unworkable:

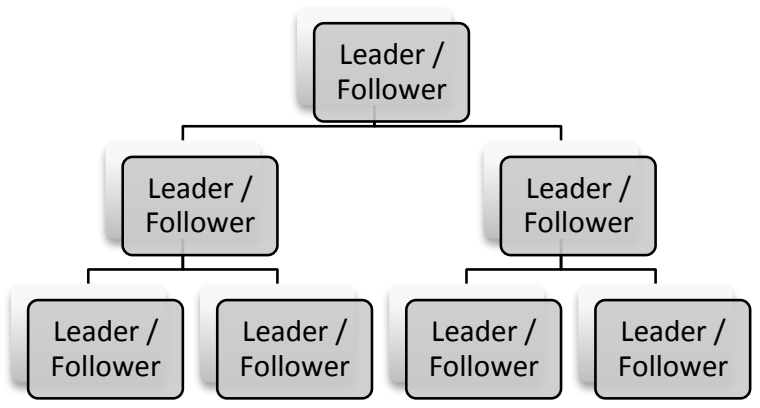

Figure 7: Balanced leader/follower hierarchy Adapted from (Dixon, 2008, p. 173) 
Where leaders are accountable for the actions of followers, Ira Chaleff notes that followers are also accountable for the leader's actions (Chaleff, 2009). A follower has responsibility to inform leaders when they believe their actions and decisions are incorrect and to help them correct their actions.

The idea of being an innocent bystander becomes an oxymoron (Blueman, 2008). Being a bystander to an inappropriate or immoral act makes us silent colluders. Ira Chaleff (2009) believes that there are circumstances when followers have further obligations, that withdrawal is not appropriate. Where a leader's actions endanger a person (physically or emotionally), organisation or community then the follower has a responsibly to intervene and that may require an act to disobey. Where the case is extreme then a follower may be required to "blow the whistle" and make the activities public.

The role of followers in participating in and preventing bad leadership is described by various authors (Kellerman, 2004; Lipman-Blueman, 2008). Barbara Kellerman (2004) writes that it is impossible to understand bad leadership without understanding bad followership. Noted above, followers "do the work" and this includes the "dirty work". There are many reasons why followers follow bad and at times murderous leaders. Thomas Blass, citing Stanley Milgram, wrote that "ordinary people simply doing their jobs and without particular hostility on their part can become agents in a terrible destructive process. Moreover, even when ...they are asked to carry out actions incompatible with fundamental standards of morality, relatively few people have resources needed to resist authority” (Blass, 2008, p. 206).

As there are toxic leaders, there are also bad followers. Barbara Kellerman (2007, p. 7) writes, "bad followers will do nothing whatsoever to contribute to the group or organisation. Or they will actively oppose a leader who is good. Or they actively support a leader who is bad". A bad follower, like the rotten apple, often has significant negative impact on others. A bad follower can become like a strange attractor and take a group in a negative direction.

Conversely, Kelley suggests, “Managers dependant on yes people and sheep for ego gratification will not leap at the idea of extra rewards for the people who make them most uncomfortable. In my research I have found that effective followers get mixed treatment....many managers insist they want independent subordinates who can think 
for themselves. In practice, followers who challenge their bosses run the risk of getting fired" (Kelley, 1988).

Other authors note how leadership occurs through the social construction process of followers (Lord, 2008; Meindl, 1995). Meindl (1995, p. 330) suggests that rather than assuming that leaders and followers are linked in a causal way, the relationship between leaders and followers is a constructed one. The behavioural linkages between a leader and follower are a derivative of the constructions of the followers, less attributed to be under the influence of the leader and more influenced by the forces that govern the social construction process. "Leadership is considered to have emerged when followers construct their experiences in terms of leadershipfollowership; that is, they interpret their relationship as having a leadershipfollowership dimension” (ibid, p. 332).

Noted by Lord (2008) the schema and internal cognitive structures through which followers interpret their work and daily events are an internal cognitive self-regulatory structure (schema) that are closely tied to self-identity. Given that these schema are developed throughout life and are part of a person's history that is brought into a relationship, leaders are dependant on follower's active construction of a schema; the leaders have limited ability to influence this process.

Meindl (1995) writes that viewing leadership as a follower-constructed phenomena would emphasize more indirect and less tightly controlled effects on followers. Manipulations of context and constructions, rather than leader behaviours or qualities, would in a sense constitute the "practice" of leadership (Meindl, 1995, p. 333). He goes on to advise that "rather than schooling leaders in the exertions of leadership, training and development programmes would represent opportunities to inculcate potential followers with the 'right way' to construct leadership" (Meindl, 1995, p. $333)$.

Using a general framework as shown in Figure 8 on the following page, Meindl (1995, p. 334) suggests that it can be used to identify input and output variables that contribute to and result from the follower's construction of leadership from both an individual and group level. 


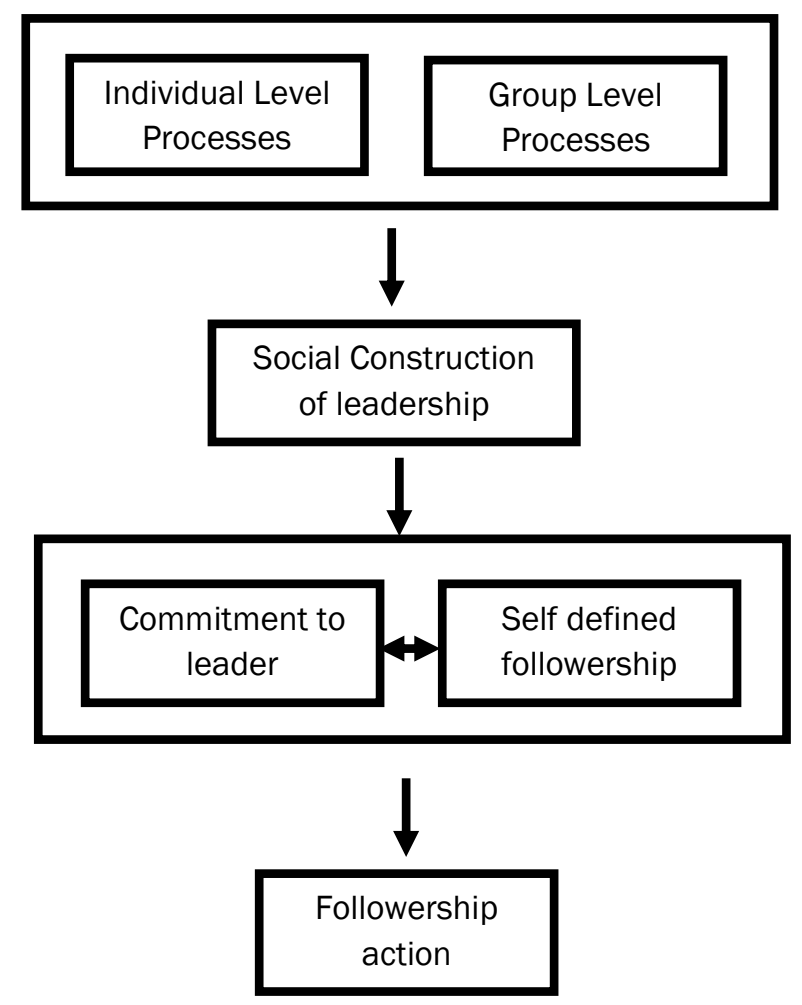

Figure 8: General Model

(Meindl, 1995, p. 334)

In addition, Meindl suggests that the model helps focus and understand construction of leadership through the emergence of actors, observers and group thought that bring into view alternative constructions through which leaders are evaluated.

Lord (2008) also suggests that a structure aggregates. Referring to the complexity sciences he suggests that "over time, individual-level perceptual, affective and selfregulatory structures of followers are aggregated and transformed through social interaction into emergent, informal social structures that play central roles in organisational functioning” (ibid, p. 256). While leaders are able to influence this process they are also constrained by it as the structures emerge and as follower's schema are in turn influenced by it.

One of the few authors that refer to sensemaking (further described below) and followership, Lord (2008) notes that it is the interaction of a leader's actions or visions with a follower's schema that gives sense to an event. The perceived benefit or harm that results is largely dependant on the internal schema of the follower. 
Leaders emerge and are constructed through fitting the follower's perceived view of appropriate leadership and the characteristics and behaviours of the leader (Lord, 2008, p. 259) in a given context and at a given point in time. "Sensemaking placing a constraint on leader's sensegiving ... an ineffective leader may not provide effective interpretive frames for followers, either because the visions of the superiors lag the realities confronted by followers or because followers do not perceive their supervisor as an effective leader" (Lord, 2008, p. 263).

Lord (2008) also suggests that followers will self-regulate, a process that will occur as they make sense of a situation or event. For example, a person's active selfidentity that is current and contextual will constrain what can occur spontaneously and may be initiated by a number of factors, including the leader. Lord argues that leaders should understand and influence these self-regulatory processes.

Referring to the complexity theorists, Lord (2008) suggests that the emergence of a structure does not depend on the formation of a hierarchy. Leadership structures develop as followers interact in local environments, often without any direct or indirect interaction with a leader. Through sensemaking and self-identity regulatory processes, leadership will emerge (from the bottom).

If the role of leader is constructed, what about the role of follower? Recent research (Carsten, et al., 2010) that focused specifically on how individuals socially construct followership roles found that followers construct their view of followership as passive (accepting and taking orders), active (offering opinions) or proactive (quiet leaders, willing to challenge). Individual followers will act in accordance with their cognitive schema and this can conflict with a leader's constructed view of followership, the leader's style and the organisational context.

What these authors reiterate is that leaders need to match their orientation to that of the organisation and subordinate; mismatches may undercut the socialisation and identification processes of subordinates, interfering with leadership processes and the development of desired organisational identities; this is the opposite of the idea of managing-up. Perhaps more fundamental, are leaders aware of the constructed nature of the leadership process and where and how it can be influenced? 
Michael Hogg (2008) introduces the theory of social identity of leadership recognising that leader and follower relationships are defined by "being members of the same group, and thus having possession of the same group and social identity" (ibid, p. 267). "Leadership is not simply a matter of leaders, or even leaders and followers. It has to do with the relationships between leaders and followers within a social group" (Reicher, et al., 2005, p. 551). Social identity theory focuses on and provides an account of group norms: shared patterns of thought, feeling and behaviour (Hogg \& Reid, 2006) and how "the representation and evaluation of self in terms of shared attributes define the group one belongs to" (Hogg, 2008, p. 268).

Representations of the attributes are called prototypes. A prototype is a set of attributes that characterise a group and distinguish it from another, e.g. dress, ethnicity, nationality, iPhone users, etc.

An important aspect of this theory is depersonalisation. We no longer see people as unique if we assign them the attributes of the group - we automatically categorise them. In addition, we attribute to ourselves (as a member of a group) the same attributes of the group. Hogg writes "self-catagorization transforms our perceptions, beliefs, attitudes and behaviours to conform to the prescriptions of the prototype we have of our group" (2008, p. 269). This theory then suggests that the leader is the person who is seen as the most prototypical of the group and this process assigns the followers a significant role in establishing the characteristics of its leadership and even the leader (Hogg, 2008, p. 269). Reicher, Haslam and Hopkins (2005) support this and note that leadership is contingent upon leaders being perceived to be prototypical of a social identity that they share with followers; and that the very possibility of leadership depends upon the existence (or manufacture) of a shared identity. When people share an identity, expect leadership to emerge (Reicher, et al., 2005). Hogg comments, "leaders who are not considered prototypical by their followers will have a significant uphill struggle. In a very real sense, it is the followers who provide the necessary conditions for effective leadership." (Hogg, 2008, p. 272).

Griffen and Stacey (2005) write that it may be more useful to think of leading as an emergent phenomenon in which individuals processing certain elements will pattern the iterative communicative interactions through their participation and expressions, other members will recognise the outcome as leading. This is nicely expressed in the 
following: "The role of leader emerges and is continually iterated in social processes of recognition. In organisations people work together and working together means engaging in communicative interaction and power relating in which people are continually choosing what to say and do next, so evoking and provoking responses from each other" (2005, p. 10) noting the everyday nature of the communication that occurs. "What emerges and is continuously iterated is a diversity of selves/identities, where each recognises and is recognised in their difference. One such difference is the role of leader. The role of leader is co-created by all these processes of recognition. The leader is as much formed by the recognition of the group as he or she forms the group in his or her recognition of the others" (ibid, p. 10). Language and power are important tools used to construct the leader role by the members of the group.

Organisations' structures truncate the emergent leadership process that is a characteristic of natural settings as described above (Smircich \& Morgan, 1982). Roles, policy and as described above, language and power help shape the reality of organisational life - they carry with them expected patterns of interaction. Smircich and Morgan (1982) note that hierarchy includes who leads and who follows. This poses difficulty for a board recruiting a new CEO, the new CEO and the existing group. A group will likely let the leader emerge regardless. They write (ibid, p. 260) that "formal structures contain a dialectical tension between the pattern of action and meaning that the structure seeks to establish and the tendency of individuals to reinterpret or even react against the structure thus defined". They further explain that "Formal organisations are often heavily populated by those that feel obliged to define the reality and experience of others with their idea of being a good leader" (ibid, p. 50). While the official leader sits in the corner office, the real leader, constructed by the group, will be somebody that embodies core values and behaviours and may not be the elected leader. This has consequences for all concerned.

Taking stock of the traditional view of followership, the current literature as reviewed so far describes a different followership view. These observations are presented in Table 6 on the following page and juxtapose the traditional ideas presented in Table 5 above. 


\section{Followership - Traditional view (from table 5) Observations from the literature}

\begin{tabular}{|c|c|c|}
\hline & Leaders lead, followers follow & $\begin{array}{l}\text { Followers often have the most relevant } \\
\text { knowledge which gives them significant } \\
\text { power. Followers have power - to follow or } \\
\text { not. }\end{array}$ \\
\hline & $\begin{array}{l}\text { Leaders are at the top of the hierarchy } \\
\text { and do not follow }\end{array}$ & $\begin{array}{l}\text { Leaders are also followers for a considerable } \\
\text { portion of the time. Leaders have a history as } \\
\text { followers. The leader's followership ability will } \\
\text { have a bearing on their leadership ability }\end{array}$ \\
\hline 3 & $\begin{array}{l}\text { Interventions are made by the leader, not } \\
\text { by followers. }\end{array}$ & $\begin{array}{l}\text { Given their direct contact in the operating } \\
\text { environment followers will often have made } \\
\text { sense of events before the leader. Resulting } \\
\text { knowledge enables them to interact } \\
\text { dynamically. }\end{array}$ \\
\hline 4 & $\begin{array}{l}\text { Followership is viewed as the attainment } \\
\text { of certain attributes and demonstrates } \\
\text { important behaviours that benefit } \\
\text { organisational goals. }\end{array}$ & $\begin{array}{l}\text { Followership classification systems show } \\
\text { follower attributes and qualities in a number } \\
\text { of different ways and demonstrate that } \\
\text { followership is more complex than individuals } \\
\text { acting as sheep. }\end{array}$ \\
\hline 5 & $\begin{array}{l}\text { Only leadership development is } \\
\text { encouraged. Followership development is } \\
\text { generally non- existent in organisational } \\
\text { learning and is not seen as part of } \\
\text { leadership development. }\end{array}$ & $\begin{array}{l}\text { Followership development and followership } \\
\text { skills are seen as important parts of a } \\
\text { leader's role. } \\
\text { Developing followership rather than imposing } \\
\text { leadership may provide opportunity for value } \\
\text { clarification, identity realisation and } \\
\text { appropriate forms of leadership and meaning } \\
\text { to emerge. }\end{array}$ \\
\hline 6 & $\begin{array}{l}\text { Followers believe they have little influence } \\
\text { on the development of a leader }\end{array}$ & $\begin{array}{l}\text { Followers see themselves as partners and } \\
\text { participate in leadership and often perform } \\
\text { the role of leaders themselves }\end{array}$ \\
\hline 7 & Leaders have power, followers do not & $\begin{array}{l}\text { The leader's role is socially constructed by the } \\
\text { followers. }\end{array}$ \\
\hline
\end{tabular}

Table 6: New views of followership

Further review of the literature begins to uncover other interesting perspectives. In their evaluation of a research trial involving prisoners and prison guards ${ }^{4}$ Reicher, Haslam and Hopkins (2005) observed that the group that was designated the guards were unable to establish a shared identity; they failed to establish a consensus about

\footnotetext{
${ }^{4}$ This became a BBC documentary called 'The experiment'
} 
who they were and how they should act. Consequently, even though the prisoners held lower position in the hierarchy, their sense of shared identity increased their leadership structure and they were able to dominate the guards. The authors suggest that the ability to lead depends on the ability to represent a group consensus which in turn is a product of shared identity. Importantly "leaders and followers are bound together....their relationship is dependant on a shared identity.... and their agreement depends on what constitutes the consensual group position." (Reicher, et al., 2005, p. 553) In this instance leadership had nothing to do with hierarchy. In their writing we again see the very important role of the follower in establishing "us-ness", "a shared sense of us". "Leadership is therefore a matter of interpreting what it means to be "us" in a given context" (ibid, p. 564). They argue that leaders "effectiveness revolves around the leader's ability to create identity definitions and to engage people in the process of turning these definitions into practical realities" (ibid, p. 556).

If "who are we" (identity) is a more critical question than "where are we going" (strategy and vision) how do our leadership development programmes address these concerns? Writers on leadership focus on creating shared vision (Kouzes \& Posner, 2007; Senge, 1990), not on establishing a shared identity. The social identity theory suggests that leadership emerges from the first question, not the second. Reicher and colleagues (Reicher, et al., 2005) make it clear that "Leaders do not have direct social power to share social reality...the transformative potential of leaders lies in their ability to define shared social identities" and "the agency of leaders does not substitute for that of followers but rather enables it and is dependent on it. It is not the leaders but the followers who have the power to transform existing social relations, and the viability of a leader's imagination is only as great as the ability of followers to bring it to fruition” (Reicher, et al., 2005, p. 560).

Many leadership development questions arise from these observations. For example, are leaders able to articulate the identity of a group? And, are they able to then know the points where identity can be altered and the kind of language, stories or behaviour that needs to be communicated and modelled to enable lasting change? Are leaders able to determine by paying attention to language and behaviour of followers, the characteristics that define a group's identity? Are followers aware of how they construct a shared identity, can they articulate it and if they desire it to be changed, do 
they know how? Do leadership development initiatives assist leaders in developing these sorts of skills?

Haslam \& Platow (2001) write that a key to successful leadership does not lie in the enduring and fixed personalities of leaders but in the higher order relationships between leaders and followers. Their experiments suggest that a leader's evenhandedness and fairness did not encourage the followers to "go the extra mile" (Haslam \& Platow, 2001, p. 1477) rather it was where the followers believed they shared the same social identity that there existed an emergent social identity in which leaders and followers are creatively united that followers willingly embrace a leader's vision.

These ideas are supported by Collinson (2006, p. 322) who suggests that in these theories of leadership and followership, leaders influence followers by shifting the salience of different elements of subordinate's identities, leaders should therefore link motivation to follower's identities, activating the appropriate self rather than directly stressing specific targets.

This understanding is a change to traditional transformation leadership thinking. An important step is in the recognition that leaders and followers are bound together by their mutual involvement in a social category (Reicher, et al., 2005). Successful leaders will seek to create an inclusive category that embraces all those they seek to mobilise and whose values are realised and of which they themselves are representative (Reicher, et al., 2005, p. 557).

The practical side of this dynamic requires the ability to provide a compelling construction of social identity (Reicher, et al., 2005, p. 561), to take ambiguous and often complex circumstances and make sense of them in terms of familiar constructions of social identity. They note that this is more than rhetoric, it requires a dialogue, rather than monologue, with followers. A number of authors observe how inappropriate the modern leadership discourse has becomes (Bohm, 1996; Senge, 1990; Shaw, 2002; Whyte, 2001). David Whyte describes it this way, "The inherited language of the corporate workplace is too small for us now. It has too little poetry, too little humanity, and too little good business sense for the world that lies before us " (Whyte, 2001, p. 240) . Of particular and practical interest is the 
implied status that inflicts conversation (Johnstone, 1981; Shaw, 2002) and its negative influence on improvisation and creativity.

Fundamental to discourse is language. Maturana and Varela (1987, p. 234) note that Robinson Crusoe kept his calendar and bible; he behaved as if he were in England, living in his linguistic domain where he had formed his human identity. Through language we constitute part of the environment in which we conserve identity and adaptation. To understand the impact of the language is to help understand our identity. While beyond the scope of this research, the language of leadership may be, as Whyte (2001) suggests, a fundamental constraint.

Shaw (2002) has noticed that management language may limit leadership capability and creativity. She writes that "we tend to focus on our ability to articulate strategies, goals and desired outcomes which we impose on an imagined future as templates in the form of project plans. Our sense of our own agency is tied up with being able to account for ourselves in these terms, to show that we can realise prior intention in the face of all kinds of difficulty and that to think in very sophisticated ways prior to action. Hence the heroic nature of most leadership mythologies in organisations" (ibid, p. 117). She points out that "current professional discourse of managing, consulting or facilitation themselves become hermeneutically closed, sealing our very experiences of ourselves" (ibid, p. 117). Shaw also suggests that improvisation and creative language that is experienced in the performing arts have a more acute awareness of paradox, of 'being in control but not in charge' providing a more in tune and accurate assessment of present reality.

Shaw's ideas of emergence and ambiguity is shared by David Collinson's (2006, 2008) post-structuralist writing on followership. Collinson's view holds that identity processes are fundamentally open, ambiguous and always in a state of flux and reconstruction (Collinson, 2008, p. 312). According to Collinson, the search for a secure, coherent identity can be contradictory given we rarely experience a singular identity (Collinson, 2008). In describing different follower identities (conformist, resistant and disguised) Collinson builds on post-structuralist views of power and questions the assumptions that leaders are able to effectively share follower's identities and that many follower practices produce outcomes that leaders may not anticipate. He warns of replacing romancing the leader with romancing the follower 
(ibid, p. 322). He suggests that identities of followers and leaders are frequently a condition and consequence of one another; "they are inextricably linked, mutually reinforcing and shifting within specific contexts" (ibid, p. 232). He challenges the traditional dualistic leader-follower view and raises important questions regarding traditional leadership development initiatives.

Research by Schyns and Felfe demonstrated that a follower's personality had an effect on the perception of transformational leadership. They suggest that "knowing that the perception of certain leadership styles is biased can help leaders to understand their follower's reactions... and these reactions will be different depending on the follower's personality" (2006, p. 533). As the authors suggest, the followers have an impact on the view of the leader, or put slightly differently, follower's personality makes followers open, or not, to transformational leadership. It would therefore seem sensible that a leader's success would be reliant to a degree on the alignment and openness of the follower's personality to their leadership style. If there were a misalignment and follower's perceptions were poor, then any form of leadership development will likely have only limited value.

Gardner, Avolio, Luthans, May, \& Walumbwa (2005, p. 345) suggest a self-based model for leader and follower development. They include followers as a key element in a leader's development. Their model reflects the need for authenticity and, from a development view they focus attention on the process whereby leaders and followers experience growth by becoming more authentic. They argue that authentic leadership and authentic followership will form authentic relationships.

Authenticity is defined by Kernis as having the qualities: awareness, unbiased processing, action and relational helping to form an unobstructed operation of one's true, or core self $(2003$, p. 1). These four components form part of Gardner, Avolio, Luthans, May, \& Walumbwa (2005, p. 346) conceptual framework for authentic leadership and followership development, see Figure 9 on the following page. In their view, followership development mirrors leadership development with authentic followership development being an integral component and consequence of authentic leadership. This model applies an authenticity view to both and does not attempt to separate leadership and followership or to categorise followership. 
"Through the interactions of the authentic leader and authentic follower both come to know who they are" (Gardner, et al., 2005, p. 348). It is not a static process, it is an interaction, it is ongoing and the moment by moment, the relationship is always in motion, open to upwards and downwards movement. What is being suggested in this framework is followership being of equal importance to leadership.

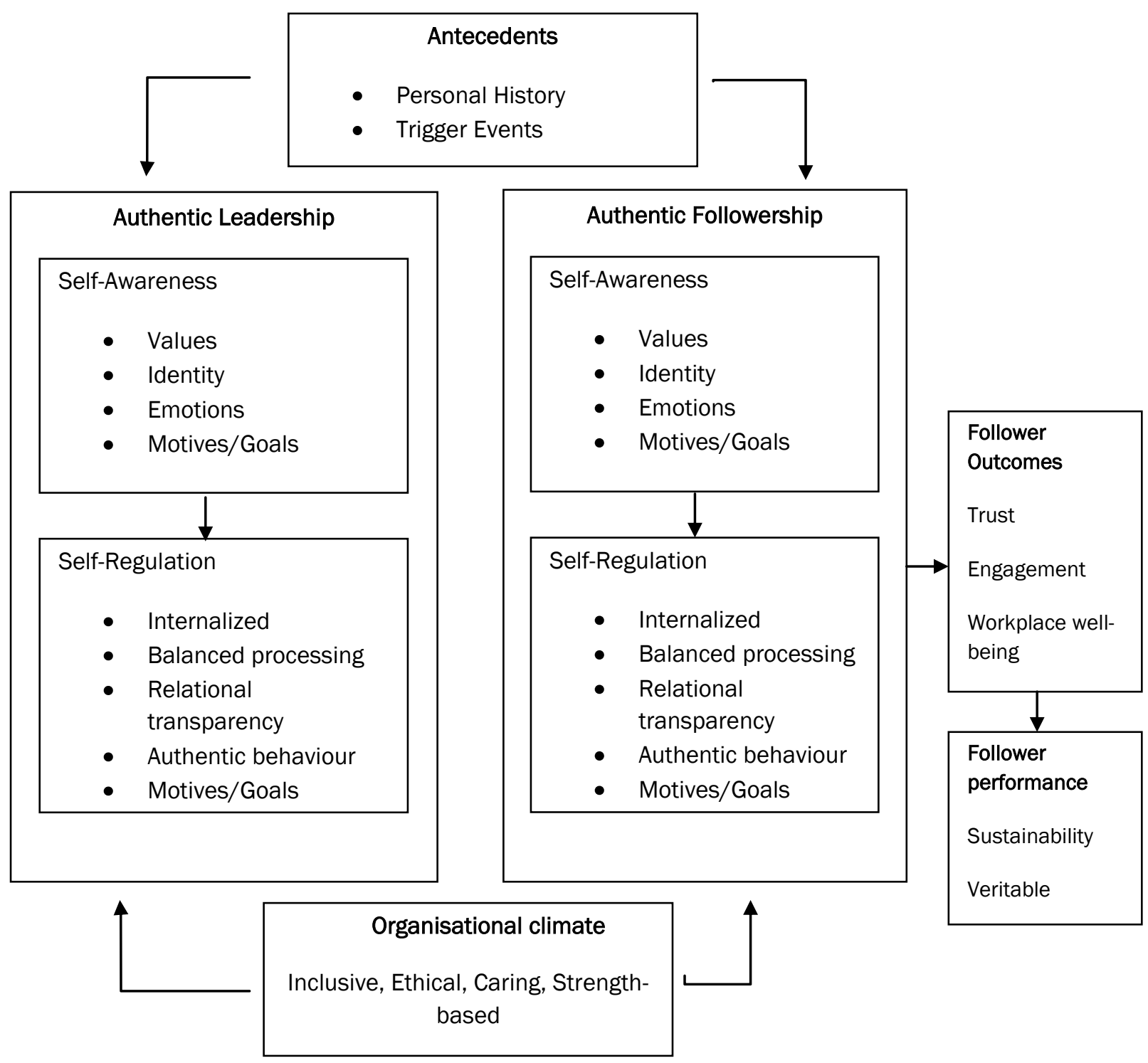

Figure 9: Framework for authentic leader and follower development

(Gardner, et al., 2005)

"Because self-concepts of leaders and followers are important determinates of follower role orientations, an important question is how alignment between leaders' and followers' self concepts can be facilitated” (Howell \& Mendez, 2008, p. 24). 
They note that effective working relationships require role orientation that fits the leader's expectations, follower's identity and context (ibid, p. 38).

Shamir, House, \& Arthur (1993, p. 590) suggest leadership can have an influence on follower's self-concept where the leader engages the follower. They suggest that positive effects occur where "leaders implicate the self-concept of the followers and engage the related motivations for self expression, self-esteem, self worth and selfconsistency”.

Along similar lines to that of Gardner and colleagues, Robert Dilts (Dilts, 1996, p. 79; O'Conner \& Seymour, 1990) suggest that leadership created change requires an understanding of people's motivations at different levels. Dilt's provides a simple yet elegant neurological model, shown in Figure 10 below, that when used in the context of authentic leadership and followership development provides opportunity for understanding the reasons why the self based models of change that work at the inner circles are likely to result in changes at the outer level.

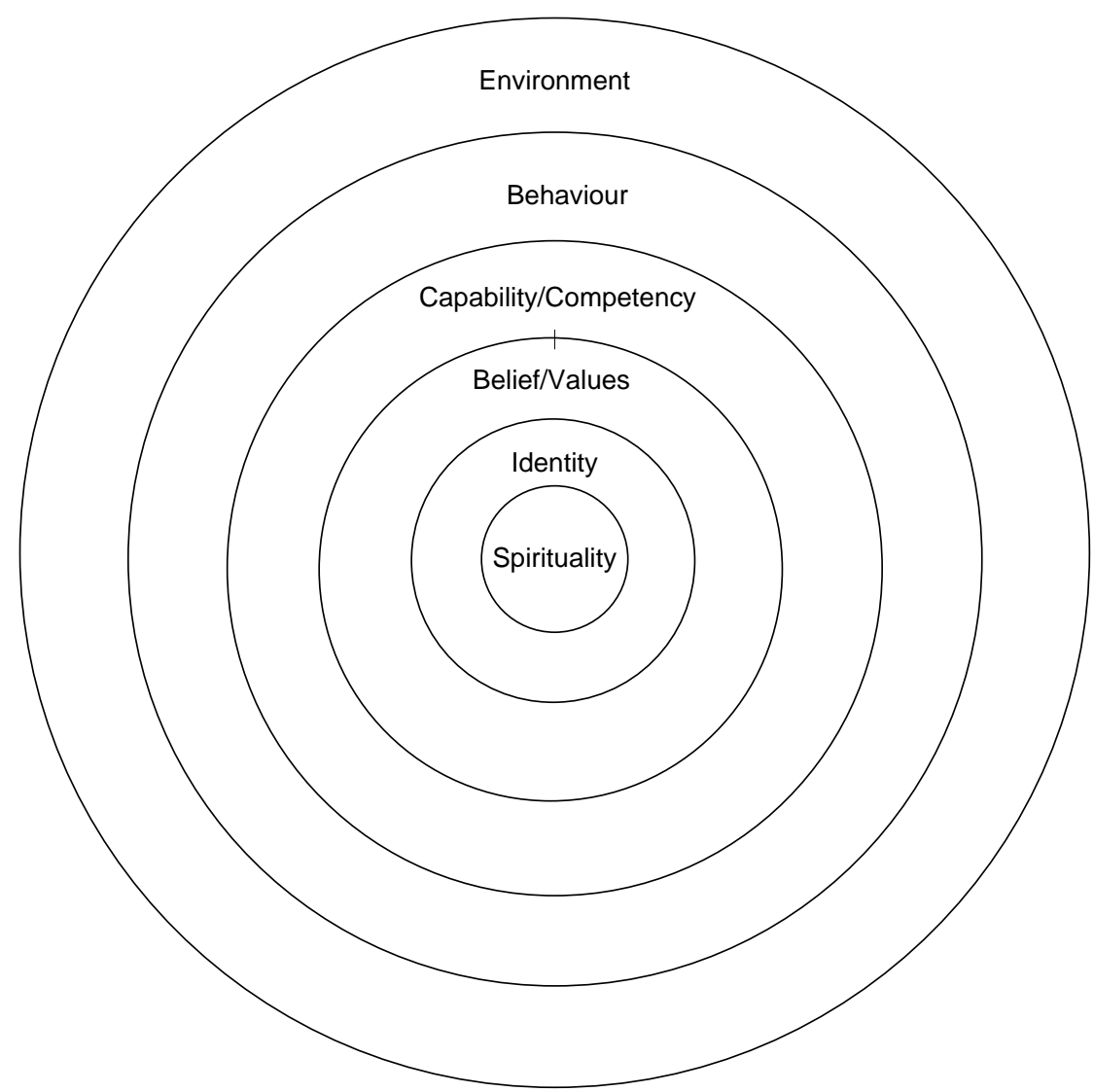

Figure 10: Neurological Levels 
The model proposes that problems have underlying (inner) triggers and it provides a framework for gathering information so the most desirable intervention points can be targeted. For example, a leader that undertakes a restructure change (environment) in the hope of seeing capability change may be disappointed. A better, but perhaps more difficult path is addressing organisational values and beliefs. Similarly, an organisation that wants to change its focus towards customer service (behaviour) where the employees see themselves as technical experts (identity) may be better employing people whose identity aligns to the role.

O'Connor and Seymour (1990) notice that behaviour is often incorrectly seen as evidence of identity or capability. Thus a person who shows up late to work (behaviour) is considered lazy (identity). For a manager or leader, handling poor followers (those that underachieve: a behaviour) is a difficult, ambiguous and complex process, often fraught with emotion because it may likely be linked to inner qualities such as values and identity. Competency and performance frameworks provide 'check sheets' or 'quick reference guides' for busy managers through which the behaviour and performance benchmarks of a follower are measured. Yet, as is clear on Dilt's model above, this may not reflect the level at which an issue needs to be understood or, indeed, resolved.

For this research paper, important question arise. Do leaders learn the required skills and dialogue, posses the time or insight required to surface the deeper issues of identify and values?

Other authors on leadership have researched the link between values of the leader and the followers (Cha \& Edmondson, 2006; Lord \& Brown, 2001). Value congruence between a follower and a leader, and a follower and an organisation suggests that where the linkages are strong and the values align, these are shown to enhance organisational performance and employee motivation (Cha \& Edmondson, 2006). Referring back to Dilt's model (Figure 10 above), values are personal and core to an individual. It makes sense that value alignment will help establish relationships that are sound.

Litzinger and Schaefer (1982) suggest that the importance of values is evident when they are not adhered to. Break the values and break the leader's (or follower's) legitimacy. They note that to have internalised the organisation's values, to have 
become an embodiment of them, is to have the potential to be a leader, a process that begins and emerges from followership. Lack of value congruence can be a major source of ambiguity for followers (Lord \& Brown, 2001) and "employee sensemaking triggered by strong organisational values can increase the risk of leader attribution hypocrisy that can lead to employee disenchantment" (Cha \& Edmondson, 2006, p. 58).

Lord and Brown (2001) suggest that while values are a strong motivational factor it is their impact on identity that provide a powerful influence. The authors present a model, Figure 11 below (reflecting that of Dilts, Figure 10), in that identity is a critical inner and salient quality that has a significant bearing on behaviour. They suggest that values and self-concept (identity) are strong regulatory guides and this influences follower's motivational, affective and cognitive processes (Lord \& Brown, 2001, p. 135).

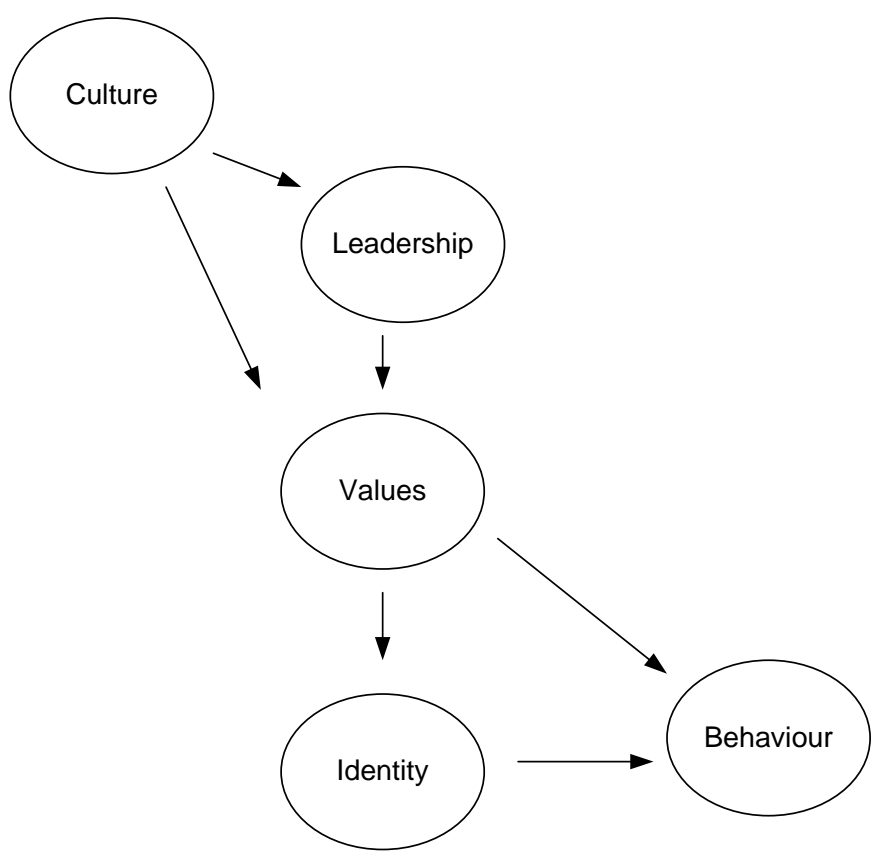

Figure 11: Linking culture and leadership to subordinate self-regulatory structures

(Lord \& Brown, 2001)

Several practical implications arise. Firstly, a leader may not consciously consider what values or identity levels are appropriate (Lord \& Brown, 2001), he or she instead focuses on accepted best practice leadership of vision setting, bold goal creation and outcome generation. Here the likelihood is that a leadership success may be viewed 
as task accomplishment by followers. This view is shorter term and not enduring as mentioned by Lord and Brown: "behaviours and specific tasks goals have a more narrow task focus and shorter temporal duration than do identities and values. While leadership and motivational interventions can be focused at the task level the duration and scope of a leaders influence will be greater if leadership actions are focused on more general properties such as values and self-identities" (2001, p. 136).

Secondly, the leader will focus on environmental and behavioural change without clarity of the intricacies within the communication and the sensemaking processes of the followers nor be able to observe the existing and emergent patterning of values, identity and power that are present (Griffin \& Stacey, 2005). The result will lead to value ambiguity.

Thirdly, as suggested by Lord and Brown (2001), leaders tend to focus on the concrete and salient issues such as subordinate behaviours and goals, rather than the more abstract regulatory processes. If goals and behaviours reflect strong constraints from identities and values, failure to consider the operation of an entire system of constraints is likely to produce leadership actions that are only marginally effective. Regulatory structures involving identities and supporting values may need to be altered to produce enduring changes.

Using the idea of values being or having a connectionist architecture, Lord and Brown (2001) suggest that values, when viewed as connected have implied constraints and when activated create patterns with a specific meaning that will influence behaviour. If the value connections are strong then there will be an effect on behaviour and goals; where the values are unorganised the effect will be weak and of little consequence. The value patterns that form as part of the value network act as cues for identity formation, leaders are often a focal point for work value creation. Salient values will influence the likelihood that a particular self-identity will emerge. Assessing the connections between values, identities and behaviours and understanding where linkages are coherent or disorganised is valuable.

\section{Followership - summary of research relevance}

What appears from the literature on leadership and followership are a number of important observations that are relevant for this research. These are detailed next (in no particular order). 
- Followers have considerable power over and influence on the success of a leader.

- Leaders are followers for a considerable portion of the time.

- The leader is the most pro-typical follower.

- Identities of followers and leaders are frequently a condition and consequence of one another. Followers will likely impact on leaders' identities.

- In a controlled environment such as the work place, power, ego, position and culture will influence the natural emergence of leadership; however, even then leadership construction takes place through followers.

- Group shared identity establishment is important in leadership construction.

- Language is the tool through which the leadership and followership relationship is constructed.

- Followership categorisation is common and useful in terms of establishing a shared language.

- Development of authenticity is the same journey for leader and follower.

- Developing inner qualities in leaders and followers is seen as more enduring than competency and skill development.

- While the traditional view of the leader is as vision and strategy setter, recent thinking suggests that a leader's role is directed towards developing the salient inner qualities of the leader/follower dynamic.

- Leadership and management discourse, the linguistic domain within which management operates, regulates organisational operational boundaries and limits creativity and imagination. It imposes a construction of leadership and followership that may not align to the actual dynamic that continually unfolds in day-to-day interactions between people.

- Value congruence is a strong motivational factor.

- Leaders and followers are legitimised by each other in a dynamic process of interaction.

- Identity and meaning construction is important in leadership emergence and occurs between people in conversation.

Followership understanding is evolving in a similar way to that of leadership. There is less distance between leader and follower, less difference and increasing similarity. 
A number of interesting questions begin to surface. Could inappropriate leadership development, where the focus is on outcomes and results, prevent the realisation of self? Are leaders aware of the constructed nature of their role and how to influence it? Do leaders develop authenticity in followers? Do they know how? Do they learn how? Do leaders learn how to identify and influence individual and group identity? Do leadership and competency programmes that seek outcomes-achievement mask authenticity development? Does this imply a darker side of leadership development may exist that is detrimental to the leader and follower? Is damage being done in leadership development?

The following section establishes the basis for sensemaking in the leadership and followership dynamic and why researching this topic with a sensemaking lens helps to ground and narrow the research question.

\section{Sensemaking}

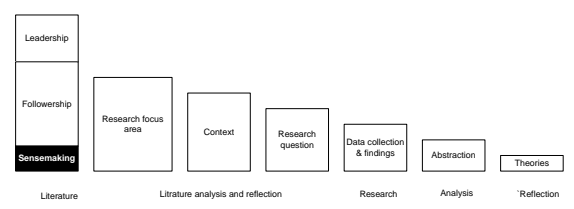

Sensemaking: "the way people choose between multi-explanations of sensory or other input as they seek to conform phenomenologically with the real world in order to act in such a way as to determine and respond to the world around them" (Snowden, 2005, p. 2). Weick (1995, p. 16) writes "sensemaking is what is says it is, namely, making something sensible". Sensemaking occurs as "perceivers construct a framework for an event or action" (Lord, 2008, p. 257). Lord suggests that sensemaking is a central component of the leadership process as it reflects that interaction of a leader's action or visions with the follower's mental schema (ibid, p. 259).

Lord uses what Aaltonen (2007) describes as the cognitive sensemaking view where a person's world view is formed through a cognitive framework and previous experience. The constructionist sensemaking view proposes that sensemaking occurs within language where ongoing discourse defines possible selves and their associated actions (Aaltonen, 2007).

Weick describes that "People make sense of things by seeing a world on which they already impose what they believe" (1995, p. 15). Lord (2008) notes how followers 
make sense of events, with or without leaders. They will also be making sense of the leader and the leader's development. Lord suggest that sensemaking acts as a mediator process between the qualities and actions of the leader and the response of the follower (ibid, p. 259).

Weick describes seven characteristics of sensemaking. As described by Aaltonen (2007, p. xvii) these are summarised below. Sensemaking is:

1. Grounded in identity construction: the notion of self is constantly under construction.

2. Retrospective: sensemaking is an examination of the past in order to learn and unlearn things about the current context.

3. Enacting: There is no objective environment separate from our interpretation of it.

4. Social: sensemaking is a social activity. Narrative, discourse and conversations are the primary media of sensemaking.

5. Ongoing: sensemaking is an ongoing process.

6. Focused on extracted cues: we pay attention and extract a particular cue, then link it with some more general idea or concept that clarifies the meaning of the cue.

7. Driven by plausibility rather than accuracy: accuracy is less important than plausibility. Sensemaking is about narratives that are socially acceptable, pragmatic and credible rather than accurate.

Citing Brenda Dervin as the "other giant of sensemaking", Aaltonen notes how sensemaking is about creating meaning. Noting the difference in experience and observation relating to context and time, sensemaking occurs as a product of human observation: "while we observe and communicate reality, we simultaneously take part in the process of creating it" (Aaltonen, 2007, p. xix).

From these descriptions it becomes evident that sensemaking is a meaning-making process and will be at play during the construction of the leader/follower and follower/leader relationships.

This literature review has already highlighted the constructed nature of leadership and the impact of follower self and identity on authentic leadership and followership 
relationship development. Weick points out the importance of identity construction as a characteristic of sensemaking: "I make sense of whatever happens around me by asking what implications do these events have for who I will be. What the situation will have meant to me is dictated by the identity I adopt in dealing with it and that choice in turn is affected by what I think is occurring" (Weick, 1995, p. 23). As a person is orientating themself through the sensemaking process, they are forming and reaffirming their identity. The identity (or reference point) they adopt, be it positive, neutral or negative, will, as we have seen from the literature review, have a direct impact on how the leader/follower relationship forms and continues to form.

Weick's sensemaking characteristics are visible in the follower/leader dynamic. The formation of sensemaking occurs in language within a social group. The enactment of sensemaking occurs through acts within the social group. Extracted cues, another of the sensemaking characteristics, "are simple, familiar structures that are seeds from which people develop a larger sense of what may be occurring” (Weick, 1995, p. 50). To direct attention to a particular cue, or to have control over what cues are to be a point of reference, is particularly powerful. Citing Smircich and Morgan (1982) Weick suggests that "leadership lies in large part in generating a point of reference, for both leader and follower" (Weick, 1995, p. 50) or it helps to draw attention to a cue from which sensemaking can take place. "The actions and utterances of leaders guide the attention of those involved in a situation in ways in which they are consciously or unconsciously designed to shape the meaning of the situation" (Smircich \& Morgan, 1982, p. 261). If the utterances are plausible (Weick's seventh sensemaking characteristic) in that they create a contextual framework that makes sense, a point of reference is able to be established allowing others to take their own action.

The extracted cues often emerge as action is taken. Citing an example where soldiers, lost in the Swiss Alps had used a map to help them return safely, only to discover the map was of the Pyrenees (Weick, 1995, p. 55), Weick writes that maps (and strategic plans and bold goals) are to animate people, to get them started, and suggests that when the environment is uncertain and complex any old map will do. Referring to the expression "the map is not the territory" he argues that the map was never the territory and the image of territories and maps is outdated (Weick, 2001, p. 94). Paying attention to the cues in the process of acting is the critical element. Regarding the 
lost soldiers, Weick notes that "the cues they extracted and kept acting on were acts of faith amid indeterminacy that set sensemaking in motion. Once set in motion, sensemaking tends to confirm the faith through its effects on actions that make material what previously had been merely been envisioned" (1995, p. 55).

Sensemaking versus decision-making has been also been highlighted by Weick (2001) in his description of fire fighter Paul Gleason. Gleason, according to Weick, when fighting fires prefers sensemaking to decision-making. Describing Gleason's approach that when he sees his work as decision making he postpones the action so he can get the decision right, after that, he makes the decision and he finds himself defending it. Rather, Gleason prefers to treat an unfolding fire as a sensemaking problem, he is less inclined to defend any decision and is more open to revision. Quoting Gleason, Weick writes "A decision is something you polish. Sensemaking is a direction for the next period" (Weick, 2001, p. 75).

The follower's sensemaking is therefore central to leadership as Lord suggests (Lord, 2008). The importance of meaning that results from sensemaking implies that understanding the sensemaking phenomena is useful. To study the sensemaking of followers, being aware of their meaning, shared or otherwise, is in itself likely to be a worthwhile exercise.

\section{Sensemaking - summary of research relevance}

Sensemaking provides an important path for this research. A number of interesting questions and issues result when considering leadership and followership from a sensemaking perspective:

- The manner in which a follower makes sense of leadership and leadership development will impact on the meaning-making of the followers: positive, neutral or negative.

- Do leaders understand the process and importance of a follower's sensemaking?

- Rather than developing a grand strategic plan and bold goals (which can be valuable in a call to action) paying attention to cues in the process of action is seen as a primary role for leaders. 
- Do leaders appreciate that while they may hold a position of power, follower's emergent meaning that is a result of their sensemaking may be in conflict with the meaning of the elected leader?

- Drawing attention to important cues and points of reference helps establish an orientation from which shared meaning (for leaders and followers) is more likely to result.

- Do leaders provide suitable interpretive frames for followers? Do the leaders know what these are and how to influence them?

\section{Research focus area}

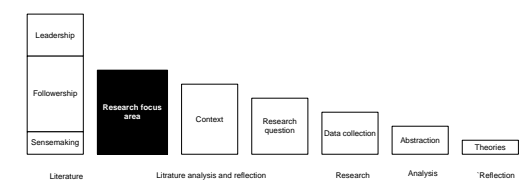

As followership is a primary focus area for this research, important questions pertaining to followership are formed from the literature review of leadership, followership and sensemaking. These are listed in the bullet points below and then elaborated in the following context section to focus and aggregate the research into manageable "chunks" suitable for the development of interview and survey questions.

Followership questions arising from the literature review are:

- Are leaders aware of their followership role?

- Are followers aware of their leadership role?

- Poor followers affect leadership profoundly, therefore improving followership understanding will influence leadership success:

$\circ \quad$ Are followers trained in followership?

- Are leaders trained in followership?

- The kind of follower the leader was will affect how he/she leads. Is this understanding present in leadership development?

- Where followership is encouraged, do leaders appreciate the consequences in terms of a follower's influence and social power (Lord, 2008)?

- Are leaders understanding and influencing the parts of the emergent systems where they can have an impact?

- Do leaders appreciate the limitations and boundaries caused by the constructed nature of the leadership role? 
- Do leadership development programmes encourage the development of followership authenticity?

- Are leadership development programmes largely about the successful achievement of organisational outcomes or do they include a balance of selfdevelopment?

- Do organisations spend equal time in followership as leadership development?

- Do the leaders learn how to identify the typology of followers as a beginning to understanding the follower role? Does the process stop there or are deeper relational and personal qualities examined?

- Are the influences of identity, shared meaning and the construction of the leader role understood?

- Do leaders develop authenticity in followers?

- Are leaders knowledgeable of the impact of the sensemaking of followers?

These questions become valuable for the research process. They are further distilled below and provide context, as described next, for the interview and survey questions.

\section{Research context}

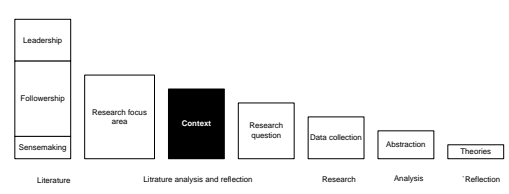

It is very evident that leadership has the prime share of academic authors' attention.

Followership has a growing share. Sensemaking within the areas of leadership and followership has minimal share in comparison.

Followership is a primary focus for this research. This requires that attention be paid to leadership and current trends in leadership development in order to determine the degree with which followership is understood and included as part of a leader's development. Similarly time has been spent, albeit somewhat less, in elaborating sensemaking characteristics to help understand how sensemaking of followers occurs and impacts on follower's meaning-making of leadership.

From the literature reviews, the summary and focus sections, several themes emerge that provide focus for the research process and set the research boundaries. The four focus areas addressed in this research are: 
1. Followership: Followers are influential in a leader's development and therefore will play a role in a leader's development success.

2. Leadership development success (follower's view): The ROI on leadership development as seen from the follower's point of view.

3. Follower's sensemaking: Followers' sense making of their leader's development is likely to impact on leadership.

4. Authenticity: Authenticity and enduring inner qualities such as values and identity contribute to meaning-making for both follower and leader.

These categories and themes are presented in Table 7 below and on the following page. In the right hand column are the questions from the preceding section now aggregated within each relevant category and theme. These were used to form the interview questions for the data collection phase of this research.

Categories/Themes

1 Followership

Leadership development and success is highly influenced by

followers and followership.

Leadership is to a degree a constructed notion resulting from people in conversation sharing a common purpose.

Followers therefore have considerable influence in the selection of a leader.

Leaders have a history as followers.

Self and group identity of followers plays a role in leader construction.
Resulting research questions

Is followership developed? Do leaders learn about followership in

their leadership development?

Do leaders acknowledge the role and importance of followership in their leadership development?

Are followers involved in a leader's development? if so how and what is their influence?

Are leaders aware of the constructed nature of leadership and the effect this has on constraining their leadership? Viewing leadership as a follower constructed phenomena emphasises a more indirect and less tightly controlled effect on followers. Manipulations of context and constructions, rather than leader behaviours, would in a sense constitute the "practice" of leadership (Meindl, 1995, p. 333). In leadership development are leaders made aware of the manner in which context and constructions are able to be influenced through values and selfidentity?

To what extent can a leader's history as a follower be used as a guide in determining current and future leadership effectiveness?

Do organisations develop followership skills? 
Are followers aware of the influence they have on leadership?

Do followers see a leader's development as a benefit to them?

Do followers know the role they play in construction of leadership?

Do leaders learn how to observe values, beliefs, identities and mechanisms where they can be influenced for enduring outcomes?

2 Leadership development success $\quad$ Do followers see a positive / neutral / negative ROI on their lives, (follower's view)

The ROI on leadership team, organisation and the leader as a result of a leader's development as viewed from the development and an organisation's leadership development programmes?

follower.

\section{$3 \quad$ Follower's sensemaking}

The ROI of a leader will be influenced by the sensemaking and interpretations that followers form of a leader and their development.

The meaning-making that results from sensemaking; what impact
does this have (positive / neutral / negative) on the outcome of the development initiative?

Are leaders aware of the sensemaking processes of followers?

Do leaders know how to observe the sensemaking of followers and how it is best influenced?

Is a follower's authenticity understood and developed through a
leader's development? Are there attempts to create authentic followers part of leadership development?

Do organisations' performance and competency programmes develop authentic followers? If so, are they working? If not, why?

Do leaders seek to develop followership through a maturing understanding of deeper structures in their followers?

How suitable is leadership dialogue and the dialogue used within a team or organisation for the development of inner structures and authenticity?

Where the end result of leadership is seen as an organisational outcome, e.g. profitability, is this a constraint on authenticity development? if so, what effective measures can be adopted in order to overcome this dilemma?

Are outcomes-driven leadership development programmes at odds with authenticity development?

Table 7: Research categories and themes 


\section{Research question}

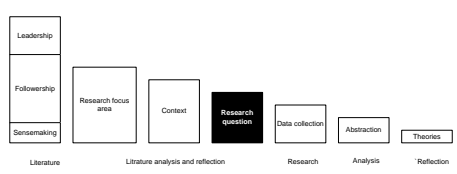

In developing the research question two important points become the centre of attention. Firstly, the importance of followers and followership in leadership construction and a leader's success has been highlighted. With regards leadership development followers are clearly important. Followers and followership becomes the primary focal point for this research.

Secondly, occurring in followers, sensemaking will be influencing leadership. As described by (Weick, 1995) sense making is a process and is grounded in a number of characteristics. Used in this context, critical elements are identity formation and meaning-making, value congruence, social construction and the ongoing nature of making sense, as a verb, through a variety of personal and organisational realities. Understanding follower's sensemaking is therefore a valuable exercise.

The primary research question becomes:

\section{"What is the influence of followers and their sensemaking on leadership}

$$
\text { development?" }
$$

With the follower in the spotlight, a number of secondary questions surface. What is the ROI of leadership development from the view of the follower? Is followership development of leaders and followers understood and encouraged? Is authenticity development reserved for leaders? Do leaders learn how to develop authenticity development in followers? And do authentic relationships actually form?

\section{Research relevance}

This research is important given the large amount of time and money that is invested in leadership development. Organisations and individuals that invest in leadership development would most certainly want to know that any positive change is a direct result of their efforts and investments and does not occur by chance. Certainly they would want to know if there was no change or if harm was being done. 
As followers are the indirect recipients of leadership development, understanding their view is valuable. If the followers see little or no impact on their lives and should the impact of leadership development on the followers be low, then modern leadership development programmes may be said to be ineffective at best or, at worst, to have failed.

The research may help to understand how sensemaking of followers impacts on a leader's development. Important to the orientation and comprehension of leadership development is how followers make sense of their leader's leadership development activities. If there is negative impact, adjustments could be made early on in the development programme. It may be possible to develop a framework whereby overall sensemaking of followers can be understood at or near the beginning of a development initiative. This may, in turn, impact on the type of engagement required by the followers in the actual process of the leader's development.

A primary goal is to see how the role of the follower in leadership, and possibly followership awareness development, may improve the overall ROI for those managers that attend leadership development programmes.

It may be argued that this research is "left of centre" in Information Management. However, a CIO, IT manager or indeed any manager who attends leadership development courses and applies new skills to assist in the achievement of organisational objectives and later wonders why the outcomes are not what they had hoped for, may benefit from an understanding of followership and the sensemaking of followers.

A CIO will likely be leading geeks (Glen, 2003) and clever people (Goffee \& Jones, 2007) noted earlier. They will be dealing with issues of changing power relationships as knowledge (especially that attributed to critical technical knowledge) that is held by followers. To aid a CIO in these situations a followership understanding becomes a valuable vantage point.

Leadership success is realised through the efforts of followers. To assess the ROI on leadership development means that it should be studied and understood through the followers. Achievement of organisational goals as an outcome of leadership applies across all disciplines, including information and technology sectors. 


\section{Research design}

This research is explorative. Given that the research design is highly related to the research question, the design elements flow directly from the research question. The methodology, methods and analysis stages presented are representative of what the researcher believes to be the best fit, based on research question, context and the researcher's experience.

This section follows the research hierarchy as presented by Pickaro (2007) who sets out the steps for the outline of a research proposal (Figure 12 below). This is used as the basis for presenting the research design.

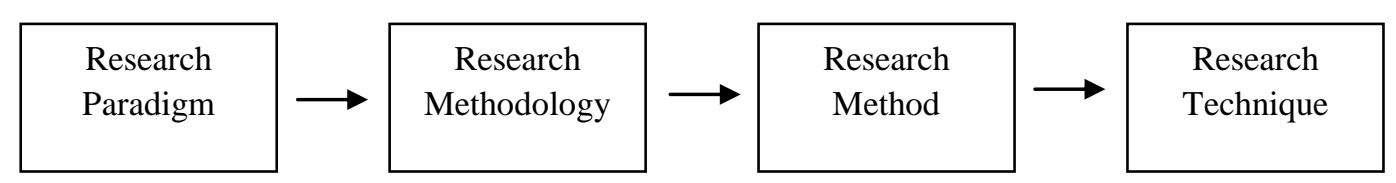

Figure 12: The research hierarchy

(Pickaro, 2007)

\section{Paradigm}

An interpretive approach has been taken for this research. As stated in the research question and presented in the literature review, followers are a central focus for this research, but not to the exclusion of leaders. It is necessary to discuss the research issues with individuals (followers and leaders alike) to understanding their feelings and thoughts regarding the development of leaders and leadership learning initiatives.

\section{Methodology}

A mixed qualitative with a quantitative research methodology has been used. As noted by Creswell (2003) it is hoped that this will bring about pragmatic and balanced understanding of the research outcomes. Creswell notes that mixed method is best when a researcher "may want to both generalise the findings to a population and develop a detailed view of the meaning of a phenomenon or concepts of individuals", (Creswell, 2003, p. 22), therefore mixed methods was a suitable fit for the purpose in this situation. The greater balance of research effort was qualitative. The quantitative research has been used to provide an additional view and to validate key findings and highlight deficiencies within the qualitative results. The intention of the research has 
been to clearly understand the issues in a way that will shed light on the future development of leaders and followers.

\section{Method}

Exploratory grounded theory was chosen as the primary research method. The topic of research is suited to the grounded theory where no or little theory exists and new theory may be generated from a set of data. Grounded theory principles of analysis and theory induction are used in the research, keeping the outcomes aligned to the data where possible.

Although theories revealed themselves and have been captured below, they do not necessarily adhere strictly to a purist view of grounded theory methods. Based on Punch's (2005) description of the analysis of research data, the method used more closely follows the Glaser perspective that trusts the emergence of concepts from the data rather than that of Strauss and Corbin, that as Punch (ibid, p. 215) suggests, that forces concepts on the data.

The literature review has been introduced initially to help discover and form the research question and scope. Given the wide starting scope the literature review helped to provide initial categories suitable for the grounded theory (refer to table 7). In addition and as noted by Punch (2005, p. 159) "the literature is seen as further data to be fed into the analysis but at a stage in the data analysis when theoretical directions become clear." Significant use of the literature helped to extrapolate theory from the research data (details in following sections). In addition, the data and ideas that emerged as the first stages were completed guided the remaining stages suiting grounded theory methodology.

In order to provide objectivity, a governance group was formed to guide the research process. The group validated the research approach and provided valuable input into the research question formation.

\section{Research technique}

A governance team was formed first to assist the researcher through the research process (see Appendix $\mathrm{C}$ for member details). The governance team played a particularly useful role and was an important part of the research design. Their participation included assistance with the development of questions and the survey. It 
is the researcher's view that such participation has helped ground the research in a practical sense.

To avoid too much commitment on the governance team members the researcher undertook the majority of the work. The questionnaire and interview questions were created by the researcher with the governance team providing input and quality assurance. This helped remove, or at least balance, personal bias in the questions.

Primary methods include:

- a qualitative study, using open-ended interviewing questioning of four leaders who had been involved in a leadership development programme. The leaders were selected from two different organisations. For each leader, a qualitative study, using open ended interviewing questions of three of their followers, a total of twelve followers (sixteen interviews in total).

- an on-line questionnaire, created with assistance from the governance group, to gather quantitative data. The survey purpose was to help validate the qualitative results. The final sample size was 40 and exceeded expectations of between 20 and 30 participants.

The interview questions were developed based on the themes from the literature reviews (see table 7) and circulated to the governance for comment. Their feedback was included in the revised questions.

An initial trial was used to test the on-line survey (from the governance team and others) and feedback from the interviews fed back to the governance team to see if changes and/or clarification was required of the survey questions, structure and focus.

Given time constraints of busy staff, including the governance group members, the researcher created and conducted the on-line survey and all the interviews. Time prevented a participatory approach.

\section{Data analysis and verification}

Both qualitative and quantitative data were verified first by the researcher looking for irregularities and outliers in the data gathered. The qualitative data was summarised, 
a copy sent the governance team. The team met and discussed the results. Learning's and refinements were then fed into the quantitative research.

Quantitative data from the on-line survey was analysed in SPSS. Following testing of data quality, further analysis included basic statistical methods and testing correlation where suitable.

For the qualitative data analysis an approach similar to grounded theory was undertaken in order to see if patterns emerge from the results and to uncover new theory. This was assisted by creating summaries of the research data followed by discussions with the governance team.

\section{Anticipated research outcomes}

As noted by Pickaro (2007), good research has a contribution to make, no matter how small. In this instance the researcher had hoped that the investigation would uncover insightful understanding of the role of a follower and follower's sensemaking and assumptions they have of their leader's development.

Followers believing that there is limited return for themselves or the organisation in the development of their leaders would potentially change the way leadership development was undertaken. It may also be that followers underestimate their own role, power and influence in a leader's development and the research may add weight to recent literature about developing followership as a forgotten and largely unpractised yet critical aspect in leadership development.

\section{Ethical considerations}

MMIM HEC was approved (see Appendix I for ethics approval email).

The on-line survey start page made clear that survey results would remain confidential. Interviewees were requested to sign a consent form and interview details being held in confidence. Only the researcher and supervisor being able to access the interview transcripts. The governance team were provided summaries of the interviews to help guide the on-line survey development. No individual details being included. 


\section{Research constraints}

A participatory method was initially considered where a group of leaders and followers would undertake the research together. Time constraints prevented this.

Another constraint for this research was in finding the leaders and followers who were prepared to participate. Initially it was thought that followers may be reluctant to participate fully given they were in effect talking about their manager. This was not an issue as they were fully trusting in their interviews and openness to questions did not appear to be a difficulty.

Given time constraints, only four leaders were interviewed. With a wide array of leadership development initiatives that are possible having only four leaders participate resulted in a narrow sample set. This proved to be limiting. In addition, the leaders selected the followers to be interviewed and would likely select those that portrayed them in a good light.

Having enough people complete the on-line survey (i.e. 30) to make the data analysis valuable was initially considered a constraint, although 40 people participated.

\section{Details of the research}

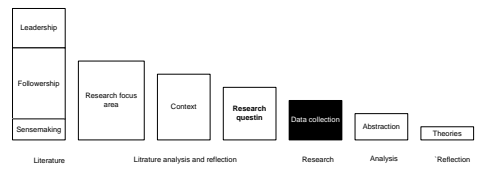

The governance group was formed first. This was carried out by the researcher contacting people known to be involved in leadership development. Three people were approached and accepted. Later one member withdrew. Another was considered but played an HR role in one of the agencies from where leaders and followers were participating. To avoid any issues of confidence another was found. A third member joined the team after the initial interview questions were developed.

The initial team of two provided feedback on the questions during initial meetings and the third giving comment by email. See Appendix A (leader) and B (follower) for the interview questions.

For the interviews, leaders were contacted from two organisations where it was known they were involved in a form leadership development. Two leaders were 
invited from each based on the researchers knowledge of the organisations and advice from local contacts. After agreement from each leader, the leaders selected three suitable followers from their team.

Interview meetings were scheduled by the researcher with a leader being interviewed first on a Monday and their three followers the following three days of the same week.

The interviews were conducted in comfortable meetings rooms of the researcher's work place. The interviews were recorded. All were undertaken without difficulty.

The interviews created considerable interest and interviewees mentioned the interesting nature of the research and how recent thinking on leadership and followership that was raised during the interviews provided points for consideration for both the leaders and the followers.

Following the interviews the audio was transcribed into note form. The interviews were carried out over a period of four weeks in June and July, the on-line survey questions were formed during this time and were finalised in early August. A summary of the findings from the interviews was presented to the governance team to help in the final drafts of the survey.

The on-line survey was created using Victoria University Qualtrics and tested by the governance team and others. Based on feedback from the research supervisor the survey was amended to have a single path rather than multiple paths as in the original design. The survey was tested again with trial results being tested in SPSS to check for ease and accuracy of analysis.

The survey was published during the week of August $16^{\text {th }}$ and remained open for ten days. 40 people participated which was more that anticipated. Results were downloaded using the Qualtrics SPSS export options and opened directly in SPSS. Excess fields were removed (such as IP address). SPSS measures were adjusted to match variable type: Nominal, Ordinal and Scale, given that SPSS export from Qualtrics assumed all variable types to be of Scale type.

Data was analysed for normality and completeness. Two participants indicated they did not wish to participate and exited at the first 'Do you wish to participate' question and were removed from the survey results. Two exited during the survey and did not 
complete it (closed their browser), their results were removed. For the remainder, all questions were answered. There were no missing values. Data was within the ranges specified.

\section{Research findings}

This section provides both the qualitative and quantitative research findings and links these to the literature review. It is noted that the research process was not static and during the interviews the research questions changed, although only slightly, largely improving the clarity of the questions. This suits grounded theory methodology.

\section{Qualitative interview findings}

What immediately became clear during the interviews was how vastly different each leader and group of followers were, even from the same organisation and where similar or identical leadership development had been carried out. Therefore, a brief summary of each interview is presented below based on the research themes outlined in Table 7 and includes reference to the literature where useful. A concluding amalgamated summary is then presented.

\section{Leader $\mathbf{1}^{5}$}

\section{Followership}

- Followers of this leader had undertaken a 360 degree feedback but no other formal role in their leader's development. They were informed that the leader was undertaking a development programme but not given specific detail. The followers did not sense that the leader used tools from the development programme.

- The followers felt that this leader already had good leadership skills and the courses validated that rather than provided new learning. Validation of skills was also mentioned by the leader.

\footnotetext{
${ }^{5}$ The leader interviews are presented in an order that is different to the actual interview order.
} 
- This leader had embodied the leader role (supported by the follower's views), but this was a recent development. The leader commented that "The course itself made you question what you want and if you were willing to commit to leadership and whether or not you knew yourself what you want, what you are capable of, and for me it reinforced that I did have capability and I did have that energy to grow it - that's what I did".

- The followers mentioned that for this leader leadership was a strong motivator and career driver.

- No specific followership learning was mentioned by the leader or followers. The leader recognised that the training programmes did not focus on followership.

\section{Leadership development success (follower's view)}

- The followers viewed this leader's development as positive (as did the leader).

\section{Follower sensemaking}

- The follower's interpretation of the leader's development was positive and encouraging toward the leader.

- Organisational values were a strong attractor in followers' reflections of leadership development.

\section{Authenticity}

- The followers were not specific in their assessment of the leader's authenticity development in followers. The leader indicated that their development did not address followership authenticity however the leader commented "If it (leadership authenticity development) succeeds in developing the qualities for the leader then there is a better chance that some of the follower's role modelling that behaviour, without it, it is less likely to happen"

- Two follower's articulated the mimicry process in relation to how well the leader was developing follower self-awareness "This is mimicry going on here - that's exactly what it is" and "through imitation I must be picking up stuff". 


\section{Summary - Leader 1}

Leader one was respected by the followers. The leader had embodied the role (Gardner, et al., 2005) and leadership had become a career path as observed by the followers.

Value congruence was mentioned by all three followers as a positive motivator and in their organisation values featured strongly (Cha \& Edmondson, 2006). One follower noted that "Some of those values are my values" when referring to organisational values. Implications of value incongruence (Cha \& Edmondson, 2006) was noted by a follower who commented "the ability to be authentic is highly correlated to the match between your own values and the organisational values - if the leader of your group is authentic but whose values are at odds with the organisation values, then you have that risk that when the leader goes it all falls apart. If the leaders are highly congruent with the organisational values, then you have built a stronger organisation rather than a cult". In addition one follower commented "where values are congruent people are happier to talk about things that are not congruent with values".

During the interviews one follower commented "... what you get some in organisations, strong or charismatic leaders, charismatic is perhaps too strong a word, who people really like to work for, when they leave the organisation, their little team follows them to the next job. From the organisation's view who has developed them as a leader, its just a big loss - so instead of growing them to step up when they leave - they take them all with them". This is contrary to the idea of authenticity presented by George and Sims (2007) who suggest that if followers are merely following the lead, then efforts are limited to the leaders vision and directions about what needs to be done. There is a danger that if a clear understanding of the meaning of authenticity is lacking, as this follower indicated, it is possible to establish a cult. 


\section{Interview - Leader 2}

\section{Followership}

- Followers had no direct or formal involvement in this leader's development. Involvement was received through feedback that has been openly invited and asked for but this was not tied to the development initiative.

- The followers were not fully aware of the leadership programme except one who was to attend the same programme in the future.

- The followers could see how the leader had learnt to adopt a style to suit individual followers. The followers see the leader's concern for their individual development and self expression.

- The followers note that the leader asks for permission to "talk into their lives" - has empathy and cares. The followers see that the leader knows of these qualities and uses them.

- There exists no formal programme for followership development although the leader made clear its importance.

- Followers articulate well their significant impact on the leader's development.

- Followers recognise their significant impact on the leader's success. This view is also held by the leader.

\section{Leadership development success (follower's view)}

- Followers see that the leader's development has a positive benefit for them, the team and the leader.

- Leadership development for the organisation is seen as "box ticking".

- This leader was seen to impact positively on inner development for the follower although it was suggested that this was likely the individual leader rather than the development programme.

\section{Follower sensemaking}

- Positive sensemaking was dependent on the relationships with the leader.

- Followers suggested that this leader's development is not typical of the wider organisational leadership initiatives and that at the organisational level such initiatives were seen as "tick box" exercises. 


\section{Authenticity}

- The followers suggest that a good leader will know how to develop authenticity. Their assessment was positive in this case.

- Developing inner qualities was seen as a focus by both the leader and followers (self realisation) but not at organisational level.

- Development of authentic followers is not seen by followers as part of leader's development programme and it is perceived to occur largely because of this particular leader's style.

- Performance and competency programmes were not considered to positively contribute in authentic followership development and was seen as "box ticking".

- This leader challenges the followers and this was appreciated by the followers.

\section{Summary - Leader 2}

This leader is valued by the followers. While not articulating authenticity as a specific development focus for the leader and the followers, when discussing authenticity the leader commented "Self transcendence of the leader is the closest it gets, developing that in others through mimicry" is in line with the thinking of Gardner and colleagues (2005). The leader is seen as self aware and recognised some issues that needed to be addressed. The leader targeted a specific leadership programme that helped address them. The leader believes that other programmes were too generic.

This leader appeared to have begun the internalisation of a leader into personal identity - noted above by Gardner and colleagues (2005). Finding time from daily work for leadership was not mentioned as the leader considered leadership learning to be important part of leadership responsibility. The leader believed $100 \%$ of their time should be devoted to the development of others. The leader was at the 'We' stage of a leader's development (George \& Sims, 2007), see Figure 2. The leader commented that success is not "a measure of success by task completion, that's not how I work, but by motivation, resonance in what followers do-when you have that, the rest falls into place”. When asked to identify the focus for leadership and followership development, identity and values featured high, tasks and outcomes low. This was 
reversed when considering the organisation, where followership development was not a focus.

One follower noted that the wider department vision had been largely articulated by this leader and not from more senior leaders/managers. This leader appeared as the 'constructed' leader for the group (Lord, 2008; Meindl, 1995).

This leader described followership development as: "Followership - should not be directed at the staff - it should be directed at the leaders because it is for them to learn how to create it" - similar to the thinking of Litzinger and Schaefer (1982). The followers were aware of the leader's attempts at helping surface their values and strengths and understanding their goals. The followers noted that this appeared to be something unique to the leader, not the organisation. The followers also viewed the leader as attempting inner development of followers, something that was received positively. The leader provided the follower with tasks that were in line with individual strengths.

At the organisational level authenticity development was neutral. One follower commented that there had been "no impact on me whatsoever, because nobody is actively discussing it or broadcasting it - no one is facilitating discussions about these things, they are just taking the course holding it themselves. They may be changing their behaviours but it is not particularly apparent, I did not even know there is a leadership programme going on" or "I can see the leadership drive for my leader, I get the feeling that the rest of the organisation it is still about management."

Each follower's view of followership differed and while recognising the need to follow instructions, the view was not of a follower of being like a sheep, rather as an active participant in an important relationship with their leader. 


\section{Interview - Leader 3}

\section{Followership}

- Aside from a 360 degree feedback, followers had no direct or formal involvement in this leader's development. Informal feedback occurs but is limited given time restrictions.

- The followers had no clear idea of the leadership programme except one follower who had attended the same course.

- There was no followership development focus in the leader's training programme.

- Followers acknowledge they have influence on the leader's development and success.

\section{Leadership development success (follower's view)}

- There was neutral benefit in the leader's development according to the followers. It was perceived positively initially but faded quickly.

- Leadership organisational development was perceived as neutral and largely "box ticking".

- Leader development was neutral on inner development for the follower.

- The followers perceived organisational leadership development to be neutral to negative.

\section{Follower sensemaking}

- A degree of scepticism and caution was at play within the followers. They perceived it to be "box ticking" with regard to organisational leader development as followers were sensing a lack of consistency at senior leadership level.

- A lot of sensemaking / construction was occurring with regard to who was the actual leader in the wider group.

\section{Authenticity development - developing authenticity in followers}

- Authenticity development for followers and the leader was not a focus.

- Authenticity development was not a part of organisational development. 
- Performance and competency programmes perceptions were split. They were seen as positive because it places an expectation on the follower, however others perceived the neutral benefit because authenticity was not evident in the programme and were largely outcomes-focused.

\section{Summary - Leader 3}

Struggling with the leadership role, this leader viewed leadership as another task on top of an already busy schedule. This leader having not internalised the role (Gardner, et al., 2005) and given perceived poor leadership from above (mentioned by two followers) this leader had not yet been able to relinquish daily tasks to focus on leadership (noted also by the followers). The leader felt to be a poor follower when asked although this was not the view of the followers themselves.

There was an initial burst of enthusiasm on returning from the leadership programme and then, shortly afterwards, returning to normal. This was reflected in the neutral return and effect on the leader's development as seen from the followers. One follower suggested that the leader lacked any on-going support and nurturing after the programme.

The constructed role of leadership (Meindl, 1995) was evident as the followers noticed that this leader often took the role of leader for the wider department. It was also suggested by one follower that other followers with strong leadership orientation also took a constructed leadership role - in both cases it was suggested that this compensated for the higher level organisational leadership that was lacking. One follower commented "In an organisation like ours that is running at 120\% capacity all the time - you strip away the ability to sit down and work out a leadership planthe only time you have that is at home in your own time-all that we see is more and more work has to be done-you take more work home, there is no time for that, plus you yourself as a leader will lose faith, lose motivation, you are just swamped. There is no way of turning the tap off - there are unrealistic expectations put on..... what I am trying to say, in a nut shell, you can set the leader up for failure, you can say you've been on the training course, we expect this, and then pile so much stuff on them". 
Authenticity development awareness was not evident in the leader or followers.

\section{Interview - Leader 4}

\section{Followership}

- While this leader's follower's had no formal role in their leader's development they were informed as to the leader's development process. Two of the three followers could articulare the nature of the training programme, the third, a recent addition to the team could not although was clear that this leader was demonstrating mature leadership ability.

- This leader brought back elements from the training and actively tried them with staff. The followers felt this was valuable.

- The followers articulated positive influence of the training and were able to recognise when the leader was influencing them with the ideas learnt on the training.

- This leader had extensive training in leadership and followership (from being in the military) and was able to clearly describe the follower role and the influence of the follower on leadership.

- This leader embodied the leader role, also noted by the followers.

- The followers were articulate in their knowledge of their influence on the leader.

- The followers were aware of their role in providing feedback as a mechanism to develop the leader. This leader made it clear it was important to hear follower's views.

- The leader recognised that the training programmes did not focus on followership.

\section{ROI - leader's success (follower's view)}

- The followers viewed this leader's development as positive, as did the leader.

\section{Sensemaking}

- There was evidence of sensemaking in the way this leader was positively impacting on the followers. Even though the leader lacked some technical expertise (noted by the followers) the followers were positive toward the way 
this leader was open about the leader's learning and that the leader made clear the recognition and reliance on the followers' subject matter expertise.

\section{Authenticity development - Developing authenticity in followers}

- Authenticity development for followers was not a direct focus for this leader but the leader was articulate in describing how, if authenticity was modelled and people were free to develop, authenticity would be an 'off-shoot' of good leadership.

- The followers noted that the leadership development approach was in developing the leader's self awareness.

- Performance and competency programmes were not used to develop authentic followership.

\section{Summary - Leader 4}

Leader four is very respected by the followers. The leader embodies the role (Gardner, et al., 2005) and notes how much more real the development programmes were when this had occurred.

This leader is aware of the impact of followers "There would be very few leaders that are not followers. Developing as a leader also contributes to your development as a follower. You lead as you would like to be led but you also follow as you would like your followers to follow" - similar to the thinking of Litzinger \& Schaefer (1982). In addition, this level of participation provided the followers with an effective interpretive framework (Lord, 2008) from which positive sensemaking developed. The high level of participation was also part of this leaders approach to empowering followers. The leader actively requested feedback about leadership approach and decisions taken (George \& Sims, 2007; George, et al., 2007) and one follower noted that emotions, values and identity were highly important to this leader's development focus.

Value congruence was evident between the followers, the leader and the organisation. It was mentioned by both the leader and followers the positive impact that cultural values had and that personal values were easily aligned (Cha \& Edmondson, 2006) for 
some of the followers. The power and influence of the cultural values was mentioned by the leader and followers alike.

This leader's extensive experience in the military also provided opportunity to contrast with public sector leadership. "In the public sector you receive leadership training after you are in the position. In the military it's before. You have to prove you are capable. You are trained to be capable before you step up at a base level, whereas public sector it is the other way round and that makes it difficult for the young analysts to step into management role. There is a gap and they have a lot of responsibility placed on people with no training to prepare them. That's different from the military where you would have to be qualified before you could issue one order and trained in a whole different training programme." It is likely that these experiences consolidated this leader's understanding of followership and, given the extensive leadership experience contributed to the leader's influence with the followers. The followers note the positive impact of these experiences on the leader and that led to positive perceptions for the followers.

\section{Qualitative - interview results summary}

The following section provides an analysis of the interview results. See appendix D (followers) and E (leaders) for summarised results.

\section{Followership}

- Followers generally had minimal knowledge of the leader's development programme except for a few situations where the follower had or were to undertake the same leadership programme.

- The leadership development outcomes were not well articulated by the followers indicating that they knew little about the programme and the desired outcomes.

- Followership development in leadership development is largely non existent (noted by leaders).

- Followers believe they have a strong impact (11 positive, 1 neutral) on a leader's development.

- Followers see themselves as having a strong impact on a leader's success (all positive). 


\section{Leadership development success (follower's view)}

The actual outcomes from the leader's development were (follower's view):

- Actual outcomes for the leader: 9 positive, 3 neutral.

- Actual outcomes for the followers: 8 positive, 4 neutral.

$\circ$ Actual outcomes for the team and organisation: 7 positive, 5 neutral.

- Effectiveness of the leader's development: 8 positive, 4 neutral.

Leader's view:

- Benefit for the leader: 3 positive, 1 neutral.

○ Benefit for the organisation: 3 positive, 1 neutral.

○ Benefit for the followers is all positive.

○ Leader's perception of follower's view were all neutral.

\section{Follower sensemaking}

- Followers were mostly positive towards their leader's development, noting that they were encouraged by a leader who was involved in a learning process.

- Leaders were unsure how their followers view their development.

- Leaders felt that followers notice no change as a result of their development.

- The sensemaking of leaders and followers appear to differ between the two organisations. Where value congruence was strong and reflected in organisational culture and leader behaviour, followers positively responded to the leader's development. Where there was less value congruence organisational leadership development was seen as a box ticking exercise. In these cases a follower's positive response appeared to align to the personality and style of the leader.

- Values were used as a reference point in sensemaking.

- It is apparent that some of Weick's (1995) sensemaking characteristics described previously, are evident in the follower's views. For example, how the leadership and followership dynamic is tied to individual identity was apparent from the interviews. This was most prevalent where identities were closely aligned. The ongoing social narrative and discourse, how leaders talked and responded to followers, was also evident in the way followers spoke of their leader, positively or otherwise. 


\section{Authenticity}

Followers note ( 7 positive, 5 neutral) that the leader is helping develop inner qualities in the follower, largely through mimicry and at the organisational level (3 positive, 8 neutral, 1 negative) not at all.

Noted by both followers and leaders, developing authenticity in followers was not a focus of leadership (10 neutral, 2 positive) or organisational development (9 neutral, 3 positive), an observation also mentioned by the leaders.

Developing authenticity is not part of the organisational competency or other development frameworks ( 9 neutral, 3 positive). Depending on the level of value congruence, this was also seen as "box ticking" where value congruence was low but a useful framework to reinforce values where congruence was high.

\section{Qualitative - interview descriptive summary}

The four leaders interviewed were at different stages of Georges \& Sims (2007) model (see Figure 2). All had various insights into authenticity. The followers had good insight into their leader's style and development and follower impact on that development. Followers see themeless as pivotal in the leader's success.

The more a leader internalised the leadership role the easier it was for them to accept the leadership responsibility and take the time necessary to seek out leadership learning and to take the time to implement the learning on the job. This is in line with the ideas from Lord and Hall (2005) noted previously. It was also apparent that where this was not the case, such a commitment was seen as difficult to "justify". Embodiment of the leadership role provided the leader more meaning to the leadership development, and when this occurred the leadership role had more purpose, meaning and focus and followers largely perceived this as a positive benefit for their leader.

Of the four leaders interviewed, two were involved in programmes that were long term ( 9 months or more). For these leaders the follower's views were mostly positive (although not completely) regarding the leader's actual outcomes, even though the followers were not informed of the programme's intent. It is also noted that these 
programmes are expensive, in excess of $\$ 10,000$ (for the Executive Masters an additional \$40,000 - see Appendix F for a cost breakdown) and would likely exclude many potential leaders and organisations. Moreover, this implies that a portion of the results presented may be skewed as the sample size may not reflect what is common in leadership programmes for many organisations.

When reviewing the research results, it is evident that one leader is struggling, something that is observed by this leader's followers. This leader has not yet embodied the leadership role and leadership development may have been detrimental. What is evident is that a non-targeted development programme that does not consider the leader's current leadership maturity and context may, as mentioned above, be setting a leader up to fail. This is potentially harmful for the followers as well.

Directly targeting follower development is not a focus in any of the leadership or organisational programmes. By and large such programmes are leader-focused and where development of follower authenticity occurs it is through mimicry (mentioned specifically by two followers). This is in line with Gardner and colleagues (2005, p. 345) who suggest that authentic follower development occurs by the followers modelling authentic practices and authentic leader behaviour. However, regardless of leadership development type, followers were clear in seeing that leadership development is largely void of direct follower authenticity development.

While all the leaders were able to articulate the follower/leader dynamic, only one leader suggested their leadership was $100 \%$ focused on follower development and comments "Follower development, should not be directed at the staff, it should be directed at the leaders because it is for them to learn how to create it, not for the others to be taught". This leader had sought a leadership programme that targeted a specific leadership weakness and this leader's followers articulated this leader's expressed view that there was a deliberate focus on the development of the follower's well-being, rather than through modelling and mimicry.

Based on the skill domains for leadership development suggested by Lord and Hall (2005) leaders and followers were asked to demonstrate the focus area for the leader's development of followership. The responses were mostly consistent for leader and 
follower. A notable exception is that while leaders see leadership development as low in tasks and outcomes focus, followers perceive this as a high focus. The same trend is also shown for the leadership development relating to followership. Leaders see this as low in tasks and outcome focus, followers as high. Both followers and leaders see organisational followership development as tasks and outcomes focused.

Follower's sensemaking was influential in the way they view leadership development. In general terms this was expressed in the manner in which the leaders were demonstrating to followers their learning and how they involved followers in that process. Here are two different views of the way followers make sense of leadership development:

It gives people faith, it sends the signals to everyone that the leaders themselves see that they are learning. It's a very important signal that [the leader] can learn like you and [that the] leaders value learning leadership skills because that is going to help us work - it sends important signals.

Compared to:

I don't think the CE is open to learning. I get the impression that he does not think he can learn anything from anybody else ....my experience is that he does not take advice from anyone... he has his set ways...then all the training and leadership courses will not help.

Regardless of the actual reality, these two comments demonstrate how sensemaking is playing a part.

The social construction of the leader's role (Meindl, 1995) was evident in several of the follower's comments. One follower commented 'I don't really have a definition of a leader....but when you are in a room and people are talking the manager will start to talk and everyone will be quiet because people will be wanting to know what to do...then the leader will talk and people will suddenly listen because that's the direction that they are going to go". In comments such as these we see a leader being constructed and also a depth of insight that was evident in many of the followers interviewed. While the followers did not directly link their group relationships with the emergence of the leader's role (Hogg, 2008), their sensemaking 
was such that they could observe how the elected leader was not necessarily the person employed as the leader.

In line with Meindl's (1995) thinking that manipulations of context and constructions would constitute the practice of leadership, this was not well reinforced or refined by the leaders. Modelling of behaviour and mimicry were perceived as the primary tools for influencing and encouraging followers.

The ideas of Reicher, Haslam and Hopkins (2005) and Haslam \& Platow (2001) regarding the sharing of social identity were also not well refined by leaders or followers. Leaders generally were not clear where follower identity can be altered and the kind of language, stories or behaviour that needs to be modelled to enable lasting change. It was not evident if leadership development initiatives assist leaders in developing these kinds of skills.

Value congruence was clear between the leaders, the followers and the organisational values for one group of leaders and followers. This was a positive motivator and led to strong connections between the people concerned. For the leaders and followers of the other organisation, values were hardly mentioned.

Based on Gardner and colleague's (2005) self-based model, the striving for authenticity in both follower and leader and the realisation of authentic relationships was not a targeted focus of the leadership programmes (noted by both the followers and leaders).

In a similar way to the follower's awareness of their role in a leader's success, the leaders reflect the influence of followership: "There would be very few leaders that are not followers...developing as a leader also contributes to your development as a follower".

\section{Quantitative survey findings}

A summary of the on-line survey is presented next. While the sample size was more than anticipated the number of participants was still small. However this was valuable in providing support to the qualitative results. See Appendix G for the survey questions and Appendix $\mathrm{H}$ for the full results. 


\section{Followership}

- Followers generally had minimal knowledge of the leader's development programme.

- Followers were largely not formally involved in the leader's development.

- Over three quarters of followers believe they have an important role in a leader's development.

- Over three quarters of followers see themselves as having a strong impact on a leader's success.

- Almost all followers believe their involvement in a leader's development would be beneficial.

- Followership development does not get much attention:

$\circ$ few participants believe that followership and leadership of equal importance.

○ few participants see leaders trained in followership.

○ No respondents see their organisation providing equal time for leadership and followership development.

\section{Leadership development success (follower's view)}

- about half see an observable positive impact of leadership development.

- one third see leadership development as effective, one third see it as not effective, and one third as neither.

- a quarter see a positive ROI, a quarter see negative ROI, the remainder neither.

- almost three quarters of participants don't know if the outcomes of leadership development are met.

- Most see a benefit for the leader, slightly over half for the team and organisation and half for the follower.

\section{Follower sensemaking}

Sensemaking questions were limited in the survey because it was difficult to ask sensemaking question in an on-line form. However the following points are extrapolated from observations made of the survey results:

- Followers see that leadership focus is largely on tasks and outcomes and less on the individual inner development.

- Followers are believed to be influential in leadership development and success. 
- Followers believe development of leadership is valuable while suggesting the outcomes are questionable.

4. Authenticity (the development if inner/personal qualities)

- About half see organisations as placing importance on developing authenticity.

- A third see developing authentic followers, yet more (closer to half) disagree this is happening.

- About half see that leaders attempt to develop authenticity in followers yet about a third.

- Close to half believe that leaders do not learn skills to develop authenticity.

Many of the quantitative results aligned to those found in the qualitative research, the most significant difference being that participants in the survey felt that leadership development was less effective and had a lower ROI than those from the interviews. As explained, this is possibly related to the small sample size of the interview group.

The following section begins the coding aspects of grounded theory and helps point the direction for theory development.

\section{Abstraction}

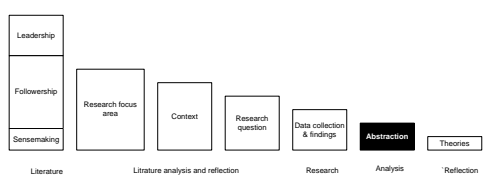

The following section provides additional abstraction from both the qualitative and quantitative results (grounded theory analysis).

\section{Followership}

- Follower's involvement in leadership development was low.

- Followers are largely “in the dark" with regard to their leader's development.

- Targeted followership development is not a feature of leadership development.

- Followers can contribute significantly to a leader's development.

- The path for followership development is the same as that of a leader. A primary difference between a leader and follower is the embodiment of the leader role into their identity.

- Followership is a not a priority for leaders or organisational development. 


\section{Leadership development success (follower's view)}

- The ROI on leadership development is highest when followers see a leader has embodied the leader role and the leader makes an effort to share learning.

- Where there exists strong and clear values and culture, organisational leadership development that aligns to the values will be seen positively by followers.

- The overall return in leadership development is varied. There were a number of factors:

○ The stage of the leader's leadership maturity and how well the specific programme is tailored to the needs of the leader.

- The generic nature of the leadership programmes.

○ The sensemaking of the followers. They quickly form an opinion of a leader and, given that the followers are largely not involved at all in a leader's development, this occurs without the leader's or organisational input.

- The organisational context does not align to the leader development.

- Development that has no ongoing support from the organisation will be lost.

Whether the more senior leaders are considered poor leaders by the followers.

○ The lack of follower's involvement in a leader's development because it:

- lessens the understanding of context of which the followers are likely to have an accurate understanding.

- lowers feedback and support opportunity that followers can provide.

- lessens opportunity for followers to see the learning of the leader. This is a powerful motivator for followers.

- Care is needed in leadership development. Where the development is cognitive and largely external, the demands on novice leaders can be high (Lord \& Hall, 2005) and potentially disruptive.

- The idea of creating an all-leadership organisation (see Figure 5) may not be advisable if the role of follower is not fully understood. 
- The follower role is not seen as something to aspire to.

\section{Follower sensemaking}

- If a leader actively engages followers in their development this supports positive follower sensemaking and not only enhances the follower's view of the leader's development but benefits the leader's development as it establishes trust and encourages honest feedback.

- Organisation-wide leadership development initiatives will have minimal impact if follower's sensemaking is negative.

- Addressing the sensemaking 'temperature' would be valuable at the beginning of the leader's development.

- The followers articulate well their role and impact on the leader. Their sensemaking is a valuable and often accurate guide to the influence of leaders and the impact of a leader's development.

\section{Authenticity}

- The development of authenticity through training programmes is heavily in favour of those that seek the role of leader.

- Authenticity development of followers is mostly passive and achieved through mimicry.

- Followers are open to leaders who actively support their growth through an inner discovery process rather than a surface, environment and outcomes view that is seen as box ticking.

This research brings into question the returns and effectiveness of current leadership development initiatives when taken from followers point of view. It has shown that the deliberate development of followership for leader or follower has received little or no time and few resources. The role of leader appears to have more important status than followership.

This research has also shown that followers and leaders alike believe that more involvement of the follower in a leader's development would be beneficial. In addition the research has shown that unless there is a deliberate and targeted effort on 
the part of the leader, followers are largely the recipient, through mimicry process at best, rather than an active participant in any development process.

The absence of followership development or the involvement of followers in a leader's development implies that leaders and organisations do not see followership as a quality that is worthy of developing. This view was supported in the research findings. The current leadership-orientated views limit the direct authenticity development to a small portion of people, the leaders.

Looking for linkages and influences between the categories studied indicated that followership and followers-sensemaking are linked to the varied effectiveness seen by followers of leadership development. In addition, followers value the inner discovery of their values and identity (although this is not a direct focus for leaders or organisations) and that is linked to positive follower's sensemaking. These connections are show in Figure 13 below. A ‘+' (positive) or '-' (negative) show influence tendencies.

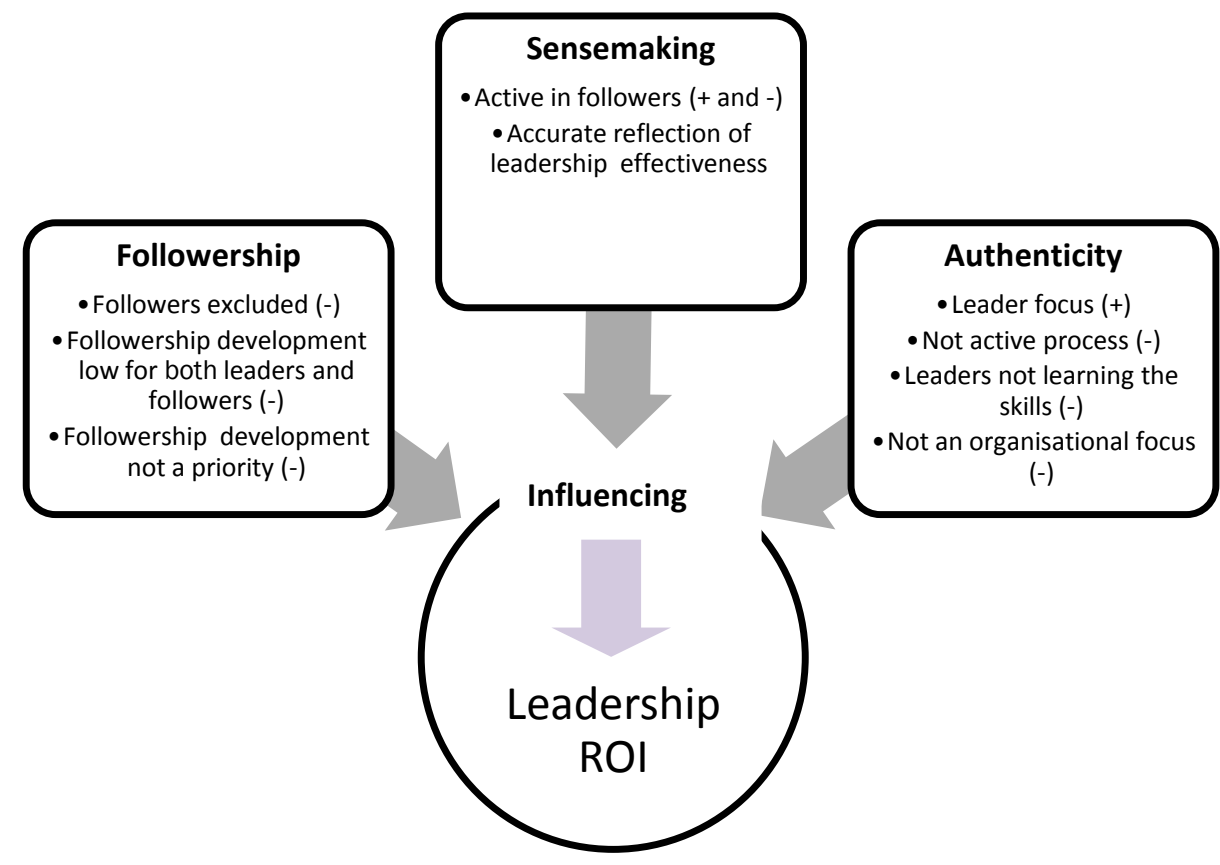

Figure 13: Connections and influences

Answering the research question "What is the influence of followers and their sensemaking on leadership development?" now becomes considerably easier. 
Followers see themselves as having a significant influence on the leader's success. This research has shown that followers currently play little active part in a leader's development although both believe they can make a significant contribution.

With regards to leadership development one interviewee commented, "if it were easy, everybody would be one". This research suggests that there are many and varied considerations, as many as there are people and organisations. Even measuring the outcomes is difficult. However it does suggest there is room for improvement and that using the leader lens in the study of followership may only take us part of the way.

Although a narrow focus for this research, it is evident that follower sensemaking impacts on leadership. Sensemaking is at play and is influencing follower's perceptions and assumptions of leadership and is therefore worthy of consideration where organisations embark on leadership development initiatives.

Referring to the literature as an additional information source to help clarify concepts and theories (in keeping with grounded theory research principles (Punch, 2005)), the section below is the final research stage and provides a conceptual storyline to present and explain the theories that have emerged from this research (Moghaddam, 2006).

\section{Theories and reflections}

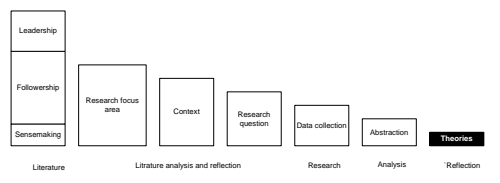

The most salient issues that are raised (the selected themes) have been followership and follower's sensemaking as being an important part of the leadership phenomena.

The benefit of developing, or at least surfacing followership as a quality worthy of development is likely to enhance leadership development and lessen the impact of the dark and potentially destructive side of leadership mentioned previously. Unless such action is taken the leadership dominant view that is present in mainstream literature will continue to generate organisational structures as in Figures 4 and 5 where leadership remains as the primary focus, leaving followership in the shadows. 
Lord and Hall (2005) write that during initial leader development stages categorisation of leadership plays a role that the novice can use for learning and orientation. As has been shown in the followership literature review, a similar categorisation process is the basis for much of the writing on followership and the associated authors suggest a similar development path, i.e. using followership categories to facilitate learning and orientation of followers. However, the use of categorisation and follower models to explain exemplary and poor followership is limited and potentially misleading. Once a follower is positioned within a category, then what?

Categorisation limits the development of our understanding of followership because it positions the role as static, without consideration of context and is not centred in the communicative interaction process between leaders and followers. The practical benefit for a leader in knowing that a follower is "disgruntled", "disengaged", a "doer" or "disciple" is momentary at best. Categorisation does not consider that a follower will play different roles depending on the leader and will also be impacting the identity of the leader. There is also a danger that any targeted followership development will be confused with competency and performance development thus ignoring the constructed and participatory nature of the relationships.

Avalio and Reichard (2008, p. 337) write that "contemporary leadership theorists have defined leadership as a process grown from the relationship between leader and follower. The question of whether leadership development programmes aimed at the development of followers will have a positive impact is still up for debate”. These authors also wonder "what the field [of leadership] would look like if instead of adopting such a leader-centric emphasis, researchers had focused only on what constituted followers and follower development” (ibid, p. 326).

To address this question, it may be tempting for leadership development programmes to include followership development and for organisations to see followership development as a forerunner to the development of leadership. While a necessary step forward is to enhance followership awareness, this will continue to contribute to the dualistic view of the leadership/followership dynamic. 
Throwing more light onto followership by turning over the leadership development coin may help, however the coin itself remains in the hands of the leader. This research has shown that followership views are mostly from the leader's position. Collinson (2008) suggests that if leaders are to cultivate a deeper understanding of followers they may need to let go of their own self-preoccupations. More directly, Collinson advises that some leaders act in highly narcissistic ways and that "current leadership development programmes frequently encourage such behaviour" (2008, p. 322).

Collinson (2008, p. 322) also warns of replacing "the romanticism of leadership with the romanticism of followership" and suggests that taking a totally followership development approach masks the fact that the leader and follower identities are linked.

Hidden assumptions in leadership development are uncovered by Stacey (2005) who notices that defining an advantageous future and using the gap between current and future forms the basis for taking action, i.e. the common process of performing a 'gap analysis'. The need for a better future is usually the starting point of organisational vision, strategy and bold goals. Stacey (ibid, p. 116) writes "this is a linear view of time in which there is a presumed movement from a past that has yielded the present to a future identified in advance". He suggests that this results in a "kind of false consciousness in which people are alienated from their ordinary lived experience of the present."

Similarly, Taylor (2005, p. 131) writes that the dominant views of leadership encourage the "identification of skills and knowledge understood from past experience and their application to a future envisioned as either different from or the same as in the present. The present is important only as a time and place for studying the past and planning the future”.

Meaning generated from sensemaking in this way is relational (to some perceived better future) and linear (steps to achieve that future). Leadership and followership become a future target, or as indicated above, a gap to be filled. The separateness and dualism that result "make it possible to view leadership as if it were a commodity or object that might be held by a person" (Taylor, 2005, p. 140). Taylor suggests that 
leadership is not an object that can be possessed by a person and that can be dissected and reproduced because it arises in participation with others. Remove the 'others' from participation and the leader no longer exists.

In a somewhat less controversial tone, Collinson (2008, p. 323) notices the changing understanding of leading and followership: "The identities and practices of followers and leaders are inextricably linked, mutually reinforcing and shifting within specific context. The current interest in distributed leadership and exemplary followership suggest that the traditional dichotomous identities of leader and follower are increasingly ambiguous and blurred". Extending the idea that the roles are not only linked but result from one another, Tobin (2005, p. 86) suggests that leadership is a social process and "that it is important to think of leading not as one person making sense for others, but rather of emerging from the communicative interaction of all members in a collective."

Collinson and Tobin's comments above make evident the 'connected' and 'interactive' nature of the leader and follower. They highlight the emergent and participatory nature of the roles, the process of interaction, meaning-making and communication that takes place. Therefore, to separate them, as has been shown to be the case in this research, lessons the possibilities for such interaction and implies a disintegration for both, or at best, a reduction in learning opportunity. As with leadership, to view followership in a relational and linear way will open it up for commoditisation, a gap to be filled.

In "its raw form, its [leadership] emergent nature, may be seen in many situations, even within the context of formal hierarchies" (Tobin, 2005, p. 87). If the role of leader is emergent, if it is constructed through the communication and interactions of followers and leaders then it is likely that each role is a construction of the other. A different perspective would be to consider that at any point in time one role helps construct the other, similar to the drawing hands as shown in Figure 14 on the following page. 


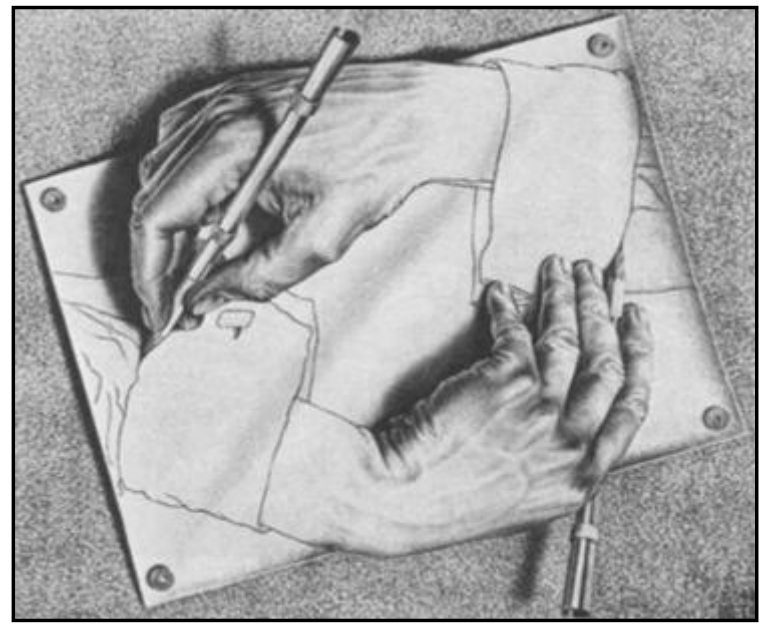

Figure 14: Drawing hands

by M. C. Escher (Maturana \& Varela, 1987)

This moves attention away from the idea of leadership being tied to how we articulate goals and desired outcomes and any special ability to think in sophisticated ways prior to action (Shaw, 2002). Identity is literally being formed through the interaction that results from being together. Change occurs not through the realisation or surfacing of hidden potential, but "in the transformative experience of movements in identities, in the relation to others and oneself" (Lee, 2005, p. 177).

Meaning arises from sensemaking through social acts and emerges in the process of communicative interaction (Griffin \& Stacey, 2005). The only way to influence meaning is to participate in its creation; one cannot participate effectively from a distance or the corner office or by being excluded, as this research has shown to be the case for followers. Griffin and Stacey (2005) write that it is the role of leaders to participate in such a way that deepens and widens communication. Taylor's experience is that attention is required to what $i$ happening rather than what should be happening and that attention to and participation in the everyday human interactions makes better sense of what is a leader (Taylor, 2005, p. 140). Such acts are not limited to the leader. Followers must be active participants as they are part of the group through which the social interaction takes place. They have similar opportunity and responsibility as the leader.

Thus, developing the skill of leadership and followership becomes the enhancement of an individual's ability to pay attention to the communicative process within which 
meaning develops (Shiel, 2005) and enhancing communicative skills through which to enable the surfacing and interpretation of themes and patterns. Initially awareness of how one is participating in and influencing the ongoing conversation is important.

Furthermore, connections are developed through the social process of forming relationships between people and "people constantly negotiate their identities while seeking to find ways to act together. In their interactions together numbers and words are a medium of their transactions with one another and themselves" (Taylor, 2005, p. 140). What this highlights is the importance of language as a primary tool used in our interactions and negotiations. The use of language is as critical in the shaping of meaning as it is in its sharing. Additionally, as noted by Rooney and colleagues (Rooney, et al., 2010, p. 174) that wise leaders are able to "understand the constructedness of organisational discourse" and are able to interpret the ontology inherent in knowledge and language. They propose the term "ontological acuity" as an important element in wisdom for understanding the overarching tacit assumptions and norms that language contains, and through which leadership and followership are constructed. In this term is seen an inner understanding of the need to pay attention to language and conversation as described above.

With regards authenticity, it is also a reasonable proposition that a leader would want followers that are authentic. It has been shown that those that aspire to the role of leader have the advantage. Developing authenticity should not be limited to leaders as to do so would not be authentic. In addition, development of authenticity does not need to be passive and limited to mimicry.

Our reactions and solutions that result from responses to problems will have embedded in them the same thinking from which initial meaning has been made of a problem or situation and how it was understood. As this research has shown, leadership development has led to marginal success and it raises a question as to whether the current embedded thinking about leadership has become a constraint. This raises a second question that development of followership may well lead to the same (less than desirable) results. 
To begin to comprehend why a solution is not effective, a place to start is by studying the thinking that is embedded in the implemented solution. Using the literature as a guide, presented in Table 8 below and on the following pages, are seven theories that have been abstracted from the research data. In part they surface current embedded understanding and how these have become constraints. In turn it becomes possible to suggest ways of thinking and acting that may overcome barriers and lead to an improvement in leadership development practice. Practical ideas are presented on following pages.

\begin{tabular}{|c|c|c|}
\hline & Theory & Proposition \\
\hline 1 & $\begin{array}{l}\text { Dualism and } \\
\text { commoditisation of } \\
\text { leadership }\end{array}$ & $\begin{array}{l}\text { A causal dualistic orientation of leadership as being something } \\
\text { separate to individual lived experience, makes leadership easier } \\
\text { to objectify. When this occurs, leadership development becomes } \\
\text { a skill and gap filling exercise and something to obtain and in turn } \\
\text { it has become a target for commoditisation. What results is the } \\
\text { proliferation of leadership courses and a belief that a course that } \\
\text { provides a set of tools that when used, provide (potentially false) } \\
\text { definition to what it means to lead. } \\
\text { The absence of followership in leadership programmes as this } \\
\text { research has shown to be the case, reflects this dualism. If it } \\
\text { were seen that leadership results from and can only take place in } \\
\text { interactions and social acts with followers, it would become } \\
\text { nonsensical to exclude followers. } \\
\text { Commoditisation helps to ensure that status is attached to the } \\
\text { leader role and helps to hide the paradoxical perspective of } \\
\text { leadership as letting go of ego and position, just being alert and } \\
\text { being humble as Collins suggests (Collins, 2001). } \\
\text { A causal and dualistic view presents opportunity for categorisation } \\
\text { as is seen in the literature for leadership and followership. It also } \\
\text { explains at least in part, why leadership is so "slippery" to define } \\
\text { because in attempting to define it some of its meaning is lost. }\end{array}$ \\
\hline 2 & $\begin{array}{l}\text { Leadership/follower } \\
\text { constructionism }\end{array}$ & $\begin{array}{l}\text { Leaders and followers are not fully aware of the construction of } \\
\text { leadership or the shifting individual and group identity and its } \\
\text { impact on how meaning and leadership emerges. As has been } \\
\text { suggested above, the leader role emerges and the act of leading } \\
\text { or following occurs between people in ongoing and everyday } \\
\text { processes of interaction. Construction and reconstruction takes }\end{array}$ \\
\hline
\end{tabular}




\begin{tabular}{|c|c|c|}
\hline & & $\begin{array}{l}\text { place through participation of people in the living present. } \\
\text { Construction comes in experience not from experience. Where a } \\
\text { leader becomes an observer or learns leadership in absence of } \\
\text { followers, this removes the leader from the act of leading. }\end{array}$ \\
\hline 3 & $\begin{array}{l}\text { Leading as a change } \\
\text { in identity awareness }\end{array}$ & $\begin{array}{l}\text { Currently, change is viewed as the awakening or surfacing of } \\
\text { hidden potential, whether in the organisation or in individuals. } \\
\text { Assuming this potential is already there and only needs to be } \\
\text { actualised, mainstream writers focus on the release of this } \\
\text { potential. } \\
\text { However, what is proposed in this theory is that change is } \\
\text { considered a shifting of identity in relation to others in the group } \\
\text { and part of a leader's role is how to influence the patterning that } \\
\text { occurs as people establish and re establish their identity. The act } \\
\text { of leading is to help enable such change. }\end{array}$ \\
\hline 4 & $\begin{array}{l}\text { Leadership } \\
\text { emergence occurs in } \\
\text { language }\end{array}$ & $\begin{array}{l}\text { Leadership development can be augmented by focusing on how } \\
\text { people are participating in ongoing conversation and in paying } \\
\text { attention to how meaning is developed and patterning occurs. } \\
\text { The role of leader then is more accurately described as the person } \\
\text { that is able to draw attention to and articulate meaning of the } \\
\text { salient aspects of conversation and less on our ability to } \\
\text { formulate complex strategies that reflect a known future. } \\
\text { The linguistic domain within which leadership construction takes } \\
\text { place, leadership is formed and relationships with followers are } \\
\text { realised, constrain possibility. }\end{array}$ \\
\hline 5 & Follower sensemaking & $\begin{array}{l}\text { This research has shown that followers are articulate in their } \\
\text { assessment of leaders, sensemaking is at play. Sensemaking is } \\
\text { an important aspect to identity formation (Weick, 1995) and how } \\
\text { people adapt to the situation they are dealing with. As such, it is } \\
\text { influencing followers and their meaning-making of leadership. } \\
\text { Current leadership thinking largely ignores this phenomena and in } \\
\text { doing so not only does it lose valuable understanding from the } \\
\text { followers view, leaders lose (or lack) the ability to be watchful for } \\
\text { individual and group identity formation and this reduces the } \\
\text { leader's ability to influence or develop shared meaning. } \\
\text { Understanding the meaning-making that results from follower } \\
\text { sensemaking is valuable. }\end{array}$ \\
\hline
\end{tabular}




\begin{tabular}{|ll|}
\hline Leadership & Followership writing is largely from the leader's perspective. This \\
dominance & limits thinking needed to fully explore the leader/follower \\
& dynamic. This is evident in that authenticity and self discovery \\
& that organisations implement are largely limited to those that \\
& seek the role of leader. Mainstream literature suggests that for \\
& followers this is a mimicry process, modelling the leader. Yet \\
& when it is a targeted aspiration of a leader (as in the case of one \\
& leader in this research) it has significant positive benefit for all \\
& concerned. \\
& Organisational competency development is not targeting inner \\
& personal qualities and is perceived by followers to an outcome \\
& and often a “box ticking" exercise. \\
\hline 7 & Deliberate followership development and followership learning in \\
fellowership & leadership development will likely improve the current low Rol on \\
necessary & leadership development efforts. Only with careful consideration \\
& and implementation will the categorisation and commoditisation \\
&
\end{tabular}

Table 8: Derived Theories

Finally, to participate in a social world as one's true self suggests that the opportunity to lead and follow authentically must be equally shared. Patricia Madson (2003, p. 174) notes that this also requires the idea that sharing control is different from the notion of "I lead and you follow". She suggests that qualities of attention, alertness and responsibility become underlying development principles. Couple these suggestions with the ideas relating to language, ontological acuity, wisdom, the participation in conversation and the constructed nature of leadership, organisations may see leadership and followership as a social act and not as a science or function of management (Shotter, 1993).

Leader or follower when expressed as verbs rather than nouns become activates. When rooted in authenticity and not seen as a position or title or an end goal or even opposite sides of the same coin (Williams, 2008), but rather an ongoing process of self discovery, then the human aspects of each becomes more evident and the idea of separation and any resulting commoditisation becomes absurd and unnatural. 
Ernest Becker (1973) suggests that people will create the reality they need in order to discover themselves thus the goal and focus on leadership or indeed followership may inadvertently mask the processes of self discovery. Or, put slightly differently, the search for self is filtered if it entails becoming something. To be truly authentic implies that there is no attachment to position or role and one is connected with the world and experiences the world fully as oneself. The clarity they have of the world is real.

Taken a step further, should the words leadership and followership be removed? One can only aspire to be an authentic self. In this light to say that "I want to be an authentic leader or authentic follower" appears an oxymoron. The idea of an authentic leader or follower then becomes irrelevant and the objective can be more simply stated - to become a more authentic self.

\section{Implications for Practice}

Before concluding, the theories and ideas above need to be presented in a way that may be of some practical value. This research effort has presented evidence provided by leaders and followers alike, that the leadership ROI is low and the role of the follower is significant because, as is now clear, they are mostly absent.

As has been discussed above, just including followers in the leader's development journey is not enough. Continuing the current followership categorisation is also not sufficient. To include followership development in competency programmes would likely be a mistake. These however are the likely reactions because for many, the skills of attention, observations of ontology within language and the construction of identity that result from people in conversation are not well understood and not apparent in development programmes. The current fixation on leadership as being strategy and the creation of clever ideas about the future, combined with the dualistic and leader centric perspective of followership, imposes constraints. In turn this limits language and thinking schema, important tools needed to take a different perspective.

How then to proceed? Recognising the inadequacies and limitations in current leadership development as described does not on its own help. The path forward is not clear. Like walking in a fog, taking one step at a time, sensing the surroundings and paying attention to the present is a likely suitable approach. Using advice from 
fire fighter Paul Gleeson cited earlier, where the future is uncertain, it is better to be making sense than making decisions. Suggestions for setting the direction for the coming period of leadership development are presented in the following bullet points.

- Leadership development programmes can be enhanced by:

○ understanding the constructed nature of the leadership role.

o understanding the impact of language and being able to be observant in conversation to the salient issues and meaning that is being made and how these may be influenced through ongoing participation.

- Recognising that leaders cannot 'manage' meaning from the outside, they are only able to influence it through active participation.

$\circ$ involving the followers at the start of development programmes with explanations of why the programme is being undertaken, what the learning outcomes are and how the followers can help and support the process.

○ actively developing authenticity in all and not excluding followers. This will assist in the establishment of authentic relationships.

○ sharing the learning experiences.

$\bigcirc$ aligning the leader's development with their stage of leadership maturity.

○ recognising the knowledge required as leadership maturity evolves and aligning development to meet the desirable knowledge requirement.

○ focussing on developing inner and richer qualities of values, beliefs, understanding and formation of identity.

○ value clarity that leads to congruence that provides stronger motivation.

$\circ$ letting go of the idea of leadership authenticity development and simply focusing on the development of authenticity, regardless of role.

- Leadership development can be destructive and harmful where:

○ novice leaders are developing cognitive leadership skills and knowledge and attempting to apply skills in a complex environment. The demands will be high and this is particularly evident where the 
leadership role has not been internalised. Followers will be sensemaking the activity, potentially negatively.

- leaders who are not open to learning will quickly establish negative sensemaking from followers. Attempts to development leadership will be seen as box ticking, a contrived, not genuine activity.

$\circ$ where the leader has not matured; generic leadership development may be detrimental.

○ where context is not considered. Noted by Lord and Hall (2005, p. 599) "the exemplars used to guide a novice leader's behaviour are not tailored to a particular context and thus may be counter productive".

- Development of followership:

$\circ$ adjust leadership training programmes to reflect Figure 7. A leader/follower orientation rather than a leader everywhere orientation (see Figure 5).

○ elevate the followership quality to be of the same status as leaders.

○ for leaders to recognise that followership is the primary means through which:

○ leadership is carried out

$\bigcirc$ things get done

○ relationships with leaders form

○ leaders gain maturity

○ bad and toxic leaders are removed

- leader's visions are realised

○ common and shared reality is formed

$\bigcirc$ trust with the leader is formed

○ identities are developed

- leadership is practiced and honed

- leadership language is developed

- leaders (good or bad) are legitimised

Before concluding, the ideas and concepts presented above are compared and contrasted with the "Five Practices of Exemplary Leadership" developed by Kouzes and Posner (2007, p. 14). See Table 9 on the following page. This is provided to 
point the way for further research and the possible development of a conceptual leadership/followership model.

\begin{tabular}{|c|c|c|}
\hline & $\begin{array}{l}\text { Five Practices of Exemplary } \\
\text { Leadership from Kouzes and } \\
\text { Posner }(2007, \text { p. 14) }\end{array}$ & Concepts - similarities and differences from the research. \\
\hline 1 & Model the way. & $\begin{array}{l}\text { Actively engage all members in authenticity development } \\
\text { and not limit direct involvement to leaders only. }\end{array}$ \\
\hline 2 & Inspire a shared vision. & $\begin{array}{l}\text { Inspire shared identity. Clarify identity. Influence identity } \\
\text { formation. "Who we are" being as important as "where } \\
\text { we are going" }\end{array}$ \\
\hline 3 & Challenge the process. & $\begin{array}{l}\text { Understand the process and the daily lived experiences } \\
\text { and constructions that take place in language and as } \\
\text { individuals and social groups interact. }\end{array}$ \\
\hline 4 & Enable others to act. & $\begin{array}{l}\text { Enables others to act, to experience wholeness through } \\
\text { their every day actions (not because of them). }\end{array}$ \\
\hline & Encourage the heart. & $\begin{array}{l}\text { Encourage the heart through an improved awareness of } \\
\text { the daily interactions and how sensemaking takes place } \\
\text { and meaning is derived. }\end{array}$ \\
\hline
\end{tabular}

Table 9: Comparative theory table

\section{Conclusion}

Is it acceptable that only a quarter of the research participants see a positive ROI on leadership development? Less than one third see it as effective (more see it as negative) and many do not know if the benefits of attending the programmes are met. Furthermore, the concern expressed by David MacKenzie (2001) noted at the beginning of this paper regarding the low ROI on leadership development has again been highlighted. For any other business investment such a result would likely be considered a failure.

Taylor writes that the mainstream leadership literature and thinking is "generalised, idealized and reified" (Taylor, 2005, p. 140) and that in "modern society, the concept of leadership has become formalised and institutionalised”. And, according to Reicher, Haslam and Hopkins, leadership has "lost its way from the textbook to the boardroom" (2005, p. 550). This research has identified a similar trend given followers by and large like to see their leaders involved in development but see it 
having marginal practical impact. The disconnection between the theory of leadership and the practical reality remains a dilemma.

Ira Chaleff writes "the mark of a great leader is the development and growth of followers. The mark of a great follower is the growth of leaders" (2009, p. 29). This research supports Chaleff's comments with evidence that both leaders and followers believe followers have an important role and considerable influence on a leader's development and success. Regrettably, the research results make clear they are largely excluded from the process. Limiting followers from the development of leaders will limit both the leader and the follower.

Rodger Adair (2008, p. 143) notices that companies spend 80 percent of their training efforts on leadership and 20 (if anything at all) percent on followership. This research has highlighted the imbalance in leadership/followership development while followers and leaders all express the importance of both, and especially followership: "Leaders have to know how to follow", "you need to be able to follow in order to lead", "to learn how to be a leader you have to learn how to be a follower" (excerpts from the research interviews). The research has shown that organisations as yet appear unwilling to acknowledge followership through time and resource commitment and this suggests that the leadership view of followership remains a powerful influence to the way in which both roles are perceived, written about and enacted in organisations.

The most obvious course of correction would be to develop followership as a forerunner of leadership, and is a likely typical leader response. While this would likely improve the leadership ROI it would fail to appreciate the dynamic of the leader/follower relationship. It may well lead to commoditisation of followership as current thinking has for leadership.

These observations do not undermine the nature and benefit of leadership but rather reinforce its importance. It does so through the need for leadership to encourage the realisation and expression of each individual life, whether leader or follower, and the realisation of authentic self. Recent literature suggests that when this is the role of the leader then trust, engagement and commitment, work satisfaction and well-being result (Gardner, et al., 2005). As David Whyte (2001) might express it: work then becomes a pilgrimage to identity discovery and not (just) the receipt of a fortnightly pay cheque. 


\section{Appendix A - Leader interview questions}

\section{Focus points}

1. Followership / leadership dynamic - are followers aware of their role in leadership development? Leadership development influence of followers and followership

2. Leadership development success: The ROI on leadership development as viewed from the follower (positive / neutral / negative).

3. Sensemaking: followers' sensemaking of their leader's development. How do they respond to a leader's development activities and opportunities and what impact does this have (positive or negative) on the outcome of the development initiative?

4. Authenticity: Enduring inner qualities such as values and identity contribute to meaning making for both follower and leader. Are these skills developed through the leadership development programme? Is there awareness for the development of authentic followers?

Questions per focus area:

\begin{tabular}{|lll|} 
& Focus point & Question \\
\hline 1 & Followership & $3,8,9,10,11,125,7,13,17$ \\
\hline 2 & $\begin{array}{l}\text { Leadership development success / } \\
\text { ROI }\end{array}$ & $2,4,6$ \\
\hline 3 & Follower's sensemaking & 16 \\
\hline 4 & Authenticity & 14,15 \\
\hline
\end{tabular}

\section{Leader Interviews}

These are scheduled to take place during the end of June / July 2010

Time for interview: 1 hour

Number to interview: 4 (minimum 3)

The leaders have been chosen because they have recently or are currently involved in a leadership development programme. 


\section{Researchers' preamble:}

The research is to learn:

a. How leadership development addresses followership. What do leaders understand of followership?

b. How involved followers are in a leader's development. Do they understand the role they play?

c. The impact/ROI of a leader's development through the lens of followership

d. The sensemaking of followers and its impact on a leader's development.

e. Developing authentic followership - how?

Some questions have values of:

Positive, neutral, negative

\section{Leader: Open Ended Questions}

1. Explanation of the leadership development programme

a. What does it cover?

b. How long does it take?

c. What form is it: workshop, course, off-site, etc?

Targets focus point: Sets the scene

Estimated time: 3 minutes

2. What will be the likely ROI from attending the leadership development programme?

For you:

Positive, neutral, negative

Explain how this is viewed/measured

For your organisation:

Positive, neutral, negative

Explain how this is viewed/measured

Targets the following focus points (see above): 2

Estimated time: 3 minutes

3. How are the followers involved in your leadership development programme?

Explain: 
Targets the following focus points: 1

Estimated time: 2 minutes

4. In your view what will be/has been the impact/ROI on the followers of the development programme - your view?

Positive, neutral, negative

Targets the following focus points: 2

Estimated time: 3 minutes

5. How will you know this, what is the difference?

For example - behaviour of followers before / after development

Targets the following focus points: 2

Estimated time: 3 minutes

6. Regarding the impact/ROI on the followers of the development programme - what do you think the followers view will be?

Positive, neutral, negative

Explain.

Targets the following focus points: 2

Estimated time: 3 minutes

7. How do your followers contribute to your leadership development? Details:

Targets the following focus points: 1

Estimated time: 4 minutes 


\section{How would you define followership?}

At this point, if there is a need, define followership as:

Real view (to use in the interview):

In a work environment, a follower(s) is a person (or group of people) that are led by another.

Constructed view:

An authentic relationship between people whereby what emerges at a point in time is a prototypical leader that is constructed through the sharing of meaning within a group of people - know as the followers.

Targets the following focus points: 1

Estimated time: 5 minutes

9. What percentage of time in your leadership development programme is spent on followership development?

Say-10\% $20 \quad 3040506070 \quad 80$ to $90 \%$

Targets the following focus points: 1

Estimated time: 1 minutes

10. In your leadership development programme, if followership was explained, describe your understanding of what was covered

Details:

Targets the following focus points: 1

Estimated time: 5 minutes 
11. Is followership trained in equal levels as leadership in your organisation?

Targets the following focus points: 1

Estimated time: 3 minutes

12. As a leader, are you a good follower? If so, why?

Targets the following focus points: 1

Estimated time: 4 minutes

13. Did/does/how your leadership development programme cover the way followers impact leaders and your own development (e.g.- socially constructed nature of leadership)?

Details:

Targets the following focus points: 1

Estimated time: 4 minutes

14. How did/does the leadership development programme help develop personal identity in the follower?

For example - a lot of the literature on both leadership and followership development describe the process as an activity that helps an individual (leader or follower) to self-realise that leads to a clearer idea of personal identity

Positive, neutral, negative

Details:

Targets the following focus points: 4

Estimated time: 4 minutes

15. Did/does/how the leadership development help to develop authenticity in the followers

Positive, neutral, negative

Details:

Targets the following focus points: 4

Estimated time: 4 minutes 
16. How does the follower understand and interpret (make sense of) your leadership development?

Extra questions if time allows:

17. What are the followership characteristics that impact your leadership development?

Details:

Targets the following focus points: 1

Estimated time: 4 minutes 


\section{Appendix B - Follower interview questions}

\section{Focus points}

1. Leadership development influence of followers and followership.

Followership / leadership dynamic: are followers aware of their role in leadership development?

2. Leadership development success: the ROI on leadership development as viewed from the follower (positive / neutral / negative).

3. Sensemaking - followers' sensemaking of their leader's development. How do they respond to a leader's development activities and opportunities and what impact does this have (positive or negative) on the outcome of the development initiative?

4. Authenticity: enduring inner qualities such as values and identity contribute to meaning-making for both follower and leader. Are these skills developed through the leadership development programme? Is there awareness for the development of authentic followers?

\begin{tabular}{|lll|}
\hline & Focus area & Question \\
\hline 1 & Leadership & $1,12,13,2,8,9,10$ \\
\hline 2 & Leadership development success / ROI & 3,5 \\
\hline 3 & Follower's sensemaking & 4,11 \\
\hline 4 & Authenticity and followership & $6,7,12,14$ \\
\hline
\end{tabular}

\section{Researchers' preamble:}

The research is to learn:

a. How leadership development addresses followership. What do leaders understand of followership?

b. How involved followers are in a leader's development and do they understand the role they play?

c. The impact/ROI of a leader's development through the lens of followership.

d. The sensemaking of followers and its impact on a leader's development. 
e. Developing authentic followership - how?

Some questions have values of:

Positive, neutral, negative

\section{Questions: Follower}

1. Explain the leadership programme being carried out by your leader. What is your understanding of the leadership programme?

Describe the programme:

Targets the following focus points: 1

Estimated time: 2 minutes

2. How are the followers involved, e.g. was there a 360 ?

Yes / No

If Yes.....how?

Targets the following focus points: 1

Estimated time: 2 minutes

3. What do you understand the stated outcome from the leadership development programme to be?

a. For the leader

b. For the organisation

c. For your team

d. For you

Targets the following focus points: 2

Estimated time: 5 minutes 
4. What did you think of when you first heard about the leadership development programme?

\section{Explain:}

Targets the following focus points: 3

Estimated time: 2 minutes

5. What effect has your leader's attendance in the leadership development programme had:

On you?

Positive / neutral / negative

Explain details behind this view

On the team?

Positive / neutral / negative

Explain details behind this view

On the organisation?

Positive / neutral / negative

Explain details behind this view

On the Leader?

Positive / neutral / negative

Explain details behind this view

Targets the following focus points: 2

Estimated time: 5 minutes

6. How well does your leader's development help you develop understanding of your inner qualities such as self awareness, personal values and personal identity?

Positive / neutral / negative

Explain details behind this view

Targets the following focus points: 4

Estimated time: 4 minutes 
7. How well does your organisation's development help you develop understanding of your inner qualities such as self awareness, personal values and personal identity?

Positive / neutral / negative

Explain details behind this view

Targets the following focus points: 5

Estimated time: 4 minutes

8. As a follower, what impact do you believe you have on the leader's development?

Positive / neutral / negative

Explain

Targets the following focus points: 1

Estimated time: 3 minutes

9. What role do followers have in the success of a leader?

Positive / neutral / negative

Explain

Targets the following focus points: 1

Estimated time: 3 minutes

10. What does 'being a follower' mean to you?

Targets the following focus points: 1

Estimated time: 3 minutes

11. Do you think the leadership development programme is effective?

Positive / neutral / negative

Explain:

Targets the following focus points: 2

Estimated time: 2 minutes 
12. Do leaders develop authentic followership?

Positive / neutral / negative

Explain:

Targets the following focus points: 4

Estimated time: 2 minutes

13. Does the organisation develop authentic followership? Are there programmes for followership development?

Positive / neutral / negative

Explain:

Targets the following focus points: 4

Estimated time: 2 minutes

14. Aside from the leadership development are there other ways followership is developed?

Or

is your organisation's performance and competency programmes help develop authentic followers?

Positive / neutral / negative

Explain:

Targets the following focus points: 4

Estimated time: 2 minutes

Additional questions:

15. What do you think of regarding the term follower? 


\section{Appendix C - Governance team}

Senior HR staff member at a large government agency

Senior manager of a government leadership development agency

Senior Lecturer: Education \& Bachelor of Arts (BA) Programme Director 


\section{Appendix D - Follower interview summary}

Note: duplicate numbers are used for multi-part questions

\section{Followers - Questions}

Responses

1. Explanation of the leadership programme being carried out by your $8 *$ Limited.

leader. What is their understanding of the leadership programme?

$4 *$ where follower had attended, was

to attend or had helped administer

the course

2. How are the followers involved? e.g, was there a 360 degree

A few - 360

process

Otherwise informal only

3. What do you understand the stated outcome from the leadership

Provision of leadership tools

development programme to be for the leader?

3. What do you understand the stated outcome from the leadership

Not well articulated - reflecting

answers to question 1

development programme to be for the organisation?

Provision of leadership tools

Developing state sector leaders

Not well articulated - reflecting

answers to question 1

3. What do you understand the stated outcome from the leadership

Provision of tools

development programme to be for the team?

Not well articulated - reflecting

answers to question 1

3. What do you understand the stated outcome from the leadership development programme to be for you?

Largely unsure - - reflecting answers to question 1

4. What did you think of when you first heard about the leadership development programme?

Largely positive for the leader development for them and the organisation

5. What effect has your leader's attendance in the leadership 8 Positive

development programme had on you?

4 Neutral

Positive / neutral / negative

5. What effect has your leader's attendance in the leadership 7 Positive

development programme had on the team? 5 Neutral

Positive / neutral / negative

5. What effect has your leader's attendance in the leadership 7 Positive

development programme had on the organisation? 5 Neutral

Positive / neutral / negative

5. What effect has your leader's attendance in the leadership 9 Positive

development programme had on the leader? 3 Neutral

Positive / neutral / negative

6. How well does your leader's development help you develop inner 7 Positive qualities such as own self awareness and personal identity Positive / 5 Neutral neutral / negative?

7. How well does your organisations development help you develop 3 Positive inner qualities such as self awareness and personal identity? 8 Neutral

1 Negative

8. As a follower, what impact do you believe you have on the leader's 11 Positive

development?

1 Neutral

Positive / Neutral / Negative

9. What role do followers have in the success of a leader? 12 Positive

Positive / Neutral / Negative 


\begin{tabular}{|c|c|}
\hline 10. What does 'being a follower' mean to you & $\begin{array}{l}\text { Following orders } \\
\text { Loyalty } \\
\text { Not as a sheep - being able to } \\
\text { present views }\end{array}$ \\
\hline $\begin{array}{l}\text { 11. Do you think leadership development programmes are effective? } \\
\text { Positive / Neutral / Negative }\end{array}$ & $\begin{array}{l}8 \text { Positive } \\
4 \text { Neutral }\end{array}$ \\
\hline $\begin{array}{l}\text { 12. Are leaders aware of the need to develop authentic followership? } \\
\text { Positive /Neutral / Negative }\end{array}$ & $\begin{array}{l}2 \text { Positive } \\
10 \text { Neutral }\end{array}$ \\
\hline $\begin{array}{l}\text { 13. Do leaders in your organisation develop followership? } \\
\text { Positive /Neutral / Negative }\end{array}$ & $\begin{array}{l}3 \text { Positive } \\
9 \text { Neutral }\end{array}$ \\
\hline $\begin{array}{l}\text { 14. Do your organisation's performance and competency } \\
\text { programmes help develop authentic followers? }\end{array}$ & $\begin{array}{l}4 \text { positive } \\
8 \text { neutral }\end{array}$ \\
\hline
\end{tabular}




\section{Appendix E - Leader interview summary}

Note: duplicate numbers are used for multi-part questions

\section{Leaders Question}

Responses

1. Explanation of the leadership development programme. What

does it cover, how long does it take, what form?

$1 *$ NZIM

1* Catapult

2 * LDC LIP

2 * ANZSOG Executive Masters

2. What will be the likely ROI from attending the leadership

3 Positive

development programme for you?

1 Neutral

What will be the likely ROI from attending the leadership

3 Positive

development programme for the organisation?

1 Neutral

3. How are the followers involved in your leadership development programme?

$2 * 360$

Informal only

\section{What will be/has been the impact/ROI on the followers of the 4 Positive}

development programme: your view?

5. How will you know this? what is the difference?

Unsure - no measures, don't know they will see a difference

Openness, confident to express their opinion, courage of their convictions

6. Regarding the impact/ROI on the followers of the development 4 Neutral

programme - what do you think the followers view will be?

\begin{tabular}{|ll|}
\hline 7. How do your followers contribute to your leadership development? & Not well articulated \\
& Feedback mentioned by 1 leader \\
\hline 8. How would you define followership? & Working toward a shared vision \\
\hline $\begin{array}{l}\text { 9. What percentage of time in your leadership development } \\
\text { programme is spent on followership development? }\end{array}$ & $\begin{array}{l}1 * 100 \% \\
3 * 0 \%\end{array}$ \\
\hline $\begin{array}{l}\text { 10. In your leadership development programme, if followership was } \\
\text { explained, describe your understanding of what was covered }\end{array}$ & $\begin{array}{l}\text { Not covered in detail } \\
\text { Impact of leaders on followers not } \\
\text { the other way round }\end{array}$ \\
\hline $\begin{array}{l}\text { 11. Is followership trained in equal levels as leadership in your } \\
\text { organisation? }\end{array}$ & 4 * No \\
\hline $\begin{array}{l}\text { 12. As a leader, are you a good follower? If so, why? } \\
\end{array}$ & $\begin{array}{l}4 * \text { Yes - Loyalty and speaking truth. } \\
(1 \text { was dependant on their leader })\end{array}$ \\
\hline
\end{tabular}

13. Did/does your leadership development programme cover the way No

followers impact leaders and your own development (e.g.- socially Unsure

constructed nature of leadership)?

Impact of leader on follower

14. How did/does the leadership development programme help 4 * No

develop personal identity in the follower?

15. Did/does the leadership development help to develop 4 * No

authenticity in the followers

16. How does the follower understand and interpret (make sense of) your leadership development?

3 * Don't know

1 * feel happier and more

17. What are the followership characteristics that impact your comfortable

leadership development?

$3 *$ Unsure

1 * Neutral respect, Loyalty, Being able to be different, Agree to

disagree 


\section{Appendix F- Programmes attended by leaders}

Programmes attended by the leaders:

○ 2 leaders involved with ANZSOG, Executive Masters: two year, part time programme. Costs are $\$ 40,000$ (excluding travel). These 2 leaders were also involved in LDC Leadership in Practice: 9 months (5 day residential followed by ongoing meetings, cost approximately $\$ 10,000$

- 1 leader with Catapult Leadership Programme: 3 day residential, $\$ 3,800$ (extras are 360 feedback - $\$ 750$, coaching $\$ 3,000$, etc.)

○ 1 leader with NZIM 4 quadrant leadership: 3 days ( $\$ 3100$ - Non members) 


\section{Appendix G - On-line survey questions}

\section{Start Page - Default Question Block}

This on-line survey forms part of a research paper leading towards a Masters Degree in Information Management at Victoria University of Wellington.

The research project is examining the role of followers in leadership development.

Survey Details:

Once the survey results have been submitted they cannot be withdrawn.

All survey responses collected will be anonymous. It will not be possible for you to be identified personally. Only grouped responses will be presented in this report. All material collected will be kept confidential.

The research paper will be submitted for marking to the School of Information Management and deposited in the University Library.

All collected materials will be destroyed two years after the end of the project. University ethics approval has been granted for this research.

In addition, one or more journal articles about this research may be submitted for publication in scholarly journals and the results may be presented at academic or professional conferences.

The survey takes between 5 and 10 minutes to complete.

Agreement of participation:

I recognize that once the results are submitted I am unable to withdraw from the survey.

I agree to participate in this survey

C

I do not wish to participate in this survey

\section{Leadership Role}

I currently have a recognised leadership role in my organisation

or

I have undertaken a leadership development programme in the last 36 months
(6) Yes
(C) No 


\section{Question 2}

I have attended one or more of the following courses

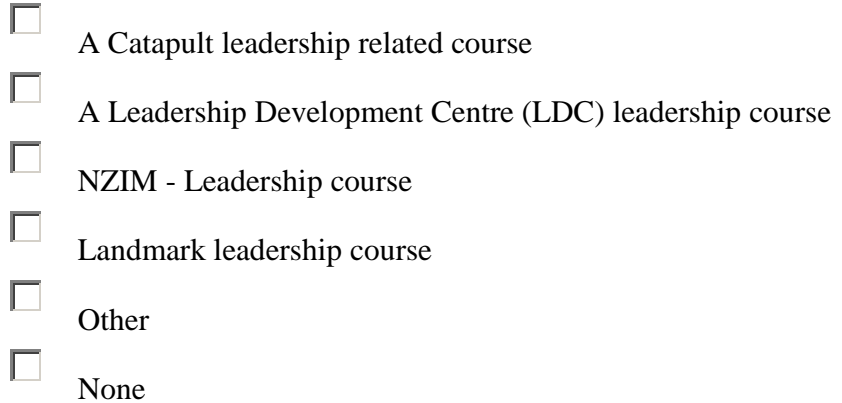

\section{Question 3}

If leaders in your organisation attend a leadership development programme, how informed are you at the start or during the programme of the intended outcomes of the programme?
Fully informed
Partially informed
Not informed
Not applicable

\section{Question 4}

If leaders in your organisation attend a leadership development programme, what form does your involvement in your leader's development take?

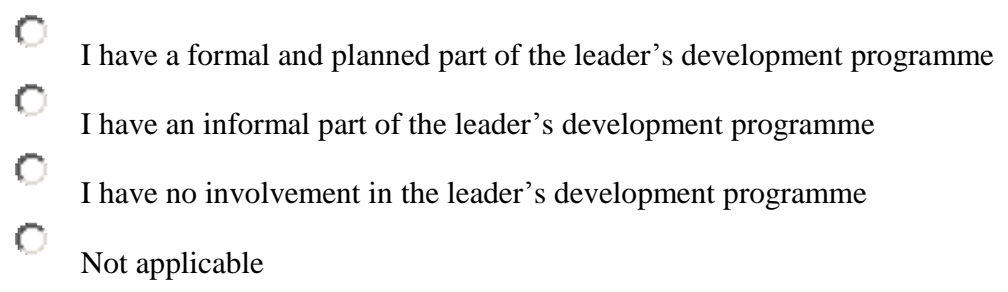

\section{Question 5}

When a leader in your organisation returns from a leadership development programme, the actual outcomes are?
Fully met
(C) Partially met
(C) Not met
Don't know 


\section{Question 6}

What is the benefit of leaders in your organisation attending leadership development programmes?

$$
\text { Very negative negative } \begin{gathered}
\text { Neutral /No } \\
\text { change }
\end{gathered} \text { Positive Very positive }
$$

\begin{tabular}{|c|c|c|c|c|c|}
\hline For the organisation & 0 & $\mathrm{C}$ & 0 & 0 & $\mathrm{C}$ \\
\hline For my team & $\mathrm{C}$ & 6 & 0 & 0 & $\mathrm{O}$ \\
\hline For the leader & 0 & $\mathrm{C}$ & $\mathrm{C}$ & $\mathrm{C}$ & $\mathrm{O}$ \\
\hline For me & 0 & $\mathrm{C}$ & 0 & $\mathrm{C}$ & $\mathrm{C}$ \\
\hline
\end{tabular}

\section{Question 7}

Please mark the choice that most accurately describes your reaction to the statement.

$\begin{array}{cccc}\begin{array}{c}\text { Strongly } \\ \text { disagree }\end{array} \quad \text { Disagree } & \begin{array}{c}\text { Neither agree } \\ \text { nor disagree }\end{array}\end{array}$ Agree $\quad$ Strongly agree

I can see an observable positive impact for my organisation, resulting from leadership development

\section{Question 8}

Time spent on followership learning.

Drag the slider left and right (or click the line) to reflect the amount of time spent on learning followership in your organisations leadership development programme.

Percentage of time
$\begin{array}{lllllllllll}0 & 10 & 20 & 30 & 40 & 50 & 60 & 70 & 80 & 90 & 100\end{array}$




\section{Question 9}

In my organisation leadership and followership development are of equal importance
(C) Yes
No
Don't know

\section{Question 10}

In my organisation leaders are trained in followership
(C) Yes
(C) No
Don't know

\section{Question 11}

In my organisation leadership and followership development get equal time devoted to it
(O) Yes
(C)
Don't know

\section{Question 12}

Authenticity Development.

Authenticity development is people learning about themselves - becoming more self-aware, becoming aware of their personal values and personal identity.

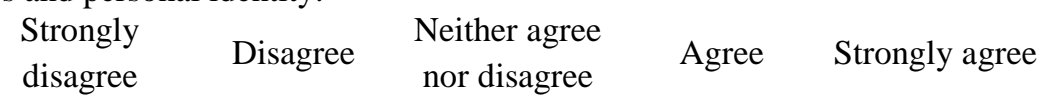

Our organisation places importance on the development of leader's authenticity

Our organisation places importance on the development of authentic followers

My leader places importance on the development of my authenticity 
Our leaders learn the skills required to develop authentic relationships with followers

\section{Question 13}

Select a choice that most closely describes your reaction to the following question.

The leader's focus in our organisation is on:
Low focus
Medium Focus
High Focus

Follower achievement of tasks and outcomes
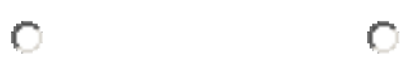<smiles>[CH]</smiles>

Follower understanding

of their emotions and

behaviours

Follower understanding of their personal values

Follower understanding of personal identity

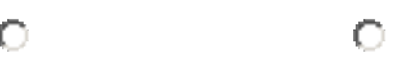

C

Question 14

Please mark the choice that most accurately describes your reaction to each statement:

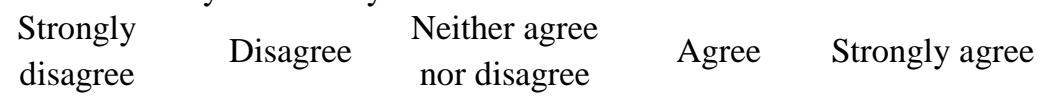

The follower plays an important role in the development of the

$$
\text { C }
$$<smiles>[CH]</smiles>

leader

The follower has considerable impact on the success of the leader

The follower's involvement in a leader's development would be beneficial to the leader 


\section{Question 15}

Leadership development in my organisation:

$\begin{array}{llll}\begin{array}{l}\text { Strongly } \\ \text { disagree }\end{array} \quad \text { Disagree } & \begin{array}{c}\text { Neither agree } \\ \text { nor disagree }\end{array} & \text { Agree } & \text { Strongly agree }\end{array}$

Is effective

C $\quad 0$

C

C

C.

Has a positive return on

C

$C$ investment 


\section{Appendix $\mathrm{H}$ - On-line survey results}

Note: there are slight rounding differences and scores may not add exactly to $100 \%$.

Question 1. Role

- $69 \%$ of participants had a recognised leadership role

Question 2: Who attended what training?

○ $13.9 \%$ (5) Catapult

○ $11.1 \%$ (4) LDC

○ $8.3 \%$ (3) NZIM

○ $2.8 \%$ (1) LandMark

○ $25 \%$ (9) Other

○ $52.8 \%(19)$ None

(this was a multi select question - could add to greater that $100 \%$ )

Question 3: How informed are people of leader's development outcomes

○ $19.4 \%$ (7) Fully Informed

○ $25 \%$ (9) Partially informed

○ $30.1 \%$ (11) Not informed

○ $25 \%$ (9) Not applicable

Question 4: How involved are people in a leader's development

○ $9.4 \%$ (3) Formal

○ $27.8 \%$ (10) Informal

○ $41.7 \%$ (15) None

○ $22.2 \%$ (8) Not applicable

Question 5: When a leader in your organisation returns from a leadership development programme, the actual outcomes are?

○ $2.8 \%$ (1) Fully met

○ $22.2 \%$ (8) Partially met

○ $2.8 \%$ (1) Not met

○ $72.2 \%$ (26) Don't know

Question 6-1 : Benefit - for the organisation

○ $2.8 \%$ (1) Very negative

○ $36.1 \%$ (13) Neutral/No change

○ $41.7 \%$ (15) Positive

○ $19.4 \%$ (7) Very positive 
Question 6-2: Benefit - for the leader
○ $2.8 \%$ (1) Very negative
○ $13.9 \%$ (5) Neutral/No change
○ $52 \%$ (19) Positive
○ $30 \%$ (11) Very positive

Question 6-3: Benefit for the team
○ $2.8 \%$ (1) Very negative
○ $2.8 \%$ (1) Negative
- $27.8 \%$ (10) Neutral/no change
○ 58.3 (21) Positive
○ $8.3 \%$ (3) Very positive

Question 6-4: Benefit - for me
○ $2.8 \%$ (1) Very negative
○ $47.2 \%$ (17) Neutral/No change
○ $36.1 \%$ (13) Positive
○ $13.9 \%$ (5) Very positive

Question 7: I can see an observable positive impact for my organisation resulting from leadership development
○ $5.6 \%$ (2) Strongly disagree
○ $13.9 \%$ (5) Disagree
○ $30.6 \%$ (11) Neither agree or disagree
○ $30.6 \%$ (11) Agree
○ $19.4 \%$ (7) Strongly agree 
Question 8: Time spent in leadership development on learning followership

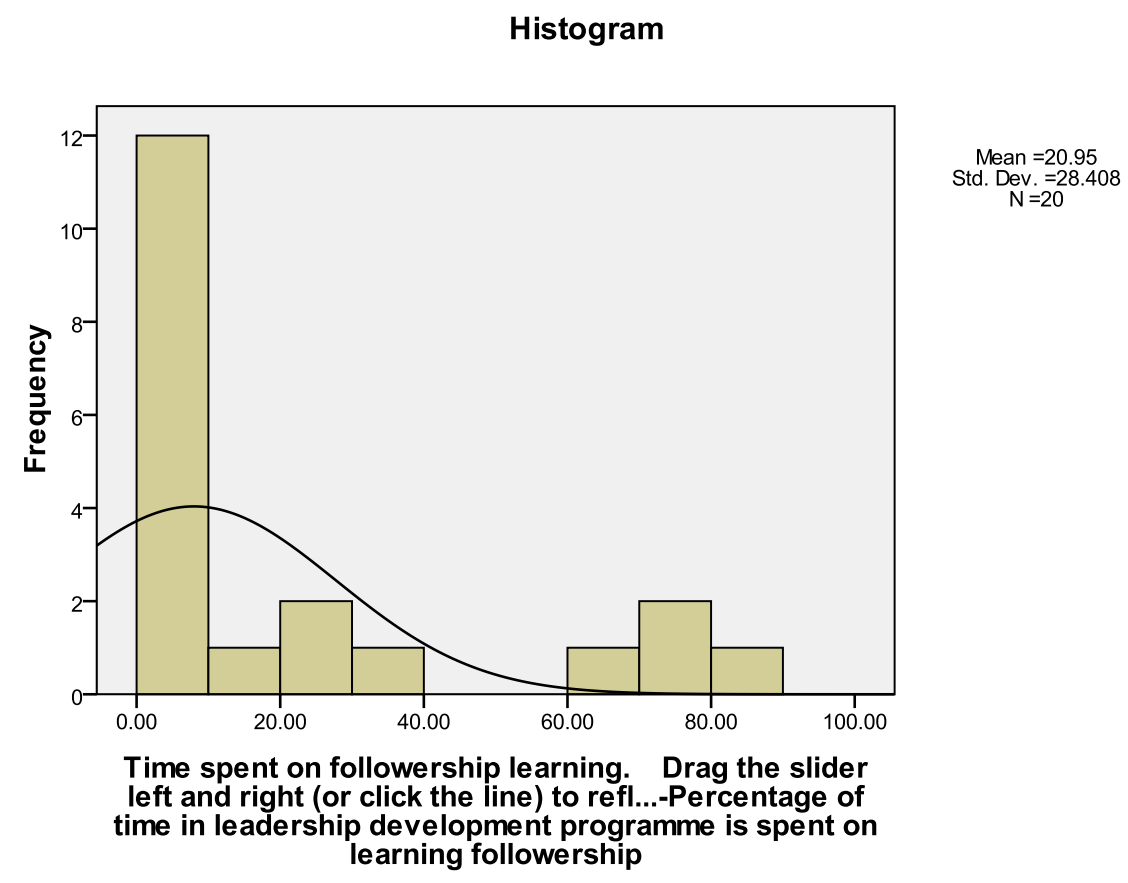

Note: 15 (44.4\%) people answered don't know (not included above).

Question 9: Followership and leadership are of equal importance in your organisation
○ $13.9 \%(5)$ Yes
○ $55.6 \%(20)$ No
○ $30.6 \%$ (11) Don't know

Question 10: Leaders are trained in followership in your organisation
○ $8.3 \%(3)$ Yes
○ $55.6 \%(20)$ No
- $36.1 \%$ (13) Don't know

Question 11: In my organisation leadership and followership development get equal time
○ $61.1 \%(22)$ No
○ $38.9 \%$ (14) Don't know 
Question 12-1: Our organisation places importance on the development of the leader's authenticity

○ $\quad 16.7 \%$ (6) Strongly disagree

○ $11.1 \%$ (4) Disagree

○ $22.2 \%(8)$ Neither agree or disagree

○ $41.7 \%$ (15) Agree

○ $8.3 \%$ (3) Strongly agree

Question 12-2: Our organisation places importance on the development of authentic followers

$\circ \quad 16.7 \%$ (6) Strongly disagree

○ $22.2 \%(8)$ Disagree

○ $30.6 \%$ (11) Neither agree or disagree

○ $27.8 \%$ (10) Agree

○ $2.8 \%$ (1) Strongly Agree

Question 12-3: My leader places importance on the development of my authenticity

○ $11.1 \%$ (4) Strongly Disagree

○ $16.7 \%$ (6) Disagree

○ $19.4 \%$ (7) Neither agree or disagree

○ $41.7 \%$ (15) agree

○ $11.1 \%$ (4) Strongly agree

Question 12-4: Our leaders learn the skills required to develop authentic relationships with followers

$\circ \quad 11.1 \%$ (4) Strongly disagree

○ $16.7 \%$ (6) Disagree

○ $44.4 \%$ (16) Neither agree or disagree

○ 25\% (9) Agree

○ $2.8 \%$ (1) Strongly agree 
Question 13-1: Leadership focus - Follower achievement of task and outcomes

○ $25 \%$ (9) Low focus

○ $33.3 \%$ (12) Medium focus

○ $41.7 \%$ (15) High focus

Question 13-2: Leadership focus - Follower understanding of emotions and behaviours

○ $66.7 \%$ (24) Low focus

○ $25 \%$ (9) Medium focus

○ $8.3 \%$ (3) High focus

Question 13-3: Leadership focus - Follower understanding of their personal values

○ $61.1 \%(22)$ Low focus

○ $33.3 \%$ (12) Medium focus

○ $5.6 \%$ (2) High focus

Question 13-4: Leadership focus - Follower understanding of their personal identity

○ $72.2 \%$ (26) Low focus

○ $25 \%$ (9) Medium focus

○ $3.1 \%$ (1) High focus

Question 14-1: The follower plays an important role in the development of a leader

○ $5.6 \%$ (2) Strongly disagree

○ $5.6 \%$ (2) Disagree

○ $11.1 \%$ (4) Neither disagree or agree

○ $52 \%$ (19) Agree

○ $25 \%$ (9) Strongly agree 
Question 14-2: The follower has considerable impact on the success of the leader

$\circ \quad 5.6 \%$ (2) Strongly disagree

○ $5.6 \%$ (2) Disagree

○ $5.6 \%$ (2) Neither disagree or agree

○ $41.7 \%$ (15) Agree

○ $41.7 \%$ (15) Strongly agree

Question 14-3: The follower involvement in a leader's development would be beneficial to the leader

○ $2.8 \%$ (1) Strongly disagree

○ $8.3 \%$ (3) Neither agree or disagree

○ $52.8 \%$ (19) Agree

○ $36.1 \%$ (13) Strongly agree

Question 15-1: Leadership development in my organisation is effective

○ $13.9 \%$ (5) Strongly disagree

○ $22.2 \%$ (8) Disagree

○ $36.1 \%$ (13) Neither agree or disagree

○ $25 \%$ (9) Agree

○ $2.8 \%$ (1) Strongly agree 
Question 15-2: Leadership development in my organisation has a positive return on investment

○ $11.1 \%$ (4) Strongly disagree

○ $13.9 \%$ (5) Disagree

○ $50.0 \%$ (18) Neither agree or disagree

○ $19.4 \%$ (7) Agree

○ $6.3 \%$ (2) Strongly agree

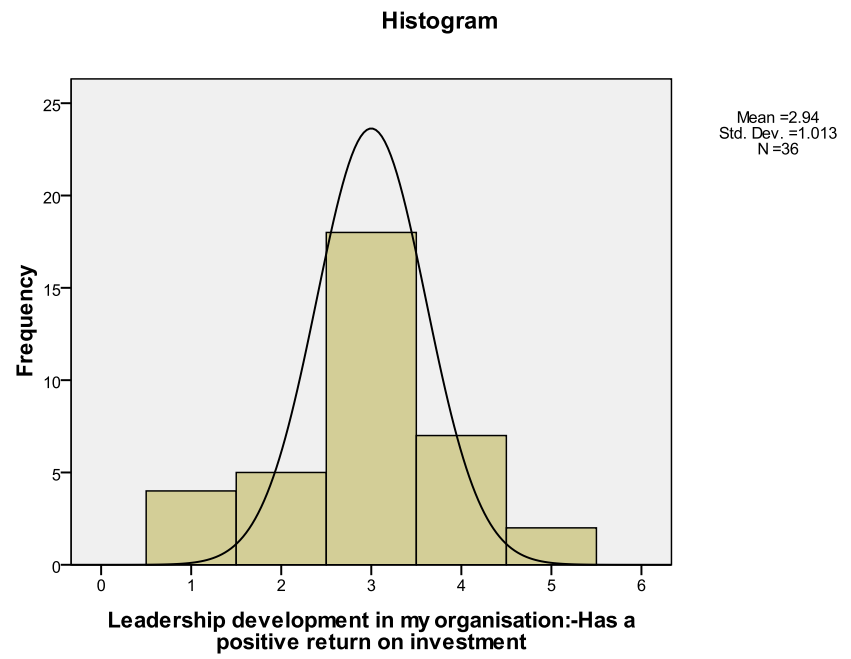




\section{Appendix I- Ethics approval}

From: Wendy Chen [wendy.chen@vuw.ac.nz]

Sent: $\quad$ Friday, 9 July 2010 3:45 p.m.

To: $\quad$ Mark Harris; Hans Lehmann

Subject: $\quad$ RE: Research - HEC forms

Hi Mark

Your signed HEC application has been received and the HEC Chair, Dan Dorner, has also signed off on it so I am archiving it in our records today.

Good luck with your research.

Wendy 


\section{References}

Aaltonen, M. (2007). The Third Lens: Multi-ontology Sense-making and Strategic Decision-making: Ashgate.

Adair, R. (2008). Developing Great Leaders, One Follower at a Time. In R. E. Riggio, I. Chaleff \& J. Lipman-Blumen (Eds.), The Art of Followership: Jossey-Bass.

Avalio, B. J., \& Reichard, R. J. (2008). The Rise of Authentic Followership. In R. E. Riggio, I. Chaleff \& J. Lipman-Blumen (Eds.), The Art of Followership: Jossey-Bass.

Bass, B. M., \& Riggio, R. (2005). Transformational Leadership (2nd ed.): Lawrence Erlbaum Associates.

Becker, E. (1973). The Denial of Death: Free Press Paperbacks.

Bennis, W. (1994). On Becoming a Leader: Perseus Books.

Bennis, W. (1999). The Leadership Advantage Leader to Leader, 12(Spring).

Blass, T. (2008). What Can Milgram's Obedience Experiments Contribute to Our Understanding of Followership? In R. E. Riggio, I. Chaleff \& J. LipmanBlumen (Eds.), The Art of Followership: Jossey-Bass.

Blueman, L. S. (2008). Bystanders to Children's Bullying: The importance of Leadership by "Innocent Bystanders". In R. E. Riggio, I. Chaleff \& J. LipmanBlumen (Eds.), The Art of Followership: Jossey-Bass.

Bohm, D. (1996). In Dialogue: Routledge.

Brown, A. D., \& Thornborrow, W. T. (1996). Do Organisations get the Followers they Deserve? Leadership and Organisational Development Journal, 17(1), 511.

Buckingham, M., \& Clifton, D. O. (2004). Now Discover Your Strengths: How to Develop Talents and Those of the People You Manage: Pocket Books.

Burke, R. (2006). Leadership and Spirituality. Foresight, 8(6), 14-25.

Burnes, J. (1978). Leadership: HarperCollins.

Cacioppe, R. (1997). Leadership moment by moment. Leadership and Organisational Development Journal, 18(7), 335-345.

Cacioppe, R. (1999). Creating Spirt at Work: Re-visioning organisation development and leadership - part 1. The Learning \& Organisation Development Journal, 21(1), 48-54.

Cammock, P. (2001). The Dance of Leadership: The Call for Soul in 21st Century Leadership: Pearson, Prentice Hall.

Carsten, M. K., Uhl-Bien, M., West, B. J., Patera, J. L., \& McGregor, R. (2010). Exploring social constructions of followership: A qualitative study. The Leadership Quarterly, doi:10.1016/j.leaqua.2010.03.015, 1-20.

Cha, S. E., \& Edmondson, A. C. (2006). When values backfire: Leadership, attribution, and disenchantment in a values-driven organisation. The Leadership Quarterly(17), 57-78.

Chaleff, I. (2008). Creating New Ways of Following. In R. E. Riggio, I. Chaleff \& J. Lipman-Blumen (Eds.), The Art of Followership: Jossey-Bass.

Chaleff, I. (2009). The Courageous Follower: Standing Up to and for Our Leaders: Berrett-Koehler Publishers Inc.

Collins, J. (2001). Good to Great: HarperCollins.

Collinson, D. (2006). Rethinking Followership: A Post-structuralist Analysis of Follower Identities. The Leadership Quarterly, 17, 179-189.

Collinson, D. (2008). Conformist, Resistant and Disguised Selves: A Post Structuralist Approach to Identity and Workplace Followership. In R. E. 
Riggio, I. Chaleff \& J. Lipman-Blumen (Eds.), The Art of Followership: Jossey-Bass.

Creswell, J. W. (2003). Research Design: Qualitative, Quantitative and Mixed Methods: Sage Publications Ltd.

Day, G. S., \& Schoemaker, P. J. H. (2008). Are you a Vigilant Leader. MIT Sloan Management Review, 49(3).

Dervin, B. (1998). Sense-making theory and practice: an overview of user interests in knowledge seeking and use. Journal of Knowledge Management, 2(2), 36-46.

Dilts, R. B. (1996). Visionary Leadership Skills: Creating a world to which people want to belong: Meta Publications.

Dixon, G. (2008). Getting Together. In R. E. Riggio, I. Chaleff \& J. Lipman-Blumen (Eds.), The Art of Followership: Jossey-Bass.

Doyle, M., \& Smith, M. (2008). Classical Leadership Retrieved June, 2009, from http://www.infed.org/leadership/traditional_leadership.htm

Eisenhardt, K. M., \& Martin, J. A. (2000). Dynamic Capabilities: What are they? Strategic Management Journal, 21(10-11), 1105-1121.

Fairholm, M. R. (2004). A New Sciences Outline for Leadership Development. The Leadership \& Organisation Development Journal., 25(4), 369-383.

Flood, R. (1999). Rethinking the Fifth Discipline: Learning within the Unknowable: Routledge.

Friedman, T. L. (2005). The World is Flat: The Globalized World in the Twenty-First Century: Penguin Books.

Gardner, W. L., Avolio, B. J., Luthans, F., May, D. R., \& Walumbwa, F. (2005). Can you see the real me? A self-based model of authentic leaders and follower development. The Leadership Quarterly, 16, 343-372.

George, B., \& Sims, P. (2007). True North: Discover your Authentic Leadership: Jossey-Bass.

George, B., Sims, P., McLean, A. N., \& Mayer, D. (2007). Discovering Your Authentic Leadership. Harvard Business Review.

Gerzon, M. (2006). Leading Through Conflict: Harvard Business School Publishing.

Glen, P. (2003). Leading Geeks: How to Manage and Lead People Who Deliver Technology: Jossey-Bass.

Goffee, R., \& Jones, G. (2007). Leading Clever People. Harvard Business Review(March), 1-7.

Goleman, D. (2004). What Makes a Leader. Harvard Business Review, January.

Greenleaf, R. K., Spears, L. C., \& Covey, S. R. (2002). Servant Leadership: A Journey into the Nature of Legitimate Power and Greatness: Paulist Press.

Griffin, D., \& Stacey, R. (2005). Complexity and the experience of Leading Organisations: Routledge.

Hamel, G., \& Breen, B. (2007). The Future Of Management: Harvard Business School Publishing.

Haslam, S. A., \& Platow, M. J. (2001). The Link between Leadership and Followership: How affirming Social Identity Translates Vision into Action. Personality and Social Psychology Bulletin, 27(11), 1469-1479.

Hersey, P. (1984). The Situational Leader: Warner Books.

Higgs, M. (2002). How can we make sense of leadership in the 21 st century. Leadership and Organisational Development Journal, 24(5), 273-284.

Hogg, M. A. (2008). Social Identity Processes and the Empowerment of Followers. In R. E. Riggio, I. Chaleff \& J. Lipman-Blumen (Eds.), The Art of Followership: Jossey-Bass. 
Hogg, M. A., \& Reid, S. A. (2006). Social Identity, Self-Categorization, and the Communication of Group Norms Communication Theory, 6, 7-30.

Howell, J. P., \& Mendez, M. J. (2008). Three Perspectives on Followership. In R. E. Riggio, I. Chaleff \& J. Lipman-Blumen (Eds.), The Art of Followership: Jossey-Bass.

Hurwitz, M., \& Hurwitz, S. (2009). The romance of the follower: part 1. Industrial and Commercial Training, 41(6), 326-333.

Isaacs, D., \& Brown, J. (2005). The World Cafe: Shaping Our World Through Conversations that Matter: Berrett-Koehler Publishers.

Jackson, M. C. (2004). Systems Thinking: Creative Holism for Managers: John Wiley and Sons Ltd.

Johnstone, K. (1981). Impro: Improvisation and the Theatre: Routledge.

Karps, T., \& Helgo, T. (2008). The Future of Leadership: The Art of Leading People in a "Post -Managerial" Environment. Foresight, 16(2), 30-37.

Kellerman, B. (2004). Bad Leadership: What it is, how it happens, why it matters: Harvard Business School Press.

Kellerman, B. (2007). What Every Leader Needs to Know About Followers. Harvard Business Review(December), 1-7.

Kelley, R. E. (1988). In Praise of Followers. Harvard Business Review(NovemberDecember), 142-148.

Kernis, M. H. (2003). Towards a Conceptualization of Optimal Self-Esteem. Psychological Inquiry, 14(1), 1-26.

Kouzes, J. M., \& Posner, B. Z. (2007). The Leadership Challenge: John Wiley \& Sons Inc.

Lee, A. (2005). Executive coaching and leading. In D. Griffin \& R. Stacey (Eds.), Complexity and the Experience of Leading Organisations: Routledge.

Lipman-Blueman, J. (2008). Following Toxic Leaders: In search of Posthumous Praise. In R. E. Riggio, I. Chaleff \& J. Lipman-Blumen (Eds.), The Art of Followership: Jossey-Bass.

Litzinger, W., \& Schaefer, T. (1982). Leadership through Followership. Business Horizons(September-October), 78-81.

Lord, R. G. (2008). Follower's Cognitive and Affect Structures and Leadership Processes. In R. E. Riggio, I. Chaleff \& J. Lipman-Blumen (Eds.), The Art of Followership: Jossey-Bass.

Lord, R. G., \& Brown, D. J. (2001). Leadership, values and subordinate self-concepts. The Leadership Quarterly(12), 133-152.

Lord, R. G., \& Hall, R. J. (2005). Identity, deep structure and the development of leadership skill The Leadership Quarterly, 16, 591-615.

Maccoby, M. (2008). What Kind of Leaders Do People Want to Follow? In R. E. Riggio, I. Chaleff \& J. Lipman-Blumen (Eds.), The Art of Followership: Jossey-Bass.

MacKenzie, D. (2001). Living Leadership Now Retrieved May, 2010, from http://linezine.com/7.2/articles/dmlln.htm

Madson, P. R. (2003). Improv Wisdom: Don't Prepare, Just Show Up: Bell Tower.

Marquardt, M. (2005). Leading With Questions: How Leaders Find The Solutions by Knowing What to Ask: Jossey-Bass.

Maturana, H. R., \& Varela, F. J. (1987). The Tree of Knowledge: The Biological Roots of Human Understanding: Shambhala.

Maxwell, J. C. (1998). The 21 Irrefutable Laws of Leadership: Thomas Nelson Inc. 
McKee, A., Boyatzis, R., \& Goleman, D. (2002). The New Leaders: Transforming the art of leadership on the science of results: Harvard Business School Press.

McKenna, B., Rooney, D., \& Boal, K. B. (2009). Wisdom Principles as a Metatheoretical Basis for Evaluating Leadership. The Leadership Quarterly, 20, 177-190.

Meindl, J. R. (1995). The Romance of Leadership as a Follower-Centric Theory: A Social Constructionist Approach. Leadership Quarterly, 6(3), 329-341.

Moghaddam, A. (2006). Coding issues in grounded theory Retrieved 18 September, 2010, from http://www.iier.org.au/iier16/moghaddam.html

O'Conner, J., \& Seymour, J. (1990). Introduction to NLP: Mandala.

O'Leonard, K. (2009). Leadership Development - Is It Really Worth The Money Retrieved October, 2010, from https://www.bersin.com/blog/post.aspx?id=e51c3cd3-8b6f-48d6-853451f9b7293e64

O'Leonard, K., \& Lamoureux, K. (2009). Leadership Development Factbook 2009: Benchmarks and Analysis of Leadership Development Spending, Staffing and Programs Retrieved October, 2010, from http://www.bersin.com/Lib/Rs/Details.aspx?Docid=10331166

Pickaro, A. J. (2007). Research Methods in Information: Facet Publishing.

Popkin, R. H., \& Stroll, A. (1956). Philosophy Made Simple: DoubleDay \& Company Inc.

Punch, K. (2005). Introduction to Social Research: Quantitative and Qualitative Approaches (Second ed.): Sage Publications.

Reicher, S., Haslam, S. A., \& Hopkins, N. (2005). Social Identity and the Dynamics of leadership: Leaders and followers as collaborative agents in the transformation of social reality. The Leadership Quarterly, 16, 547-568.

Riggio, R. E., Chaleff, I., \& Lipman-Blumen, J. (2008). The Art of Followership: Jossey-Bass.

Rooney, D., \& McKenna, B. (2006). Wisdom In Public Administration: Looking for a Sociology Of Wise Practice. Public Administration Review.

Rooney, D., McKenna, B., \& Liesch, P. (2010). Wisdom and Management in the Knowledge Economy: Routledge.

Rost, J. (2008). Followership: An Outmoded Concept. In R. E. Riggio, I. Chaleff \& J. Lipman-Blumen (Eds.), The Art of Followership: Jossey-Bass.

Schyns, B., \& Felfe, J. (2006). The Personality of Followers and its Effects on the Perception of Leadership: An Overview, a Study and a Research Agenda. Small Group Research, 37(5), 522-539.

Seligman, M. (2002). Authentic happiness: using the new positive psychology to realize your potential for lasting fulfilment Free Press.

Senge, P. M. (1990). The Fifth Discipline: The Art and Practice of the Learning Organisation: DoubleDay.

Senge, P. M., Ancona, D., Malone, T. W., \& Orlikowski, W. J. (2007). In Praise of the Incompetent Leader. Harvard Business Review(September).

Shamir, B., \& Eilam, G. (2005). What's your story? A life-stories approach to authentic leadership development. The Leadership Quarterly, 16, 395-417.

Shamir, B., House, R. J., \& Arthur, M. B. (1993). The Motivational Effects of Charismatic Leadership: A self-Concept Based Theory. Organisational Science, 4(4), 577-594.

Shaw, P. (2002). Changing Conversations in Organisations: A Complexity Approach to change: Routledge. 
Shiel, M. (2005). Leadership, learning and skill development. In D. Griffin \& R. Stacey (Eds.), Complexity and the Experience of Leading Organisations: Routledge.

Shotter, J. (1993). Conversational Realities: Constructing Life Through Language: SAGE Publications Ltd.

Smircich, L., \& Morgan (1982). Leadership: The management of meaning. Journal of Applied Behavioural Science, 18, 257-273.

Smith, C. (2007). Working from the inside out: Management and leadership through the lens of the perennial wisdom tradition. Journal of Management Development, 26(5), 475-483.

Snowden, D. J. (2005). Multi-ontology sense making: a new simplicity in decision making. Management Today Yearbook, 20, 1-11.

Stacey, R. (2001). Complex Response Processes in Organisations: Learning and Knowledge Creation.: Routledge.

Stacey, R. (2005). Values, spirituality and organisations: a complex response process perspective. In D. Griffin \& R. Stacey (Eds.), Complexity and the Experience of Leading Organizations: Routledge.

Stead, W. E., \& Stead, J. G. (1994). Can Humankind Change the Economic Myth? Paradigm Shifts Necessary for Ecologically Sustainable Business. Journal Of Organisational Change Management, 7(4), 15-31.

Stech, E. L. (2008). A New Leadership-Followership Paradigm. In R. E. Riggio, I. Chaleff \& J. Lipman-Blumen (Eds.), The Art of Followership: Jossey-Bass.

Stone, G., Russell, R. F., \& Patterson, K. (2004). Transformation versus servant leadership: a difference in leader focus. The Learning \& Organisation Development Journal, 25(4), 349-361.

Taylor, J. (2005). Leadership and cult values: moving from the idealised to the experienced. In D. Griffin \& R. Stacey (Eds.), Complexity and the Experience of Leading Organisations: Routledge.

Tobin, J. (2005). The role of leader and the paradox of detached involvement. In D. Griffin \& R. Stacey (Eds.), Complexity and the Experience of Leading Organisations: Routledge.

Townsend, P., \& Gebhardt, J. E. (1997). For Service to Work right, skilled leaders need skills in followership. Managing Service Quality, 7(3), 136-140.

Tzu, S. (2003). The Art of War (R. D. Sawyer, Trans.): Running Press Miniature Editions.

Ulrick, D., Zenger, J., \& Smallwood, N. (1999). Results-Based Leadership: How to build the business and improve the bottom line: Harvard Business School Press.

Weick, K. E. (1995). Sensemaking in Organisations: Sage.

Weick, K. E. (2001). Leadership as the Legitimation of Doubt. In W. Bennis, G. M. Spreitzer \& T. G. Cummings (Eds.), The Future of Leadership: Today's top leadership thinkers speak to tomorrows leaders: Jossey-Bass.

Wheatley, M. (1999). Leadership and the New Science: Discovering Order in a Chaotic World.: Berrett-Koehler Publishers.

Wheatley, M. (2005). Finding Our Way: Leadership For An Uncertain Time: BerrettKoehler.

Whyte, D. (2001). Crossing the Unknown Sea: Work as a Pilgrimage of Identity: The Berkley Publishing Group. 
Williams, G. S. (2008). The Hero's Journey to Effective Followership and Leadership: A Practitioner's Guide. In R. E. Riggio, I. Chaleff \& J. Lipman-Blumen (Eds.), The Art of Followership: Jossey-Bass. 